


\section{An Assessment of the Transformational Potential of REDD+ in Tackling Drivers of Deforestation}

Janice Weatherley-Singh 


\section{Thesis committee}

\section{Promotors}

Dr A. Gupta

Associate Professor, Environmental Policy Group

Wageningen University \& Research

Prof. Dr A.P.J. Mol

Professor of Environmental Policy

Wageningen University \& Research

\section{Other members}

Prof. Dr B.J.M. Arts, Wageningen University \& Research

Prof. Dr L.H. Gulbrandsen, Fridjof Nansen Institute, Lysaker, Norway

Prof. Dr M. Peña-Claros, Wageningen University \& Research

Dr A. Kalfagianni, Utrecht University

This research was conducted under the auspices of the Graduate School of Social Sciences 


\title{
An Assessment of the Transformational Potential of REDD+ in Tackling Drivers of Deforestation
}

\author{
Janice Weatherley-Singh
}

\section{Thesis}

submitted in fulfilment of the requirements for the degree of doctor at Wageningen University by the authority of the Rector Magnificus,

Prof. Dr A.P.J. Mol, in the presence of the

Thesis Committee appointed by the Academic Board to be defended in public on Monday 9 December 2019 at 1.30 p.m. in the Aula. 
Janice Weatherley-Singh

An Assessment of the Transformational Potential of REDD+ in Tackling Drivers of Deforestation, 138 pages.

$\mathrm{PhD}$ thesis, Wageningen University, Wageningen, the Netherlands (2019)

With references, with summary in English

DOI: https://doi.org/10.18174/505276

ISBN: 978-94-6395-193-7 


\section{Acknowledgements}

Having considered doing a PhD for around fifteen years, I finally embarked on this journey in part due to the encouragement of Dr. Martin Kaonga, my supervisor at the time at A Rocha International. He was a big advocate of undertaking a $\mathrm{PhD}$ for professional development and it is largely due to him that I started down this road. I would also like to thank other colleagues at A Rocha International that supported me at the beginning of this process, particularly Will and Rachel Simonson, Peter and Miranda Harris, Barbara Mearns and Melissa Ong.

I particularly want to thank my supervisor and promotor, Dr. Aarti Gupta, for responding to my initial application letter and then sticking with me during these past six years. Thank you for your patience and persistence especially when I was struggling to manage my $\mathrm{PhD}$ around other competing professional demands. I appreciate how much time Aarti put into reviewing drafts, giving feedback and continually pushing me to improve the quality of my work. It is because of her teaching that I have learnt how to write for peer-review journals and I would never have got to this point without her ongoing support and time investment. I also want to thank my promotor Prof. Dr. Arthur Mol who encouraged me from the beginning and also invested considerable time in providing valuable feedback on my draft chapters.

Working as an external student has meant relatively limited interaction with other staff and students at WUR but I would like to thank those who have helped me along the way, especially Corry Rothuizen. It has not been a lonely road, however, as I have benefited from the wonderful company of colleagues within the IUCN office in Brussels. I would particularly like to thank my dear friends Anouska and Chantal with whom I've shared so much personally and professionally over many years and thousands of cups of tea. Thank you both for making it a pleasure to come to the office every day.

I would also like to thank my colleagues at the Wildlife Conservation Society (WCS), especially my supervisor Dr. Sue Lieberman, who is a great encouragement and who has never complained about me 'fitting in' a PhD around a busy working life. I particularly want to thank my colleagues at WCS Madagascar, especially Alison Clausen, who helped me organise my field trip and interviews in Madagascar in 2014 and 2015. Thanks also to all my other colleagues at WCS who are too numerous to list here but with whom I enjoy working and continue to learn from.

Finally, I would like to thank all my friends and family who are such an important part of my life. In particular, my wonderfully supportive parents who have always believed in me and passed on a joy of learning from a young age. Also my brother Andy, whose advice on many areas of life I respect and value immensely. Lastly, I must thank my husband Raj, who has been my greatest supporter throughout this whole project, despite the negative impact it has sometimes had on our family life. Thank you for continuing to push me to keep going - without that I would never have finished! And to our son John, who was born halfway through this project - who has helped keep everything in perspective, as well as being the greatest gift and joy. 


\section{Table of Contents}

Acknowledgements $\quad$ i

List of Figures $\quad$ v

List of Tables $\quad$ v

Abbreviations

1. Introduction 1

1.1 Problem Statement 1

1.2 Tropical Deforestation and Forest Degradation: The Nature and Scope of the Challenge 3

1.3 Conceptual Lens: Multi-level Networked Environmental and Forest Governance 7

1.3.1 Multi-level networked environmental governance $\quad 7$

1.3.2 Multi-level networked forest governance 9

1.3.3 Situating REDD+ within the environmental and forest governance discourse 10

1.4 Research Objective and Questions 12

$\begin{array}{lll}1.5 & \text { Research Methodology } & 13\end{array}$

$\begin{array}{ll}\text { 1.5.1 General approach } & 13\end{array}$

$\begin{array}{ll}\text { 1.5.2 Selection of case studies } & 13\end{array}$

1.5.3 Research methods and internal validity 13

$\begin{array}{ll}\text { 1.6 Overview of the Thesis } & 16\end{array}$

2. Envisioning REDD+ in a post-Paris Era: Between Evolving Expectations and Current Practice 19

2.1 Introduction

2.2 Evolving Expectations and Experiences: Assessing Three Conceptualisations of REDD+ 20

2.2.1 Carbon-centred REDD+: assessing expectations and experiences 20

2.2.2 Co-benefit-centred REDD+: assessing expectations and experiences 23

2.2.3 Landscape-centred REDD+: assessing expectations and experiences 26

2.3 Conclusion: The REDD+ Paradox and Merits of Heterogeneity 28 
3. Drivers of Deforestation and REDD+ Benefit-Sharing: A Meta-Analysis of the (Missing) Link 31

3.1 Introduction 31

3.2 Drivers of Deforestation and REDD+ Benefits: Linkages and Theories of Change 32

3.2.1 Conceptualising REDD+ benefits and benefit-sharing mechanisms 32

3.2.2. Conceptualising drivers of deforestation and forest degradation 33

3.3. Methodology and Approach: A Meta-Analysis of the State of the Art 34

3.3.1 Selecting and reviewing the scholarly literature 34

3.3.2 Selecting and reviewing REDD+ project design documents 36

3.4. Findings of the Meta-Analysis 36

3.4.1 Assessing linkages between drivers and benefits: meta-analysis of the scholarly literature 36

3.4.2. Assessing linkages between drivers and benefits: meta-analysis of REDD+ PDDs $\quad 40$

3.5 Discussion: (How) are REDD+ Projects Addressing Drivers? 45

3.6 Conclusions and a Future Research Agenda 46

4. An Ecological Landscape Approach to REDD+ in Madagascar: Promise and Limitations? 48

$\begin{array}{ll}4.1 \text { Introduction } & 48\end{array}$

4.2 Conceptualising Landscape Approaches to REDD+: A Typology 50

4.3 Deforestation, Forest Degradation and an Emerging Ecological Landscape Approach to REDD+ in Madagascar $\quad 52$

4.4 An Ecological Landscape Approach to REDD+ in Madagascar: Tackling Indirect Drivers? 54

4.5 An Ecological Landscape Approach to REDD+ in Madagascar: Tackling Direct Drivers? 56

$\begin{array}{ll}4.6 \text { Conclusion } & 60\end{array}$

5. 'Embodied Deforestation' as a New EU Policy Debate to Tackle Tropical Forest Loss: Assessing Implications for REDD+ Performance $\quad 62$

5.1 Introduction $\quad 62$

5.2 From Fragmented to Networked Forest Governance: A Conceptual Shift 64

5.3 Methodology and Methods of Analysis $\quad 65$

5.4 Mapping the Fragmented Evolution of EU Tropical Forest Policy 66

5.5. Tackling EU Embodied Deforestation: A New Approach to Addressing Drivers? $\quad 68$ 
5.5.3. From fragmentation to integration in networked EU forest governance: what role for REDD+?

6.2.2 Is REDD+ bringing transformational change through policy integration? 86

6.3 Contribution to Knowledge and External Validity

Appendix 6 Questionnaire for semi-structured interviews with national level REDD+ stakeholders

Appendix 7 Questionnaires for international-level stakeholders involved in policy discussions on 'embodied deforestation' 


\section{List of Figures}

Figure 1.1 Causes of forest decline $\quad 5$

Figure 1.2 Primary drivers of forest cover loss for the period 2001 to 2015

Figure 1.3 The situation of early REDD+ within the environmental governance discourse 10

Figure 1.4 The situation of REDD+ at the forest-climate-agriculture policy nexus 11

Figure 4.1 Conceptualisations of landscape approaches to REDD+ 51

Figure 4.2 Location of the Makira REDD+ project 57

Figure 6.1 Evolution of REDD+ into different conceptualisations 81

Figure 6.2 REDD+ at the nexus of policy domains within and beyond the environment 87

Figure 6.3 How evolution of REDD+ in policy and practice reflects wider debates and developments in environmental and sustainability governance

\section{List of Tables}

Table 1.1 The countries with the greatest change in primary forest area between 1990 and 2015 (Area '000s Ha)

Table 1.2 Overview of the primary sources of information

Table 1.3 Overview of the governance level and research questions discussed in chapters 2 to $5 \quad 16$

Table 3.1 Scholarly analyses of REDD+ projects: articles included in the meta-analysis 35

Table 3.2 Scholarly analyses of REDD+ projects: targeting drivers through benefits 38

Table 3.3 Analysis of REDD+ PDDs: targeting drivers through benefits 42

Table 5.1 Emphasis given to action on climate change, the SDGs and REDD+ in relevant EU policy documents

Table 5.2 New suggested policy measures to combat tropical deforestation within documents published by or for EU policy-makers

Table 6.1 Diverse conceptualisations of REDD+ and their impact on drivers: overview of findings 


\author{
Abbreviations \\ CBD Convention on Biological Diversity \\ CBFM Community-based forest management \\ CCB Climate Community Biodiversity Standards \\ CCBA Climate Community Biodiversity Alliance \\ CITES Convention on International Trade in Endangered Species of Wild Fauna and \\ Flora \\ COP Conference of the Parties \\ EC European Commission \\ EU European Union \\ FAO Food and Agriculture Organisation \\ FCPF Forest Carbon Partnership Facility \\ FLEGT Forest Law Enforcement Governance and Trade \\ FPIC Free prior informed consent \\ FSC Forest Stewardship Council \\ GHG Greenhouse gas \\ IPBES Intergovernmental Science Policy Platform on Biodiversity and Ecosystem \\ Services \\ ICDP Integrated conservation and development project \\ IPCC Intergovernmental Panel on Climate Change \\ ITTO International Tropical Timber Organisation \\ LED-R Low emission rural development \\ LULUCF Land use, land use change and forestry \\ MDG Millennium Development Goal \\ MRV Monitoring, reporting and verification \\ NAMA Nationally appropriate mitigation action \\ NGO Non-governmental organisation \\ PDD Project design document
}


PES Payments for ecosystem services

PPP Public private partnership

RED Reducing emissions from deforestation

REDD+ $\quad$ Reducing emissions from deforestation and forest degradation

RSPO Roundtable on Sustainable Palm Oil

SDG Sustainable development goal

SFM Sustainable forest management

UN United Nations

UNFCCC United Nations Framework Convention on Climate Change

UNFF United Nations Forum on Forests

UN-REDD United Nations reducing emissions from deforestation and forest degradation programme 


\section{Introduction}

\subsection{Problem Statement}

Tropical deforestation and forest degradation constitutes one of the most pressing and urgent global challenges, with extremely high environmental and social costs of inaction (Franklin and Pindyck 2018). While harbouring more than $75 \%$ of the world's terrestrial biodiversity, forests perform many functions essential to human life, including: providing timber, food, medicines and other important products; stabilising the soil and climate; regulating water flows; and contributing to climate change mitigation and adaptation (FAO 2016). The 2015 global forest assessment by the United Nations (UN) Food and Agriculture Organisation (FAO), which is widely referred to by policy-makers, demonstrated a slowing in the world's deforestation rate between 2010 and 2015 in comparison to the 1990s (FAO 2015). It also showed, however, that forest loss is now occurring almost exclusively in poor, tropical countries. Keenan et al. (2015), for example, calculated that natural forest in tropical countries declined by $11 \%$ from 1,935 to 1,713 million hectares between 1990 and 2015. Hansen et al. (2013) found that despite a well-documented reduction in deforestation rate in Brazil, forest loss in the tropics increased by more than 2,100 $\mathrm{km}^{2}$ a year between 2000 and 2012 because of increasing deforestation in Indonesia, Malaysia and elsewhere.

Unlike other global environmental challenges, such as climate change or biodiversity loss, there is no globally-agreed international treaty on forests under the UN which is designed to address the global challenge of deforestation and forest degradation. This absence of a single overarching global agreement (Pistorius 2012) has led to a highly fragmented approach to forest governance from the international to the local level. Discussions on 'reducing emissions from deforestation in developing countries' (known as RED) were therefore initiated under the umbrella of the United Nations Framework Convention on Climate Change (UNFCCC) by a group of developing countries, led by Papua New Guinea and Costa Rica in 2005 (UNFCCC 2005). The proposal was to financially reward developing countries for conserving the carbon stored in tropical forests, thereby representing the first international forest policy mechanism to be developed under an international treaty, accompanied by a viable financial mechanism (McDermott et al.). The RED concept was later expanded to also include compensation for the sustainable management of forests and the enhancement of forest carbon stocks in developing countries. This occurred at the UNFCCC Conference of the Parties (COP) in 2007 (UNFCCC 2007), with the financial mechanism becoming widely known as 'reducing emissions from deforestation and forest degradation' or REDD+. By setting out to financially reward developing countries for preventing deforestation and forest degradation, early REDD+ was thus conceptualised as a global payments for ecosystem services (PES) scheme (Corbera 2012). As the first forest policy initiative to be introduced into the climate policy-making arena, REDD+ represented an innovative approach to forest policy-making at the nexus of two different environmental policy areas, namely forest and climate. It was welcomed by many stakeholders as the long-awaited solution to the problem of deforestation; widely touted as a 'win-win' solution that brought a joint solution to the global environmental problems of deforestation and climate change (Gupta 2012). 
Even as REDD+ was evolving in the manner described above, the broader forest governance discourse has been heavily influenced by the concept of networked governance, as its highly fragmented nature has led to it being both multi-actor, with a variety of stakeholders involved, and multi-level, with the drivers of deforestation operating at different levels and policies being implemented to tackle these at local, national and international levels (Arts 2014). REDD+ brought this multi-actor, multilevel approach particularly to the fore, with diverse actors involved at different levels in pushing forward its development with a limited level of national government involvement (Korhonen-Kurki et al. 2017).

The networked governance approach is linked to recent discussions in the environmental governance literature on integrated policy approaches at international level, at the nexus of different environmental policy areas, as essential to stimulating much needed 'transformational change'. This is demonstrated most directly by the adoption of the 17 UN Sustainable Development Goals (SDGs) and a proposed new Global Pact for the Environment (Kotzé and French 2018). As attention is turning towards the need to address sustainability challenges from a more integrative approach, it is instructive to look at forest governance in particular, as one recent study showed this to be the sustainability issue with the lowest level of collaborative and cooperative governance (Bergsten et al. 2019). Furthermore, whilst 'transformation' has become the latest buzzword in environmental governance, it is still unexplored as a concept and there are inherent risks to its embrace within the sustainability realm without further research, such as a further shift of the burden of responsibilities on to weaker parties (Blythe et al. 2018). In particular, as well as studying the integration of policies at a global level, there is a need to complement this with research from a bottom-up perspective, since transformations will emerge from complex interactions at multiple scales (Patterson et al. 2017).

As an initiative that has developed at an environmental policy nexus, which is multi-level in nature and has brought together a wide range of actors with diverse interests, REDD+ is ideally placed to shed light on whether and how fragmented or integrated approaches to policy-making lead to the hoped-for transformational change needed to address environmental challenges and achieve the environmental SDGs. This thesis therefore examines the transformational potential of REDD+ to tackle tropical deforestation. It uses a networked governance lens to analyse its multi-level evolution at local, landscape and international levels. In particular, it analyses whether diverse conceptualisations and operationalisations of REDD+ are addressing direct and indirect drivers of deforestation and forest degradation and whether these varied operationalisations represent a shift over time from a fragmented to a more integrative approach to multilevel forest governance. Taken together, these two components of the study further scientific knowledge of the potential of REDD+ to deliver transformational change, as well as contribute to scholarly debates about the conditions under which integrated approaches to sustainability can deliver over more fragmented approaches. 


\subsection{Tropical Deforestation and Forest Degradation: The Nature and Scope of the Challenge}

Tropical deforestation and forest degradation have a number of negative consequences, not least because of their significant contribution to global greenhouse gas emissions. From 1990 - 2015, global carbon stocks in forest biomass decreased by almost 11 gigatonnes (Gt) (FAO 2015) with carbon losses from deforestation accounting for around $10 \%$ of all greenhouse gas emissions from 1990 - 2010 (Achard et al. 2014). Although annual emissions resulting from deforestation in developing countries decreased between 1990 and 2015, emissions from forest degradation increased three-fold over the same time period (Federici et al. 2015). Deforestation and forest degradation in the tropics is also negatively impacting biodiversity, because many species are endemic to tropical primary forests which declined by 10\% between 1990 and 2015 (MoralesHidalgo 2015). Tropical deforestation also has a high social cost due to the loss of substantial ecosystem services and benefits, including for people that live locally and depend on forests directly for their livelihoods (Franklin and Pindyck 2018). Table 1.1 shows the continuing loss of primary forest in many tropical countries, which is of disproportionate importance for biodiversity and many other ecosystem values, (Morales-Hidalgo 2015).

Table 1.1 The countries with the greatest change in primary forest area between 1990 and 2015 (Area '000s Ha) (Redrawn from a figure by Morales-Hidalgo et al. 2015)

\begin{tabular}{l|ccc}
\multicolumn{1}{c}{ Country } & $\begin{array}{c}\text { Primary forest area } \\
\text { Change } 1990-2015\end{array}$ & $\begin{array}{c}\text { \% of the change } \\
\text { at country level } \\
\text { (1990 baseline year) }\end{array}$ & $\begin{array}{c}\text { \% of Global primary forest } \\
\text { area (1990 baseline year) }\end{array}$ \\
\hline Brazil & $-15,549$ & -7.1 & -1.3 \\
Papua New Guinea & 13,730 & 43.8 & 1.1 \\
Gabon & -8130 & -38.8 & -0.7 \\
Mexico & 6387 & 16.2 & 0.5 \\
Bolivia, Plurinational State of & -4640 & -11.4 & -0.4 \\
Peru & 3842 & 5.5 & 0.3 \\
Guyana & -3000 & -31.7 & -0.2 \\
Congo, the Democratic Republic of & -2503 & -2.4 & -0.2 \\
the & & & \\
Ecuador & -2119 & -14.5 & -0.2 \\
Central African Republic & -1912 & -49.0 & -0.2 \\
Guatemala & -1617 & -54.8 & -0.1 \\
Nigeria & -1536 & -98.7 & -0.1 \\
Suriname & -967 & -6.5 & -0.1 \\
Malawi & & & -0.1 \\
Canada & -882 & -51.1 & 0.0
\end{tabular}


Promoting policies to combat tropical deforestation and forest degradation is highly complex, not least because of the difficulties in determining the causes. Deforestation and forest degradation are often caused by the intersection between a range of local, direct (proximate) drivers with indirect, underlying drivers acting at multiple scales, which have been classified as demographic, economic, technological, policy and institutional, and cultural (Lambin et al. 2001). For example, Figure 1.1, from a widely cited paper by Lambin and Geist (2002), shows some of the major proximate or direct drivers of deforestation as well as the underlying or indirect drivers, which are demographic, economic, technological, institutional or cultural in nature. Many studies have focused on direct drivers, however, and have underestimated the importance of indirect drivers (Moonen et al. 2016) which are less obvious and often geographically distinct from the place where deforestation is actually taking place. Indirect drivers linked to globalisation are, however, now recognised as critically important due to the continued growth in international agricultural trade and commodity flows (Austin et al. 2017; Leblois et al. 2017). A recent and widely publicised study (from which the map in Figure 1.2 is taken) indicated that $27 \%$ of global forest loss is due to deforestation for commodity production (Curtis et al. 2018). 


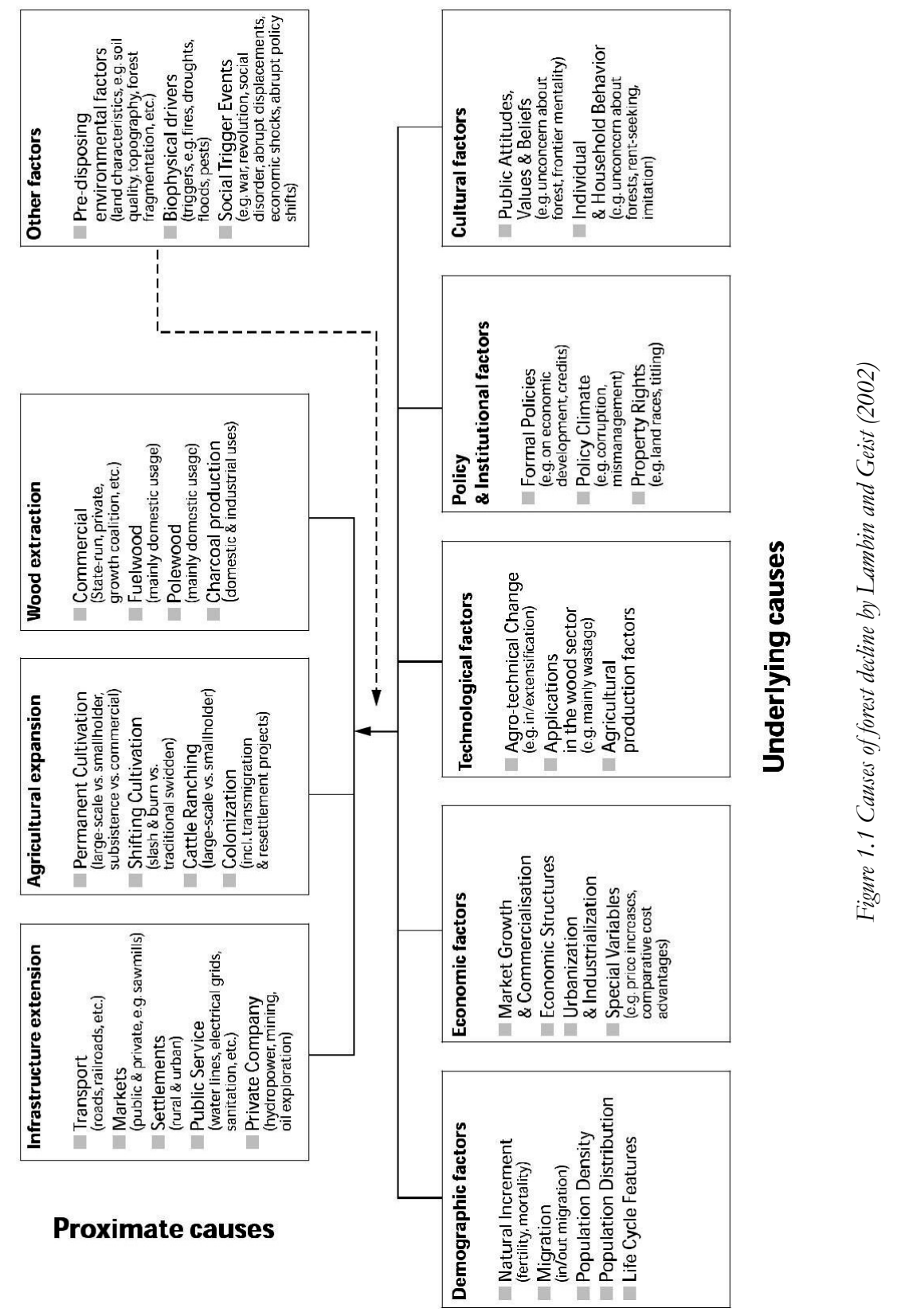


There are, however, strong regional variations in the primary drivers of forest loss, as shown in the map by Curtis et al. (2018) in Figure 1.2. Although much of the deforestation in Southeast Asia is driven by commodity production; in Latin America cattle ranching is also an important deforestation driver; whereas in Sub-Saharan Africa clearance for subsistence agriculture remains important (Lambin and Geist 2003; Curtis et al. 2018). Logging for timber is the major driver of forest degradation in Latin America and Asia, whereas in Africa fuelwood collection and charcoal production is the most significant driver of forest degradation, (Hosonuma et al. 2012; Kissinger et al. 2012). The strength and capacity of forest governance systems also impacts deforestation, with corresponding regional variations. The deforestation rate in South America, for example, has decreased with a corresponding increase in forest governance capacity; South Asia has been increasing its governance capacity to managed remaining forest areas although these areas are critically small; whereas weak forest institutions across Africa have left many forest areas highly vulnerable to deforestation and degradation (Sloan and Sayer 2015).

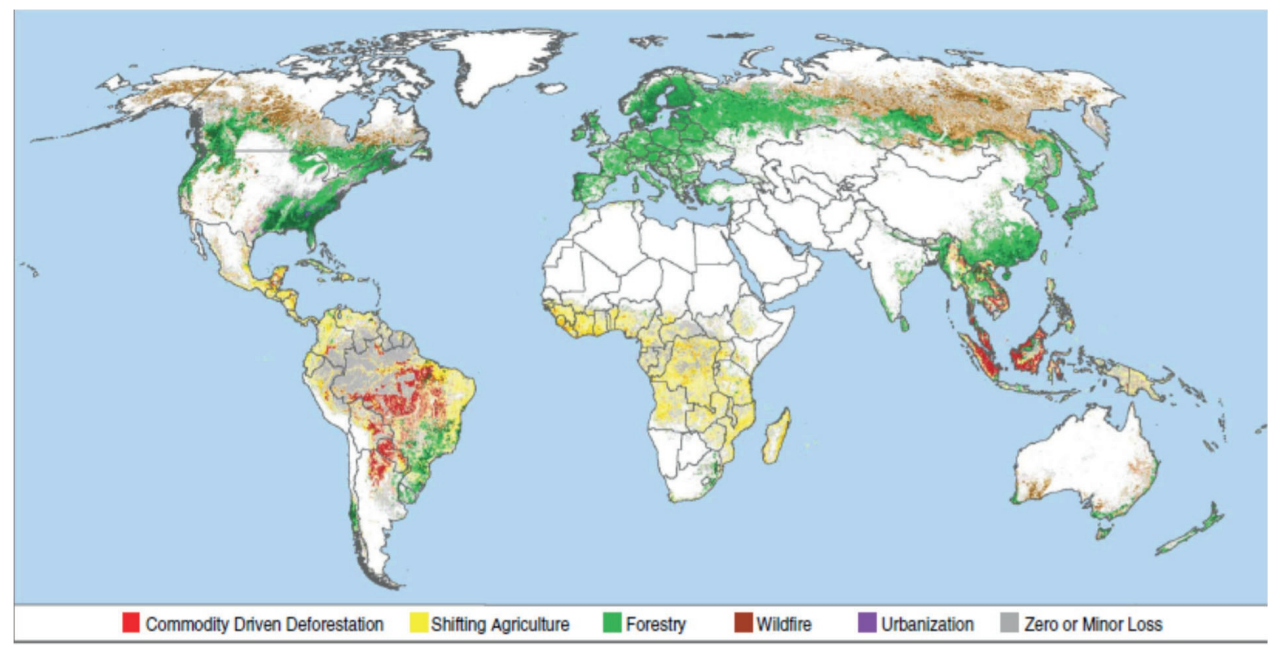

Figure 1.2 Primary drivers of forest cover loss for the period 2001 to 2015 (from Curtis et al. 2018)

The scale of the problem and the social and environmental consequences of inaction mean that the need to address drivers of deforestation and forest degradation is incredibly urgent. This issue is particularly complex to address, however, because of the wide range of drivers that are multi-level and geographically disparate in nature. It thereby presents a difficult global environmental governance challenge, which is far from being solved. Furthermore, the challenge is exacerbated by the fact that governments have not been able to agree on the adoption of a single international treaty on forests. The issue has instead been dealt with in a fragmented manner through a range of more or less inter-related policy instruments. The need to understand which environmental and forest governance approaches are best able to address deforestation and forest degradation drivers is 
therefore imperative. Recent developments in multi-level, networked systems of environmental governance and their implications for forest governance, and the REDD+ policy initiative, in particular, are thus discussed in the next section, as a conceptual lens through which to examine these issues.

\subsection{Conceptual Lens: Multi-level Networked Environmental and Forest Governance}

This section provides an introduction to multi-level environmental governance, before describing how it is evolving in response to the increased prominence of relatively new debates in the environmental policy discourse. Such debates include the increasing emphasis on sustainable consumption and production and the recognition of the need to stimulate transformational change through new forms of governance at the nexus of different policy areas.

\subsubsection{Multi-level networked environmental governance}

Environmental governance encompasses a wide range of theories and frameworks (for example, see the review by Bennett and Satterfield 2018) and is described by Clement and Standish (2018:37) as the social coordination needed to resolve common challenges, particularly “....the interactions between state and non-state actors undertaken to address these challenges, and includes the institutions and principles mediating those interactions". One of the greatest challenges for environmental governance is developing responses to ecological problems that occur across a range of scales and jurisdictions that no one institution has the mandate to govern (Gallemore 2017). This has led to the emergence of multi-level, networked governance and polycentric systems of governance (for example, Carlisle and Gruby 2017; DiGregorio et al. 2012). A plurality of terms is used to describe such multilevel, multi-actor governance arrangements across a range of environmental sectors (Sattler et al. 2018) but in general they describe systems in which decisionmaking takes place at multiple scales, across a number of jurisdictions, in support of common goals (Bennett and Satterfield 2018). Such concepts are also increasingly used to analyse sustainability of production and consumption chains, in which the difficulties facing state regulation of global supply chains have led to hybrid public and private governance arrangements emerging at vertical and horizontal levels (Bush and Oosterveer 2007; Bush et al. 2015).

With increasing recognition that more traditional approaches to environmental governance based on assumptions of 'incremental change' have been woefully inadequate to deal with the scale of global environmental challenges, more recent discussions have centred around governance approaches that lead to rapid, disruptional change (Biermann et al. 2012; Ashford and Hall 2018). This has been influenced by parallel discussions in the ecological sciences. For example, as noted by Chaffin et al. (2016), environmental governance concepts have been strongly influenced by newer understandings that ecological processes are not necessarily linear and predictable but can be abrupt once thresholds are reached. This is exemplified by the planetary boundaries concept (Galaz et al. 2012; Nilsson and Persson 2012), which attempts to define the thresholds of environmental change and has been widely cited by policy-makers. As ecosystems are rapidly changing due to unprecedented human 
impacts, new ecological concepts are also emerging, such as that of 'novel ecosystems', in which the species composition of ecosystems is dramatically altered due to human activities (Clement and Standish 2018).

Discussions in the environmental governance academic literature have, therefore, shifted in recent years towards discussions around transformational environmental governance, which is described by Chaffin et al. (2016:399) as an approach with "the capacity to respond to, manage, and trigger regime shifts in coupled social-ecological systems (SESs) at multiple scales. The goal of transformational governance is to actively shift degraded SESs to alternative, more desirable, or more functional regimes by altering the structures and processes that define the system." Although the concept is still under-developed (Blythe et al. 2018), different approaches to achieving transformational change are emerging, including the creation of pathways to sustainability or new pathdependencies (Patterson et al. 2017), as well as 'transformative adaptation' which attempts to find new ways of addressing drivers of change on socio-ecological systems through adaptively managing trade-offs (Colloff et al. 2017). The importance of transparency and accountability mechanisms has also been recognised as key to achieving transformational change (Ciplet et al. 2018). This new emphasis on transformation in environmental discourse is also influencing the literature on sustainable production and consumption, although the terms 'transition' or 'sustainability transition' are often used instead of 'transformation', to signify non-linear disruptive change (Hölscher et al. 2018; Loorbach et al. 2017). Discussions are therefore also emerging on how to achieve transformational change in the management of multi-tier sustainable supply chains (Jia et al. 2018; Koberg and Longoni 2019; Tseng et al. 2019).

There is also a recognition that transformational change requires new governance at the points where different environmental sectors interlink, with several analytical studies now analysing these points, often termed the 'nexus'. Examples include the water, energy and food nexus (Pahl-Wostl et al. 2018; Weitz et al. 2017) and the trade environment nexus (Yasmeen et al. 2018). A new concept of integrative environmental governance (IEG) has been proposed in which the relationships between different governance instruments is the point of departure rather than a specific instrument (Visseren-Hamakers 2015), which may help convert trade-offs into synergies (Scherer et al. 2018). Attempts to achieve policy integration across sectors are not new but the level of ambition is now being raised through new international policy approaches, such as the SDGs adopted by the UN in 2016 (Scherer et al. 2018; Karlsson-Vinkhuyzen et al. 2018), and the recently launched UN Global Pact for the Environment (Kotzé and French 2018).

With this new momentum at global level to move towards more integrative approaches to addressing global environmental challenges, there is a particular need to identify and evaluate new approaches to tropical forest governance. This issue has long been highly fragmented in nature and is now reported to be the environmental sustainability issue with the lowest level of collaborative and cooperative governance (Bergsten et al. 2019). In the next section, I thus discuss the development of multi-level forest governance to date and how this is intersecting with some of the more recent environmental governance thinking relating to sustainable consumption and production and the need to catalyse transformational change. 


\subsubsection{Multi-level networked forest governance}

As noted above, combatting deforestation and forest degradation at the global level is particularly complex due to the fragmented nature of forest policy-making, which is dealt with through a range of global policy instruments which do not have a primary focus on forests (Pistorius 2012). These include the UN Convention on Biological Diversity (CBD), the Convention on International Trade in Endangered Species of Fauna and Flora (CITES), and more recently, the UNFCCC. Networked governance and multi-level governance are dominant concepts within the forest governance literature (for example, Reinecke et al. 2014; Jedd and Bixler 2015), not least because the issue is multi-actor - involving both state and non-state actors - and multi-level with international policies playing a strong role (Arts 2014; Juerges and Newig 2015). Linked to this, a substantial literature has also developed around the benefits of community-based rather than state-based forestry (Ostrom 1990 ) and the need for greater equity and recognition of forest people's rights (for example, Larson et al. 2010).

The forest governance literature also intersects with the literature on trade and sustainable consumption and production in relation to the sustainability of timber trade. The issue came to the fore with the adoption of the European Union (EU) Forest Law Enforcement Governance and Trade (FLEGT) initiative adopted in 2003, with research focusing on impacts on governance structures and participation in forest policy-making in developing countries (Satyal 2018; SpringateBaginski et al. 2014). With recent attention turning to the importance of the global trade in agricultural commodities as a driver of deforestation, analysis of the two issues is now also intersecting over how supply chains can be governed to ensure they are sustainable and not linked to deforestation. Questions of accountability and transparency are important components of this discussion (Gardner et al. 2018), to examine whether and how multinational companies live up to their zero-deforestation commitments. Initiatives such as Trase, ${ }^{1}$ which provides publicly available information on commodity flows, are therefore being developed to increase transparency and examine private sector impacts on deforestation. In the case of forest networked governance in particular, the growing environmental governance literature on achieving transformational change requires examining how transformational change can be achieved to halt tropical deforestation in the context of global commodity supply chains and the major governance challenges they present.

International forest policy negotiations have also been strongly influenced by ecological perspectives, with many discussions attempting to achieve a balance between conservation and use and achieve sustainable forest management (Pirlot et al. 2018), but recently becoming more heavily influenced by actors from economic and utilitarian perspectives (Giessen et al. 2014). Parallel shifts from conservation to economic objectives can also be observed in the academic literature on 'landscape approaches', which originally focused on ecologically-defined landscapes, but more recently have incorporated social and economic objectives and 'multifunctional landscape' concepts (Sayer et al. 2013). Similarly, the growing literature on PES signalled a move away from governance arrangements established primarily to achieve conservation outcomes, towards market-based

\footnotetext{
${ }^{1}$ See the Trase weblink to view maps and information for beef and soy exports linked to specific jurisdictions and companies operating in Brazil and Paraguay https://trase.earth/ accessed 2 February 2019
} 
governance arrangements based around the provision of forest ecosystem services such as water or carbon storage (Costanza et al. 1997).

The initiative developed under the UNFCCC to reduce emissions from deforestation and forest degradation (known as REDD+), which I next turn to discuss, was also heavily influenced by the PES discourse and involves developed countries paying developing countries to keep tropical forests intact for their carbon storage (den Besten et al. 2014; Karsenty et al. 2014). It can thus be conceptualised as an attempt to create a global-scale PES scheme (Corbera 2012). REDD+ became the dominant discourse in the climate-forest policy nexus (Buizer et al. 2013) and the major forest governance tool to be promoted and adopted by a wide range of stakeholders, including governments. A high level of expectation was placed on it as a solution to the problem of tropical deforestation and forest degradation. It is thus particularly important to analyse whether and the extent to which it has been able to tackle multiple, direct and indirect drivers of deforestation and forest degradation.

\subsubsection{Situating REDD+ within the environmental and forest governance discourse}

As mentioned previously, the introduction of REDD+ represented an important and controversial conceptual shift in international forest governance, because it was the first time that forests were formally introduced within climate policy discussions as opposed to other environmental policy discussions, such as biodiversity. Discussions on the role of tropical forests in climate change mitigation were formally initiated under the UNFCCC in 2005 and REDD+ was formally discussed at the UNFCCC COP in 2007 (UNFCCC 2008). This situation of early REDD+ within the wider environmental governance discourse, located as a 'win-win' solution at the nexus of the forest and climate governance discourse, is shown in Figure 1.3.

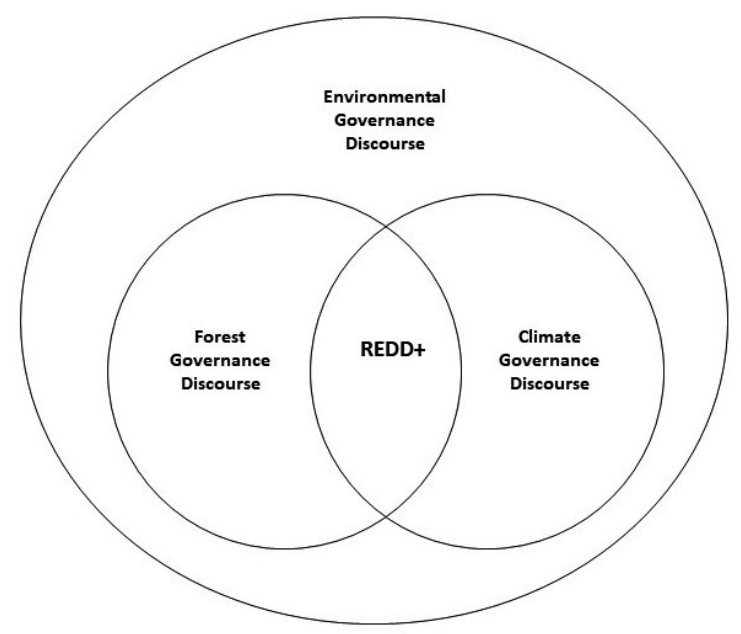

Figure 1.3 The situation of early REDD+ within the environmental governance discourse 
As no international REDD+ agreement was reached under the UNFCCC and the hoped for market-based funding largely failed to materialise, early REDD+ was instead largely implemented initially via a plethora of local projects, often supported by government funding (Blom et al. 2010). This led to calls for 'nested approaches' under which REDD+ projects would be incorporated under larger national and international agreements (Chagas et al. 2011). In addition, many stakeholders became involved in pushing the development of REDD+ forward, to the extent that it started to represent a new form of forest governance involving a diverse range of actors with limited government control (Korhonen-Kurki et al. 2017). REDD+ therefore represents an interesting case study of networked governance, being both multi-level in nature and involving a diverse range of stakeholders, including both state actors as well as representatives of non-governmental organisations (NGOs) and the private sector.

As REDD+ continued to evolve with the advent of landscape-based approaches, including closer integration with agricultural policies, it developed from being an environmental policy issue at the forest-climate nexus, to being situated at the more complex global forest-agriculture-climate nexus (Soto Golcher and Visseren-Hamakers 2018). While REDD+ has been described as being situated at the nexus of these three policy issues, integration with the agricultural policy discourse has been weaker than the integration between forest and climate policies. Figure 1.4 shows REDD + at the climate-forest-agricultural policy nexus, and acknowledges the weaker integration with agricultural policy, shown by a dotted line (adapted from a diagram presented by Soto Golcher and VisserenHamakers 2018).

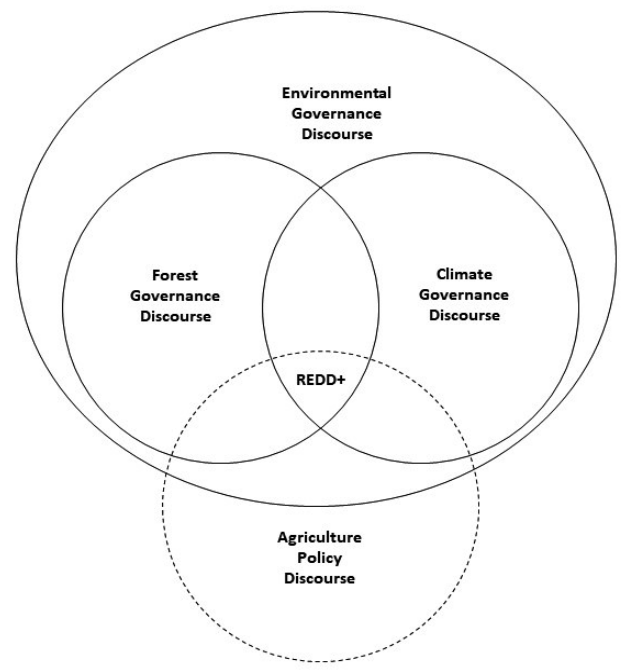

Figure 1.4 The situation of REDD+ at the forest-climate-agriculture policy nexus (adapted from Soto-Golchur and Visseren-Hamakers, 2018) 
In recent years, there has been renewed interest worldwide in halting deforestation, with governments collectively committing to achieve zero deforestation globally by 2020 in the UN SDGs. ${ }^{2}$ Similarly, many multinational corporations have made 'zero-deforestation commitments', which have been defined as 'public declarations of intent to eliminate deforestation from their supply chains' (Newton and Benzeev 2018:126). These commitments by private companies have also received support from a number of European governments through the Amsterdam Declarations. ${ }^{3}$ This increasing action and interest from the private sector and governments is generating momentum to tackle tropical deforestation and forest degradation, as well as impacting the evolution of REDD +. Increased attention is now being given towards tackling indirect drivers associated with the global trade in agricultural commodities, providing an opportunity to build on this momentum and devise forest governance systems that can better tackle deforestation and forest degradation drivers.

In sum, given the prominence of REDD+ over the last decade as the dominant initiative to address deforestation, it is particularly important to examine the role it plays in addressing drivers, including indirect drivers. This also requires analysis of how well different conceptualisations of REDD + are able to address drivers, and how its evolution at the nexus of climate, forest and agricultural policy aids in this process. Another timely concern is how REDD+ is being impacted by growing interest from the private sector and consumer countries in achieving zero deforestation targets. If REDD+ is able to play a role in addressing indirect drivers of deforestation and forest degradation associated with global trade in agricultural commodities, this would be a game-changer, in terms of global efforts to address tropical deforestation. This could then be viewed as achieving transformational change.

\subsection{Research Objective and Questions}

This thesis thus analyses whether REDD+ is fulfilling this transformative potential. As it continues to evolve, it is important to first identify how REDD+ is being conceptualised in policy and practice, and how effectively (if at all), evolving conceptualisations of REDD + are addressing the direct and indirect drivers of deforestation and forest degradation. The first question I consider in this thesis, is therefore, "To what extent have evolving conceptualisations of REDD+ effectively tackled direct and indirect drivers of deforestation and forest degradation, operating at different levels?"

Furthermore, given that REDD+ has evolved at the nexus between interlinked environmental policy areas, it is now timely to identify whether and how integrating different policy domains leads to transformational change, by which is meant here success in combating indirect drivers of deforestation and forest degradation. The second question to be analysed in this thesis is therefore:

\footnotetext{
2 https://sustainabledevelopment.un.org/sdg15 (accessed 10 January 2019)

3 https://partnershipsforforests.com/partnerships-projects/the-amsterdam-declarations/ (accessed 10 January 2019)
} 


\section{"From a networked governance perspective, to what extent is REDD+ becoming integrated across diverse policy domains and how is this impacting its ability to deliver transformational change?"}

\subsection{Research Methodology}

\subsubsection{General approach}

This thesis utilises a qualitative and meta-analytical approach to answering the research questions. It also draws on the use of case studies as a primary approach because this provides a rigorous methodology through which to empirically investigate and evaluate a contemporary phenomenon in an in-depth manner and within a real world context (Yin 2014).

\subsubsection{Selection of case studies}

Two case studies were used to help answer the research questions of this thesis. The first was a case study of landscape level REDD+ implementation in Madagascar (chapter 4). This country was selected because of the relatively long history of REDD+ implementation on which to base an evaluation (Ferguson 2009). In addition, most studies of landscape level REDD+ have been based on case studies outside Africa (mostly notably in Indonesia and Brazil), in countries with relatively high capacity for REDD+ implementation and a strong involvement by both regional level government and the private sector (for example, Fishbein and Lee 2015). Madagascar was therefore selected as a case study to add to the existing research by exploring a contrasting context, as a poor, low-capacity country, with limited regional government and private sector involvement in REDD+. To research this case study, 24 days were spent in Madagascar to become familiar with the national context, and 10 days were spent in the north-east region of Analanjorofo to make a field visit to the Makira REDD+ project to interview project beneficiaries located in three different remote forest villages.

The second case study was selected to analyse whether and how international policy-making is now moving towards tackling the drivers of deforestation linked to exports of agricultural commodities connected with deforestation in developed countries (chapter 5). This analysis took the EU as a case study because it has been a leader in attempting to integrate environmental goals into other sectoral policies (Visseren-Hamakers 2015) and is currently a global frontrunner in the development of sustainable production and consumption policies (Wang et al. 2019). Furthermore, the EU is actively engaged in working to influence global forest policy discussions beyond its borders (Pirlot et al. 2018), and may therefore drive forward change in other global regions.

\subsubsection{Research methods and internal validity}

Different methods were used throughout this study, which combined desk-based (mainly systematic document analysis) with field-based research and semi-structured interviews. The rationale to use mixed methods was to enhance internal validity (Creswell and Plano Clark, 2011:12). Methods of data generation and analysis include qualitative methods of primary, secondary and grey literature 
review, semi-structured interviews and field visits. Research for this thesis included systematic reviews of 102 documents and semi-structured interviews with 63 individuals, across all chapters.

As REDD+ is conceptualized and implemented by different actors at various inter-connected levels (the so-called nested approach), chapter 2 first examines the diverse conceptual and operational approaches being taken to REDD+ in multiple settings over time, through a detailed review of scientific literature. Following this, the thesis analyses the first research question through examining the relationship between REDD+ and the drivers of deforestation and forest degradation at the following levels: local/project level (chapter 3), landscape level (chapter 4), and the international policy level (chapter 5). The relationship between national level REDD+ readiness plans and strategies and drivers, was not examined as this was already analysed thoroughly in studies by Kissinger et al. (2012) and Salvini et al. (2014), upon which this thesis also builds.

For chapters 3 to 5 , the desk-based research and meta-analytical literature review entailed analysing diverse document types to distil evolving conceptualisations of REDD+ (chapters 3 to 5). A primary method employed was systematised screening of the literature. This widely-used approach relies on identifying a purposive sample of relevant literature, without attempting to achieve a fully comprehensive study of all available articles (for example, Sattler et al. 2018) As shown in Table 1.2., for the analysis of local REDD+ projects (chapter 3), 19 project case studies were systematically selected for review from the peer-reviewed scientific literature, as well as 28 non-academic REDD+ project design documents (PDDs), as listed in Appendix 1. For chapter 4, as REDD+ at the landscape level was still emerging and not well documented in the academic literature at the outset of this research project, I analysed this particular conceptualisation of REDD+ through reviewing academic and grey literature, in addition to field research and semi-structured interviews (chapter 4). For the international case study in Chapter 5, 55 EU level policy documents were systematically reviewed from the European Commission, European Parliament and other sources. These policy documents covered a range of policy areas, including climate change, environment, trade, and development, as shown in Appendix 2.

The used of semi-structured interviews was employed as an additional approach for the analyses in chapters 4 and 5 . This approach is widely used when investigating complex behaviours and opinions, and is useful for collecting a diversity of experiences and for gaining insights in to what people do and think (Longhurst 2016). As another means of enhancing internal validity, interviewees were selected after an initial stakeholder mapping to represent a range of different interest groups and sectors with experience in REDD+ development and implementation at local, national and international levels, as shown in Table 1.2. The only stakeholder group difficult to engage in interviews was the private sector, so this interest group remains somewhat under-represented compared to the others in this thesis. A list of national level stakeholders (for the analysis in chapter 4) is provided in Appendix 3, and a list of international level stakeholders (interviewed to contribute to the analysis in chapter 5) is provided in Appendix 4. Questionnaires used for the semi-structured interviews are provided in Appendices 5, 6 and 7.

The specific methodologies and methods of data generation and analysis pertinent to each chapter are also elaborated further in each of the chapters themselves. In addition, chapters 2 to 5 of this thesis have been published as articles in international peer reviewed journals, which provided opportunities to receive feedback on the research validity. Furthermore, the initial findings of 
chapters 3 and 5 were presented in international, academic conferences, ${ }^{4}$ which gave further opportunities to 'test' the wider validity of the preliminary findings with other researchers.

Table 1.2 Overview of the primary sources of information

\begin{tabular}{lccc}
\hline & $\begin{array}{c}\text { Chapter 3 } \\
\text { (local } \\
\text { level) }\end{array}$ & $\begin{array}{c}\text { Chapter 4 } \\
\text { (landscape } \\
\text { level) }\end{array}$ & $\begin{array}{c}\text { Chapter 5 } \\
\text { (international } \\
\text { level) }\end{array}$ \\
\hline Numbers and types of documents analysed* & & & \\
\hline Type of documents: & 28 & & \\
$-\quad$ Local project design documents & 19 & \\
$\quad$ (PDDs) & & \\
- Academic papers describing local & & \\
$\quad$ projects & & \\
- Official international policy document & & \\
$\quad$ International supporting policy & & \\
\hline
\end{tabular}

Geographic representation of (local level)

REDD+ projects:

- Africa

- Asia

- Latin America

Representation of policy documents

(international level):

- Climate and energy

- Development/sustainable

development/foreign policy

- Environment

- Trade and agriculture

- General/overarching policy

Numbers and types of stakeholders interviewed

Level of stakeholder involvement in REDD+:

- Local

- National

20

- International

Representation of interviewed stakeholders:

- Community members

- NGO sector

- Public sector (government and

intergovernmental)

- Private sector (companies)

- Independent experts and researchers

8

(1)

*As explained in section 1.4.1, national level REDD+ documents were not included in the analysis as they were already analysed by other researchers

\footnotetext{
${ }^{4}$ Preliminary results for chapter 2 were presented in a workshop at the Earth Systems Governance conference in Norwich, UK in 2014, and for chapter 4 in a workshop at the Earth Systems Governance conference in Utrecht, the Netherlands, in 2018
} 


\subsection{Overview of the Thesis}

This thesis is organised into six chapters. This introduction is followed by the analysis of how REDD+ has evolved over time and its different conceptualisations (chapter 2). I then move to examine two specific conceptualisations of REDD+ which have been most widely adopted in practice (the co-benefit and landscape conceptualisations) in more detail, to analyse their ability to address drivers of forest loss (chapters 3 and 4). Chapter 5 then analyses the evolving forest policy discourse and the continued evolution of REDD+ through the new lens of 'embodied deforestation'. An overview of the governance level and specific research questions covered in each of these chapters is provided in Table 1.3 below. Chapter 6 presents the overarching findings and conclusions of the thesis.

Table 1.3 Overview of the governance level and research questions discussed in chapters 2 to 5

\begin{tabular}{|c|c|c|c|c|}
\hline & Chapter 2 & Chapter 3 & Chapter 4 & Chapter 5 \\
\hline Title & $\begin{array}{l}\text { Envisioning } \\
\text { REDD+ in a } \\
\text { post-Paris era: } \\
\text { between evolving } \\
\text { expectations and } \\
\text { current practice }\end{array}$ & $\begin{array}{l}\text { Drivers of } \\
\text { deforestation } \\
\text { and REDD+ } \\
\text { benefit } \\
\text { sharing: a } \\
\text { meta-analysis } \\
\text { of the } \\
\text { (missing) link }\end{array}$ & $\begin{array}{l}\text { An ecological } \\
\text { landscape } \\
\text { approach to } \\
\text { REDD+ in } \\
\text { Madagascar: } \\
\text { Promise and } \\
\text { limitations? }\end{array}$ & $\begin{array}{l}\text { "Embodied } \\
\text { deforestation" as a new } \\
\text { EU policy debate to } \\
\text { tackle tropical forest } \\
\text { loss: assessing } \\
\text { implications for } \\
\text { REDD+ performance }\end{array}$ \\
\hline $\begin{array}{l}\text { Governance } \\
\text { level } \\
\text { examined }\end{array}$ & Overview: all levels & Local project & $\begin{array}{l}\text { Landscape / } \\
\text { regional }\end{array}$ & $\begin{array}{l}\text { International, EU } \\
\text { policy }\end{array}$ \\
\hline $\begin{array}{l}\text { Specific } \\
\text { research } \\
\text { question (s) }\end{array}$ & $\begin{array}{l}\text { Have current } \\
\text { conceptualisations } \\
\text { of REDD + lived } \\
\text { up to the various } \\
\text { expectations } \\
\text { associated with } \\
\text { them? }\end{array}$ & $\begin{array}{l}\text { Are benefit- } \\
\text { sharing } \\
\text { mechanisms } \\
\text { via REDD+ } \\
\text { projects } \\
\text { addressing } \\
\text { drivers of } \\
\text { deforestation } \\
\text { and forest } \\
\text { degradation? } \\
\text { Are theories } \\
\text { of change } \\
\text { being } \\
\text { advanced to } \\
\text { analyse the } \\
\text { links (or lack } \\
\text { of) between } \\
\text { benefit- } \\
\text { sharing and } \\
\text { drivers? }\end{array}$ & $\begin{array}{l}\text { How are } \\
\text { landscape } \\
\text { approaches to } \\
\text { REDD+ being } \\
\text { conceptualised } \\
\text { in the academic } \\
\text { and policy } \\
\text { literature? } \\
\text { Which REDD+ } \\
\text { landscape } \\
\text { approach is } \\
\text { emerging in } \\
\text { Madagascar, } \\
\text { and if so, is it } \\
\text { able to address } \\
\text { both direct and } \\
\text { indirect drivers } \\
\text { of deforestation } \\
\text { and forest } \\
\text { degradation? }\end{array}$ & $\begin{array}{l}\text { Will a focus on } \\
\text { embodied } \\
\text { deforestation } \\
\text { marginalise REDD+ } \\
\text { or give it fresh } \\
\text { relevance? How is } \\
\text { REDD+ performance, } \\
\text { particularly in relation } \\
\text { to tackling } \\
\text { international drivers, } \\
\text { related to this new } \\
\text { approach, if at all? } \\
\text { Will tackling embodied } \\
\text { deforestation become } \\
\text { one of many initiatives } \\
\text { aiming to address } \\
\text { tropical deforestation } \\
\text { within the EU, } \\
\text { contributing to further } \\
\text { fragmentation, or will } \\
\text { it facilitate a more } \\
\text { integrated approach? }\end{array}$ \\
\hline
\end{tabular}


The second chapter of this thesis analyses and synthesises how REDD+ is being conceptualised in practice, which sets the context for the subsequent chapters. This chapter includes preliminary observations about how diverse conceptualisations are suited or not to addressing direct and indirect drivers of deforestation and forest degradation. The three conceptualisations of REDD+ described and examined in this chapter are: a co-benefit-centred REDD+ (wherein REDD+ aims to achieve co-benefits for biodiversity and communities); a carbon-centred REDD+ (in which REDD+ is mainly a climate mitigation strategy); and a landscape-oriented REDD+ (in which REDD+ is instituted along with broader agricultural and sustainable land use practices). The chapter also explores each of these conceptualisations in relation to: financing; the establishment of national monitoring, reporting and verification (MRV) systems; and governance. The co-benefit and landscape approaches to REDD+ are then discussed in more detail in chapters 3 and 4, as these are the main conceptual approaches being implemented in practice.

Chapter 3 analyses a co-benefit conceptual approach to REDD+ through the development of projects, which was the main way that early REDD+ was implemented. It aims to better understand how well REDD+ projects are addressing multi-level drivers of deforestation and forest degradation, through the implementation of activities that provide a range of benefits to local communities. A meta-analysis is undertaken of REDD+ projects as described in the growing academic literature and in project documents (e.g. PDDs) to identify the main drivers encountered (at multiple levels), and the main project interventions and associated benefits proposed to address them. It provides a meta-level overview of the extent to which multi-level drivers are being addressed through REDD+ projects, by reviewing existing projects and the interventions being undertaken in order to identify posited links to drivers.

Chapter 4 moves on to examine the next step in the evolution of REDD+, namely the landscape approach, and its ability to tackle drivers of deforestation and forest degradation. An examination of the grey and peer-reviewed literature revealed the emergence of a typology of landscape approaches which are described here. I then analyse in detail what I term an 'ecological landscape approach' and its ability to address drivers of deforestation and forest degradation, as it is the landscape approach which has been given the least attention to date in the REDD+ literature. The chapter focuses on Madagascar as a case study for the development and implementation of such an approach. The novelty of this analysis is that it diverges from most academic studies to date of landscape approaches, given that it is a case with low involvement of the private sector and lack of involvement or influence by provincial governments.

Chapter 5 considers the issue at the international level by analysing new discussions emerging in the international forest policy realm and the implications for the continued evolution and conceptualisation of REDD+ and its ability to address drivers. It describes the emergence of a new policy debate at EU level termed 'embodied deforestation', which views deforestation as an externality generated by EU imports and targets indirect international drivers of deforestation and forest degradation linked to EU commodity imports. A networked governance approach is used to examine: first, the extent to which a shift towards an embodied deforestation approach is taking place; second, if so, the implications of this new approach for REDD+ and its ability to tackle indirect drivers of deforestation and forest degradation operating at the international level; and, 
third, whether these discussions signify a move towards a more integrated approach to forest policymaking.

Chapter 6 brings the thesis to a conclusion by summarising the research findings and identifying general lessons learned in order to draw wider conclusions on the relationship between REDD + and drivers, and on conditions stimulating transformational change in the sustainability domain. It distils lessons regarding different conceptualisations of REDD+ and whether and how, taken as a whole, REDD+ is able to provide a multi-level approach that addresses direct and indirect drivers operating at different levels. Based on this analysis I also discuss how REDD+ is continuing to evolve and the implications of this for the ability of integrated approaches to deliver transformational change. The chapter concludes by identifying how thesis findings apply to other, multi-level, networked environmental governance issue-areas. 


\section{Envisioning REDD+ in a post-Paris Era: Between Evolving Expectations and Current Practice ${ }^{5}$}

\subsection{Introduction}

In the collective global challenge posed by climate change, the idea of reducing or avoiding carbon emissions through forest conservation and sustainable use has attracted considerable attention. The global mechanism REDD+ has been, arguably, the most prominent site of multilateral political negotiations and activities on the ground with regard to mitigating forest-related carbon emissions. REDD+ stands for 'reducing emissions from deforestation and forest degradation in developing countries; and the role of conservation, sustainable management of forests and enhancement of forest carbon stocks in developing countries (UNFCCC 2007). It has been negotiated under the UNFCCC since 2005, as a mechanism to compensate developing countries for their efforts to reduce forest-related emissions (Corbera and Schroeder 2011). Over the years, multiple REDD+ activities have been initiated, with bilateral and multilateral support from the World Bank and the UN REDD programme. This has resulted in the development of national REDD+ strategies and in execution of more than 1000 REDD+ activities on the ground in developing countries by the end of $2015 .^{6}$

In initial debates on REDD+ (then referred to as RED - Reducing Emissions from Deforestation), reducing carbon emissions through preventing further deforestation was portrayed as being relatively simple and efficient compared to other climate change mitigation strategies (Stern 2007). In this relatively simple conceptualisation, developing countries would receive financial support for reducing emissions from forest loss, calculated at the national level against an established baseline or reference level. This attracted a range of stakeholders, who were optimistic about the potential of REDD + to offer a win-win solution for both climate and forests, and who considered REDD+ as an unprecedented opportunity to bring political attention and new financing for tropical forest conservation (Canadell and Raupach 2008; Harvey et al. 2010).

Almost in parallel, another conceptualisation emerged, which emphasised not a double but a triplewin REDD+. In this vision, the emphasis was not only on the potential of REDD+ to lower carbon emissions and conserve forests, but also to improve livelihoods of forest-dependent communities, thereby facilitating poverty reduction and sustainable development in countries in which REDD+ interventions were to take place (so called 'non-carbon or co-benefits'). This triple win conceptualisation also attracted different stakeholders within the development community, who valued the benefits that REDD+ could provide for forest communities, (Campbell 2009; VisserenHamakers, Gupta et al. 2012; Pistorius 2012) and for its potential role in improving forest governance (Kanowski et al. 2011).

\footnotetext{
${ }^{5}$ This chapter has been published as: Turnhout, E., Gupta, A., Weatherley-Singh, J., Vijge, M.J., de Koning J., Visseren-Hamakers, I.J., Herold, M. and Lederer, M. 2016. "Envisioning REDD+ in a Post-Paris Era: Between Evolving Expectations and Current Practice." Wiley Interdisciplinary Reviews: Climate Change. https://doi.org/10.1002/wcc.425

${ }_{6}^{6}$ VRD. Voluntary REDD+ database. Available at: http://reddplusdatabase.org/ (accessed 10 May 2016)
} 
Conceptualisations of REDD+ have again shifted in recent years, this time to include a landscape approach to REDD+, which emphasises the importance of governing landscapes (including forests, agriculture and other land uses) from an integrated perspective and including relevant stakeholders and sectors (Visseren-Hamakers, McDermott, et al. 2012; McDermott et al. 2012). In this third conceptualisation, REDD+ is envisioned to serve as a catalyst for more integrated 'climate smart development' pathways in forested landscapes of tropical countries, particularly at the sub-national or jurisdictional level (Hansen et al. 2010; McCarthy and Tacconi 2011; Someshwar 2008). This, however, will require REDD+ to go even further beyond the relatively simple focus on reducing carbon emissions from deforestation that it started with, and encompass a wide variety of cobenefits in a wide variety of land uses (Locatelli et al. 2015).

Over the years, the shifting conceptions of REDD+ have garnered not just support, but also criticism. From the outset REDD+ has been fiercely debated in both scholarly literature and policy practice (Phelps et al. 2011; Mahanty et al. 2012; Fletcher et al. 2016; Sandbrook et al. 2019; Corbera 2012). This article thus undertakes a timely assessment of the current state-of-the-art understanding of whether and how REDD+ has lived up to the various expectations associated with it. It also assesses what the gaps between evolving expectations and experiences might imply for the future evolution of REDD+ in a post-Paris era.

Such a stocktaking exercise is timely, given the prominence accorded to REDD+ in Article 5 of the agreement reached during the $21^{\text {st }}$ Conference of the Parties (COP 21) of the UNFCCC in Paris in 2015 (UNFCCC 2015a). It is particularly important in light of the potential role that forest-based mitigation is likely to play in meeting the long-term climate change mitigation goal of remaining 'well below' $2^{\circ}$ (UNFCCC 2015a). It is also relevant in the context of meeting the SDGs agreed in 2015, in particular Goal 15.2 that aims to promote sustainable forest management, restore degraded forests, and halt deforestation by 2020, which was linked to REDD+ at COP 21 (UNFCCC 2015a; Climate Focus 2016).

\subsection{Evolving Expectations and Experiences: Assessing Three Conceptualisations of REDD+}

We turn here to assessing the extent to which the evolving expectations associated with the three conceptualisations of carbon, co-benefit, and landscape-centred REDD+ are being realised. In doing so, we focus in particular on financing for REDD+, and the establishment of national-level measuring, reporting, and verification (MRV) systems intended to report on performance, as two necessary elements in converting REDD+ into reality. We also touch upon other aspects, as relevant, including REDD+ governance arrangements and its engagement (or not) with broader deforestation drivers.

\subsubsection{Carbon-centred REDD+: assessing expectations and experiences}

As we outline above, the first conceptualisation of REDD+ relates to its promise to provide an efficient and effective way to reduce or avoid forest-related carbon emissions and thereby mitigate climate change, while at the same time conserving forests. However, incentivising this depends upon the establishment of a viable financial mechanism for REDD+. The Warsaw Framework, agreed to at the UNFCCC COP 19 in Warsaw, specifies that REDD+ finance will support developing 
countries in three sequential phases of REDD+ implementation: (1) readiness, demonstration activities, and (3) results-based actions. This implies that, before payments for verified forest-carbon emissions reductions can flow, some preparatory $e x$ ante finance is needed for countries to 'get ready for REDD+' through developing national REDD+ strategies and establishing institutional arrangements, and building technical capabilities for, among others, setting up MRV systems (Gupta et al. 2016; Voigt and Ferreira 2015). Only then can result-based payments occur.

To date, about $90 \%$ of all REDD+ finance, for such stages, has come from public sources (Ballesteros et al. 2010; Streck 2012; Lee and Pistorius 2015). This has included, for instance, funding from the UN-REDD programme, the World Bank's Forest Carbon Partnership Facility (FCPF); and national government programmes, such as from Norway or Germany's REDD+ Early Movers Programme. In line with the Warsaw rules, most of this finance has gone to national governments in developing countries (Voigt and Ferreira 2015; Buizer et al. 2014). At this moment, however, the level of finance is insufficient. Currently, pledged finance for REDD+ only amounts to less than half the estimated supply of carbon credits, assuming a standard price of USD 5/tonne of $\mathrm{CO}_{2}$ (a price used, for instance, by the FCPF), and also assuming that all finance goes to phase 3 to pay for verified reduced emissions and not to preparatory capacity building (Lee and Pistorius 2015). Besides public funding for REDD+, available private funding has been disbursed through voluntary carbon markets. In the absence of including forest credits in compliance markets, where entities with legally set emission obligations might use REDD+ offsets as one potentially efficient and flexible way of reaching their targets, voluntary carbon markets are currently the only place wherein REDD + credits are being traded. The only state-driven market where forest offsets might be used in the near future is California's cap-and-trade market that plans to include REDD+ offsets from 2018 on.

The current financial situation of REDD+, including public funding and the voluntary carbon market, is a clear indication that the ambitions related to REDD+ in providing payments for avoiding or reducing emissions from forests may not be realised. This is mirrored in the international negotiations where no decision regarding the finance of REDD+ has been made but instead the compromise formula is being used that funds should 'come from a variety of sources, public and private, bilateral and multilateral, including alternative sources (UNFCCC 2013a). Consequently, as many studies have pointed out, REDD + will not be able to easily incentivise change away from deforestation and forest degradation because the opportunity costs are so high that REDD+ is unable to compete with other, less sustainable, land uses (Butler et al. 2009; Limberg et al. 2009; Irawan et al. 2013; Fischer et al. 2016; Mahanty et al. 2013). This implies that while countries are getting ready for REDD+ and are preparing to supply carbon credits, it is unclear what exactly they are getting ready for, in terms of the financial mechanisms to be put in place, the conditions attached to it, and whether there will be sufficient finance available (Vijge 2016). According to Vijge (2016), this has created a wait-and-see attitude among developing countries.

This also has implications for the widely held view (and criticism) that REDD+ embodies a marketbased and neoliberal approach to environmental governance, whereby forest carbon emissions are to be valued and made into a tradable commodity (Kosoy and Corbera 2010). The process of commodification implies commensuration across diverse types of carbon emissions, regardless of the location, or social conditions of their generation, so that they can be traded and exchanged (Stephan 2012). According to many, this is risky because it could result in forests only being valued for their carbon content, a process termed carbonification (Kosoy and Corbera 2010) or 
carbonization (Vijge 2016; Vijge and Gupta 2014; Gupta et al. 2012) thereby neglecting local realities and the needs of forest-dependent communities (Corbera 2012; McAfee 2012; Nielsen 2014). These criticisms resonate with broader debates and critiques of a PES approach to environmental governance. REDD+ is often seen as one of the most prominent current examples of PES approaches, since it aims to pay developing countries for providing the environmental service of mitigating forest-related climate emissions (van Noordwijk and Leimona 2010; Swallow et al. 2009; To et al. 2012). Further criticism has emerged about the potential of REDD+ to become an offset mechanism for developed countries to compensate their own poor greenhouse gas (GHG) mitigation performance (Gupta et al. 2012; Lohmann 2005).

However, in the absence of a global compliance market for forest carbon, and with the current low demand for and price of carbon, the claim that REDD+ is contributing to a large-scale commodification of the forest remains empirically unfounded. In fact, the forest is already very much commoditised and has been brought under global extractivist markets, unrelated to REDD+ (Fletcher et al. 2016). Moreover, it has also been argued that avoided emissions have not (yet) been fully turned into a commensurable commodity in REDD+: avoided emissions from forests are not all treated the same, and the location and conditions of production do matter (Fischer et al. 2016). Particularly at the project level, as we discuss in more detail later, results-based finance and carbon transactions do not yet take centre stage (Stephan 2012).

In addition to financing and marketization aspects, the extent to which REDD+ will meet the objectives of climate change mitigation depends also on the development of carbon accounting methodologies, and the establishment of MRV systems. Carbon accounting has thus been centre stage in policy and scholarly debates, on-the-ground interventions, and REDD+ readiness activities (Herold and Johns 2007; Herold and Skutsch 2011). Data and methods need to be robust for countries to report REDD+ performance since REDD+ result based payments will only be granted on the basis of the adequate measurement, reporting and verification of avoided carbon emissions. As such, experts have suggested that accounting and MRV systems need to stay focused on carbonrelated estimation only (De Sy et al 2012).

MRV relating to assessments of forest carbon stocks and changes is, however, a complicated matter. As much scholarly analysis has documented, monitoring and accounting technologies, approaches, and technical and institutional capacities are unevenly distributed across scales, domains and REDD+ countries (Gupta et al. 2012; Gupta et al. 2014; Ochieng et al. 2016; Verchot and Petkova 2010; Salvini et al. 2014; Turnhout, Skutsch 2015; Jagger et al. 2014; Romijn et al. 2012; Leach and Scoones 2013). The availability of robust and credible data, particularly in developing countries, remains a key challenge, given uncertainties and political considerations associated with calculating baselines or reference levels against which to assess REDD+ performance. This is also the case in determining the scale (national, sub-national, or local) at which to account for avoided carbon emissions. Despite such challenges, most technical MRV experts increasingly believe that reliable systems that assess stocks and flows of carbon at a national scale are feasible and countries' forest monitoring capacities have significantly improved (Romijn et al. 2012).

A growing body of work in the critical social sciences has highlighted, however, the political implications of the debates around carbon accounting and MRV systems, including those pertaining to issues of data availability, reliability and integration. Such writings note the political salience that accounting rules and outcomes acquire when financial rewards become linked to them (Turnhout, 
Skutsch 2015; Skutsch et al. 2014), even though they continue to be framed as technical matters to be negotiated and institutionalised within expert settings (Gupta et al. 2012; Gupta et al. 2014). A related strand of work notes that the requirements for stringent MRV systems may also lead to unequal access to REDD+ interventions in developing countries, as some countries have greater capacity to establish such systems and/or to negotiate their content (Gupta et al. 2014). Combined with the current focus on carbon and the mostly national scale used to balance stocks and flows of carbon, this would suggest that through MRV systems, REDD+ may end up reproducing existing inequalities between experts and administrators and local forest dependent actors.

Taking into account the issues discussed in relation to carbon-centred REDD+, it is evident that the early win-win enthusiasm for REDD+ was exaggerated: it has not proven to be a simple and efficient way to mitigate climate change or conserve tropical forests. We turn next to the second conceptualisation of REDD+, where the focus shifts from carbon to also include co-benefits.

\subsubsection{Co-benefit-centred REDD+: assessing expectations and experiences}

As we pointed out above, from early on, REDD + was expected to not only help to mitigate climate change and conserve forests but also to deliver environmental and social benefits, such as contributing to livelihoods, sustainable development, enhanced governance, and biodiversity conservation. These are referred to collectively as co-benefits or REDD+ safeguards (VisserenHamakers, McDermott, et al. 2012; McDermott et al. 2012; Chhatre et al. 2012). There is an important but subtle difference between these two notions: while the idea of safeguards (anchored in the UNFCCC guidance on REDD+) focuses on the prevention of harm, a push for co-benefits from REDD+ requires it to do more good, thus creating a positive externality.

Although there are currently no specific REDD+ payments linked to co-benefits at the international level, countries are strongly encouraged to actively pursue such benefits in their national-level REDD + implementation according to their specific needs, interests and national circumstances (UNFCCC 2015b). This call is also reflected in several policy documents at the national level, suggesting widespread support for the importance of co-benefits, including through involving local communities in the design and monitoring of REDD+ (Vijge et al. 2016). However, the rather centralised design of REDD+ as specified in the UNFCCC Warsaw Framework may prevent such benefits from being realised in practice (Sandbrook et al. 2019; Phelps et al. 2010). Some argue that the financial resources that will flow to developing countries may incentivise national governance to recentralise forest governance, thereby undermining any potential positive effects of earlier decentralisation efforts. Others stress that decentralisation of forest management is not necessarily favourable to local communities and only works better under very specific circumstances (Wunder 2010). Some go further in supporting current recentralisation efforts and calling for a stronger national involvement in REDD+ governance, given that formerly decentralised governance arrangements are seen, in such a view, as problematic in generating co-benefits (Davis and Daviet 2010). What is evident is that it will be up to national governments to decide to what extent and how local actors receive results-based payments from REDD + . As such, concerns persist that REDD+ funds will remain at national (rather than subnational or local) levels (Sandbrook et al. 2019; Phelps et al. 2010; Minang, Duguma, et al. 2014; Balderas Torres and Skutsch 2012; Skutsch et al. 2015).

Extensive REDD+ literature has also demonstrated that the delivery of co-benefits requires appropriate governance arrangements, including institutional and contract design (Muradian 2013; Tacconi et al. 2013). Doing this effectively and equitably, however, remains a challenge, particularly 
for poorer countries where governance is weak, corruption often prevalent and enforcement feeble (Kanowski et al. 2011; Skutsch et al. 2014; Hufty and Haakenstad 2011; Karsenty and Ongolo 2012). REDD+ can therefore also be seen as a large-scale governance experiment or an attempt at state building in those areas where the state has historically been weak (Lederer 2012). Similarly, while stakeholder participation is mentioned in most project documents and minimum requirements of free, prior and informed consent (FPIC) in implementing REDD+ projects are mostly adhered to, the participation of local communities in the decision-making and design of REDD+ projects varies significantly across projects (Lawlor et al. 2013). Furthermore, when questions of access and inclusion stem from contested land tenure-related national policies, REDD+ interventions cannot resolve these (Larson 2011; Sunderlin et al. 2014; Larson et al. 2013). Initial assessments do demonstrate, however, that socioeconomic benefits are limited when REDD+ implementation disregards the skills, interests and potential of local actors through top-down, predefined development strategies (Pokorny et al. 2013).

Notwithstanding these problems and challenges facing the implementation of REDD+ with broader benefits, there are clear signs that co-benefits are being taken seriously in the implementation of REDD + . This means that to date, there is little evidence of extensive carbonization occurring in practice. In contrast, some research has shown that the potential to generate biodiversity and community benefits are among the most important reasons for the selection of specific areas for REDD+ demonstration activities (Cerbu et al. 2011). Furthermore, though actual poverty reduction impacts of REDD+ projects remain limited (Lawlor et al. 2013), most REDD+ projects focus more strongly on socioeconomic and environmental co-benefits than on carbon benefits (Fischer et al. 2016).

This is also evident from the fact that only around $20 \%$ of the REDD+ projects are currently engaged in actual carbon transactions and of these, only a few rely solely on finances from such transactions (Fischer et al. 2016). Moreover, $81 \%$ of all REDD+ projects that involve carbon transactions are also certified by a standard for co-benefits such as the Climate, Community Biodiversity standards (CCB), the Forest Stewardship Council (FSC) or Rainforest Alliance (Goldstein and Gonzalez 2014). In part, this can be explained by the fact that many REDD+ projects already existed as nature conservation or integrated conservation and development projects prior to the introduction of REDD+ (Sunderlin et al. 2014). According to some, however, this state of affairs raises questions about the additionality of REDD + , and hence the effectiveness of REDD+ as a climate mitigation strategy (Fischer et al. 2016).

Thus, to date, we see implementation of REDD+ based on different sources of financing, which target the delivery of a wide variety of social, economic, and biodiversity benefits without an exclusive focus on carbon. In light of the future financial prospects for REDD+ vis-à-vis carbon benefits noted above, this diversity of funding may prove a useful strategy for securing the necessary financing for diverse REDD+ interventions, while at the same time ensuring the delivery of cobenefits (Hufty and Haakenstad 2011). Such a strategy would also fit well with recent developments within REDD+ negotiations in an international context, where it is increasingly linked to sustainable development imperatives. In the Paris Agreement, for example, the link between REDD + and the sustainable development goals is noted, (UNFCCC 2015a; Climate Focus 2016) and current donor preferences also reflect a strong emphasis on securing social and sustainable development benefits from REDD+. 
In considering the prospects that REDD+ will generate co-benefits, a related issue has been whether such benefits are also to be monitored, reported on, and verified, at what level, and to what end. To date, the mainstream understanding (also within the UNFCCCC) has been that co-benefits are important for REDD+, but are not to be included in MRV systems. Although they may be included as safeguards or conditions for payment, they will not be used to determine the payment itself. Indeed, this seems to be the dominant trend in practice as well, given that there are very few initiatives designed explicitly to monitor co-benefits (Jagger et al. 2014; Vijge et al. 2016; Dickson and Kapos 2012).

Furthermore, most developing countries, even those with relatively advanced forest monitoring systems, lack the capacity to implement co-benefit and community-based monitoring (Jagger et al. 2014; Pratihast et al. 2013). Capacities for social monitoring that covers, among others, rights, participation and other social benefits, and environmental monitoring that includes biodiversity, soil, water and other ecosystem services are sometimes in place, but they have usually been developed by different expert communities who remain largely disconnected from each other (Pistorius 2012; Visseren-Hamakers, McDermott, et al. 2012). There are some suggestions to aim for such interdisciplinary integration, at least for environmental aspects. Scholars have noted, for example, that many of the same remotely sensed and field-based datasets that are being leveraged to measure changes in forest carbon emissions can also be used to assess changes in biodiversity, hydrology and water resources, and soil resources. However, this may not be possible for social parameters. Thus, while it may be possible to take advantage of multiple data streams, including field measurements from community-based monitoring, and remote sensing data analysis (Pratihast et al. 2013), and use them for inter-calibration and validation (Bellfield et al. 2015; Vergara-Asenjo et al. 2015), there remains a problematic disconnect between the widely available large-area data on forest change derived from remote sensing (Hansen et al. 2013) and the fine-scale data needed to monitor processes and changes in social conditions (Jagger et al. 2014). While some observers assess that progress in this realm has been made (Romijn et al. 2012), another observed tendency is for governments and other actors to shy away from taking on monitoring tasks in situations where key datasets are missing and basic capacities need to be established, unless there are clear (financial) incentives to do so. Finally, the issue of sovereign decision-making comes up again, as governments in tropical forest countries rightly claim that co-benefits are also not systematically measured or linked to any financial transfers in countries of the global North. This suggests that debates relating to accounting for REDD+ (both for carbon, but also for co-benefits that go beyond carbon) are likely to continue in the foreseeable future.

In sum, therefore, existing experience highlights that, while on the project-level, REDD+ is characterised by a strong focus on co-benefits, developments relating to finance and MRV systems continue to be primarily concerned with carbon. Results-based payments are to be granted relative to avoided carbon emissions documented through sufficient and credible evidence generated by accounting and MRV. If co-benefits remain excluded from the accounting and financing architectures of REDD + and are not seen as results to be awarded with payments, REDD+ may yet result, in certain instances, in a carbonization of forest governance (Vijge 2016).

This suggests that in practice, rather than generating triple wins, REDD+ interventions are likely to be characterised by trade-offs between forest conservation, climate change mitigation, and local development and livelihood benefits (Blom et al. 2010; Ghazoul et al. 2010; Caplow et al. 2011; Hirsch et al. 2011). For example, research has shown that the forests to be conserved when aiming 
for maximum carbon emission reduction impact will not always be the most urgent areas for biodiversity conservation (Paoli et al. 2010; Strassburg et al. 2010; Potts et al. 2013; Larsen et al. 2011; Pandey et al. 2014). Fears are also being raised that the establishment of REDD+ related conservation areas will lead to the expulsion of local forest dependent people as was recently observed in Lao PDR (Dwyer et al. 2016).

As we have discussed in this section, the implementation of co-benefit-centred REDD+ reveals a mixed picture, with evidence of REDD+ taking co-benefits into account at the project level, but at the same time, a persistence of trade-offs and a continued foregrounding of carbon in REDD+ finance and MRV systems. We turn next to the expectations and current experiences with the newest conceptualisation: landscape-centred REDD+.

\subsubsection{Landscape-centred REDD+: assessing expectations and experiences}

As we noted in the introduction, the third, most recent, conceptualisation of REDD+ widens its scope of activities and/or the context within which it is to be conceived and implemented considerably. In this third, landscape-centred conceptualisation of REDD+, the linkages between forests and other forms of land use, particularly agriculture, come to the fore, with concurrent extensive focus on engaging relevant stakeholders beyond traditional forest-related multi-level decision-making arrangements (Robiglio et al. 2014; Ngendakumana et al. 2014; Minang and van Noordwijk 2014). This implies that REDD+ decision-making has to go beyond forest-related ministries and departments (Visseren-Hamakers, Gupta, et al. 2012; Skutsch and McCall 2010) and become integrated with other policy areas that affect stocks and flows of forest carbon, including drivers of deforestation (Salvini et al. 2014; Minang, Duguma et al. 2014).

The most important direct driver of tropical deforestation is commercial agriculture, in particular large-scale industrial agriculture (Houghton 2012; Hosonuma et al. 2012; Lambin and Geist 2002; Boucher and Elias 2013). Commercial logging, selective logging activities, illegal logging, fuel wood collection, and charcoal production are other known drivers. So far, however, REDD+ has not been able to effectively address the political economy underlying these drivers, among others because decision-makers prioritise short-term economic priorities and entrenched powerful interests (Brockhaus et al. 2013a; Dkamela et al. 2014; Di Gregorio et al. 2015). The problem of conflicting government agendas undermining REDD+ policies is well documented, especially in relation to land tenure, (Larson et al. 2013; Naughton-Treves and Wendland 2014) and economic activities such as infrastructure development and mining (Murdiyarso et al. 2012). Even in Indonesia, a forerunner of REDD+ with strong political support (Brockhaus et al. 2012), there is opposition to zerodeforestation pledges by palm oil companies because of the potential socio-economic impacts. The consequence is that, even if forest policies are effective in enhancing carbon stocks, they are likely to ultimately fail because the drivers of deforestation remain unaddressed (Locatelli et al. 2011).

Those advocating for a landscape approach to REDD+ note that for it to be able to address drivers, REDD+ needs to be situated within the broader context of multi-level climate, forest, and biodiversity policies, and the broader dynamics of land use in forested landscapes in tropical countries (Corbera and Schroeder 2011). Specifically, such a conceptualisation envisions REDD+ becoming integrated into wider decision-making about land use, beyond that pertaining directly to forests. Our current state of understanding with regard to such an approach in practice includes, pre-dominantly, initiatives for cross-sectoral integration in national contexts such as Indonesia and Brazil. In both these contexts, the expansion of industrial agriculture is a significant driver of 
deforestation, and land-use decision-making is heavily influenced by large and powerful agribusiness companies (Cerbu et al. 2011; Nepstad, Irawan et al. 2013). REDD+ implementation in these contexts has thus also been characterised by efforts to incentivise agricultural private sector stakeholders to reduce their land-use emissions and impacts on deforestation, including through involvement in developing Nationally Appropriate Mitigation Actions (NAMAs) under the auspices of the UNFCCC (van Noordwijk et al. 2014). Such initiatives have taken the form of zero deforestation commitments, agricultural commodity roundtables, or deforestation-free supply chains, which are intended to be implemented in a landscape across commodity production areas (Boucher and Elias 2013; Brack and Bailey 2013).

Less well documented to date are examples of landscape approaches to REDD+ being tried in contexts where agribusiness companies do not play a substantial role, and where deforestation is driven by small-scale or subsistence agriculture. While in some such cases, local REDD+ projects may be scaled-up and may influence decision-making across agricultural and multifunctional landscapes, most REDD+ projects are insufficiently connected with national or jurisdictional approaches to stimulate such broader change (Fischer et al. 2016; Peters-Stanley et al. 2013).

Other key stakeholders that influence land-use decision-making are the regional authorities or provincial governments, who influence decision-making within their jurisdictional areas. Again, Brazil and Indonesia are often cited as examples where regional authorities have taken a leading role in exploring landscape approaches (Nepstad, Irawan et al. 2013; Toni 2011) particularly because regions from both countries were involved early on in the Governor's Climate and Forest (GCF) taskforce. These early jurisdictional approaches are now catalysing new initiatives such as Low Emission Rural Development (LEDR), which recommends combining efforts led by regional governments to decrease land-based emissions across a particular jurisdictional area, with efforts by the agricultural private sector to decrease emissions. Another, similar, conceptualisation is the 'green economy' approach, through the creation of 'productive, profitable, and sustainable landscapes that sequester and store more carbon and will enable enhanced delivery of environmental services' (UNEP 2014). For REDD+ this would imply the development of business models that are in line with sustainable forest management practice, thereby shifting the focus of REDD+ from a conservation to a sustainable livelihood strategy (Bustamante et al. 2014).

Despite these initiatives, practice to date suggests that REDD+ has so far not effectively adopted a landscape approach. In general, plans to link REDD+ to other policy sectors such as agriculture, for example, remain vague (Vijge and Gupta 2014) and the disconnect in policy, research and practice between the forest and agriculture sector remains one of key areas overlooked in REDD+ (Minang, van Noordwijk et al. 2014; De Sy et al. 2015). This means that the hoped-for transformational change towards landscape approaches to REDD+, as a trigger for more climate-smart development pathways, will remain difficult, at least in the short to medium term (Fischer et al. 2016; Brockhaus et al. 2013; Di Gregorio et al. 2015).

The enormity of the challenge should not be underestimated. Landscape level REDD+ may also require integrated accounting and MRV systems that go beyond existing demands of forest carbon (and non-carbon) monitoring, to also assessing the dynamics of carbon stocks and flows in a landscape. However, the typical complexities of land-based systems, including different human impacts, past land uses, and unforeseen events such as fires and extreme weather events make assessment of their mitigation potential complicated, adding considerable complexity to accounting 
and MRV systems. Moreover, cropland, grassland and forestland are currently being treated separately in the IPCC land use accounting guidelines, which will make integration of such different land uses difficult (IPCC 2006). Also the issue of co-benefits will be further complicated in a landscape approach, as the variety of stakeholders, land uses, and non-co-benefits derived from land will be more diverse.

In relation to finance, adopting a landscape approach could further catalyse the already discernible trend to combine different sources of funding in REDD+. For example, REDD+ could be aligned with existing private flows and development finance (Edwards et al. 2014). One approach has been to promote new value chains of non-timber forest products that can enhance local incomes while conserving forests (Nunes et al. 2012). Agricultural value chains too, particularly of tropical commodities (e.g., cocoa and coffee) may be integrated in REDD+ (Nepstad, Irawan et al. 2013; Newton et al. 2013). If REDD+ will be able to establish relationships with other markets and financial instruments, its impacts can be significant (Lee and Pistorius 2015). However, it is important to recognise that the complexity of REDD+ will nonetheless increase. Specifically, the distribution of benefits and financial rewards is likely to become increasingly demanding, complicated and difficult to justify. Although scholars and policy practitioners continue to debate policy integration in REDD+, (Ochieng et al. 2013; Visseren-Hamakers 2015) the fact that the Paris Agreement does not mention agriculture shows that an integrated, landscape approach to REDD+ is likely to remain politically contested and is still a long way to go (Climate Focus 2016).

\subsection{Conclusion: The REDD+ Paradox and Merits of Heterogeneity}

Our review of the expectations and experiences associated with diverse and evolving conceptualisations of REDD+ provide a portrait of the challenges and opportunities facing REDD+ implementation in a post-Paris era. We have shown that the current level of financing is insufficient, and that currently no compliance market for forest carbon credits exists. As such, we can conclude that the expectations that carbon-centred REDD+ would be a simple and efficient mechanism for climate mitigation are not currently being met. At the same time, there is a growing recognition that REDD+ needs to generate co-benefits. Even as their delivery is challenging and there are signs of trade-offs between climate, biodiversity and social benefits, our review shows that REDD+ projects do take co-benefits into account and there is little evidence that carbon concerns are systematically dominating at the expense of communities and their livelihoods. Thus, while there is arguably still much to be desired in this area, experiences so far allow for cautious optimism that the expectations of co-benefits-centred REDD+ can be furthered. This also suggests that the fears that REDD+ would contribute to large-scale commodification and carbonization of the forest at the expense of communities and co-benefits have not materialised.

However, before such a conclusion can be justified, we need to reconsider the relation between these two conceptualisations of REDD+ and their implementation. Carbon-centred REDD+ implementation has not yet materialised at scale, partially because of a lack of stringent and wellfunctioning compliance markets for carbon trading in recent years, and a viable price for carbon. These financial constraints have created a situation in which the trading of carbon credits is limited and takes place only in the voluntary market. However, in a post-Paris context, this could be set to change as article 6 of the Paris Agreement envisions a new 'sustainable development mechanism.' 
Whether this will include REDD+ as a market-based offset mechanism is an open issue and remains very contested in the context of the UNFCCC (Streck et al. 2016).

Nonetheless, such a mechanism is likely to again foreground carbon. REDD+ continues to have a strong focus on carbon as the basis for results-based payments, based on systems that can measure, report and verify outcomes, and there is currently no indication that the delivery of co-benefits may become included in MRV systems or in payments. Consequently, if and when results-based payments occur at scale, a potential carbonization of forest governance remains a possibility. This implies an emerging paradox for REDD + , where the failure to meet carbon-related financial expectations has created optimism about (at least) the delivery of co-benefits, yet where attempts to meet such financial expectations, for example, by establishing a global REDD+ financial mechanism, may risk existing achievements with respect to co-benefits.

The third, newest conceptualisation of landscape-centred REDD+ also needs to be considered in this light, since it requires REDD+ to take into account an even wider variety of carbon and noncarbon benefits, land-uses and actors. There is recognition of the importance of going beyond carbon and beyond forests even in the (more technical) REDD+ literature that addresses carbon accounting and MRV challenges. However, such acknowledgement is routinely tempered by arguments that high-light existing financial and data hurdles to making even a carbon-centred REDD+ work (Visseren-Hamakers, Gupta, et al. 2012; De Sy et al. 2012). While a REDD+ that goes well beyond generating carbon benefits is likely to be seen as more legitimate by a broader group of actors, the potential for such a conceptualisation of REDD+ to be operational and effective remains rather limited, given the current focus on carbon in finance and monitoring (McDermott 2014). As such, a carbon-centred REDD+ may increase the likelihood of effectively resolving data and financial issues, but not without risking delivery of co-benefits. In light of this, with regard to the potential for REDD+ to become a catalyst for sustainable landscapes and more 'climate-smart development,' our review highlights that such conceptualisations can only further exacerbate the REDD+ paradox.

This suggests that, rather than asking whether and how REDD+ can overcome implementation challenges associated with ever-broader conceptualisations, the more pertinent question becomes whether broader conceptualisations are desirable in the first place, and at what cost. Addressing this requires viewing the different concerns associated with REDD+ as more than just implementation challenges, but rather as a politically contested question of what REDD+ should be.

In considering what REDD+ should be, and its future evolution, our assessment suggests that a pragmatic and heterogeneous approach to conceptualising and implementing REDD + is likely to prevail. REDD+ interventions will (continue to) use forest carbon accounting data as the basis for financial rewards, while proactively incorporating co-benefits as safeguards and as conditions for payments. Such a pragmatic approach does not place carbon and non-carbon benefits on equal footing from a global REDD+ policy, MRV or financing perspective and it maintains distinctions between forests and the wider landscapes in which they are situated.

In view of the diversity of REDD+ expectations and experiences discussed in our review, the idea of REDD+ serving as one coherent, integrated, top-down global financial mechanism with one (set of) objectives, is unlikely to come to pass. Instead, REDD+ may well remain a patchwork of different initiatives driven by distinct conceptualisations and associated objectives, with a focus on carbon, co-benefits or landscapes, as relevant (aligned with the merits of a more polycentric 
approach to governance) (Ostrom 2010). This implies, nonetheless, that the paradoxes, dilemmas and trade-offs across diverse conceptualisations of REDD+ will remain. However, as long as there remains scope for context-specific variation and adaptation, including prioritisation of co-benefits, such a pragmatic, polycentric approach may still enable REDD+ to make a distinctive and important contribution to keeping forests and their multi-functionality on the international agenda. 


\section{Drivers of Deforestation and REDD+ Benefit-Sharing: A Meta-Analysis of the (Missing) Link ${ }^{7}$}

\subsection{Introduction}

REDD+ was first discussed as RED (reducing emissions from deforestation) during the eleventh Conference of the Parties (COP) to the UNFCCC in 2005, and was subsequently launched as REDD $+{ }^{8}$ at the thirteenth UNFCCC COP in 2007. REDD+ has been described as "the world's largest experiment in Payments for Ecosystem Services (PES)" (Corbera 2012: 612), under which international financial transfers to the national or sub-national level (in developing countries) are expected to incentivise change that reduces deforestation and forest degradation. REDD+ was initially welcomed with enthusiasm as a seemingly simple and cheap solution to the problem of greenhouse gas emissions from deforestation and forest degradation. Yet it has become evident that it will be far more challenging to implement than originally thought and the initial optimism has since been tempered (Pistorius 2012; Buizer et al. 2013; Gupta et al. 2012).

In recent years, debates about various facets of REDD+ have expanded greatly, with a plethora of stakeholders debating whether and under what conditions such a mechanism is likely to be successful. A growing body of REDD+ research has been undertaken by both natural and social scientists (Den Besten et al. 2014; Visseren-Hamakers, Gupta et al. 2012), a consequence of which has been that important sub-topics are now addressed in a fragmented manner (for a recent analysis, see Gupta et al. 2016). While natural scientists are now actively participating in analysing drivers of deforestation, REDD+ benefit-sharing has remained largely the domain of social science.

It remains important, however, to bridge the divide between these two critical aspects of REDD+. An implicit assumption underpinning REDD+ scholarly debates and/or REDD+ interventions is that benefits accruing from REDD+ will target (at least some) actors who are in a position to reduce the direct and indirect drivers of deforestation and forest degradation, and thereby ensure that they are incentivised to change their behaviour. Yet whether this assumption is a valid one, and whether such a link between drivers and REDD+ benefits indeed exists, has not been comprehensively and systematically analysed, and/or has been analysed only for specific REDD+ projects. A number of economic studies analyse whether financial incentives distributed via REDD+ benefit-sharing mechanisms are sufficient to compensate the opportunity costs of leaving forest intact versus converting them to alternative land uses, with mixed results (Börner et al. 2010; Butler et al. 2009; Irawan et al. 2013). However, little attention has been given to analysing whether the full range of REDD+ project interventions and associated benefit-sharing (much of which is non-financial in nature) can incentivise behavioural change that also targets drivers. To our knowledge, there is as yet no systematic meta-analysis of the state of the art knowledge of this relationship, as distilled from existing scholarly analyses. In this paper, we thus analyse how the links, if any, between benefits

\footnotetext{
${ }^{7}$ This chapter has been published as: Weatherley-Singh, J. and Gupta, A. 2015. "Drivers of Deforestation and REDD+ Benefit-Sharing: A Meta-Analysis of the (Missing) Link.” Environmental Science \& Policy 54: 97-105. https://doi.org/10.1016/i.envsci.2015.06.017

${ }^{8}$ REDD stands for reducing emissions from deforestation and forest degradation in developing countries. REDD+ includes the addition of further climate mitigation activities in the forest sector, namely the role of conservation, sustainable management of forests and enhancement of forest carbon stocks, as introduced in the UNFCCC (2007) Bali Action Plan
} 
accruing from REDD+ projects, and drivers of deforestation and forest degradation, have been examined to date in the burgeoning scholarly literature and in the large number of REDD+ project design documents now available. Through such an analysis, we aim to not only further conceptual clarity about the nature of this relationship, but also distil generalised observations that can facilitate future research.

We proceed as follows: the next section briefly synthesises how drivers and benefits have been discussed in REDD+ scholarly analyses. Section 3 then outlines the methodology we followed for our meta-analysis. In Sections 4 and 5, we present and discuss our findings, followed by a conclusion.

\subsection{Drivers of Deforestation and REDD+ Benefits: Linkages and Theories of Change}

In this section, we briefly review how benefits, and drivers of deforestation and forest degradation are being analysed in the REDD+ literature to date. We also assess if "theories of change" are being advanced in analysing (lack of) linkages between them.

\subsubsection{Conceptualising REDD+ benefits and benefit-sharing mechanisms}

While benefits are a mainstay of the rapidly expanding literature on REDD+, the concept has been understood in multiple ways. Luttrell et al. (2013), for example, describe three types of REDD+ net benefits (i.e. gross benefits minus costs). These include, first, the direct (financial) benefits accruing to a REDD+ project from selling carbon credits, or receiving donor or government funding. Second, they can include indirect (financial and non-financial) benefits resulting from improved forest-related ecosystem services. These may include, for example, regulation of water supplies for irrigation, reductions in flood and landslide risk, and provision of income from non-timber forest products, such as latex, wild cocoa, honey, gums, and nuts (Secretariat of CBD 2001; Mullan 2014). Third, benefits can include indirect (non-financial) benefits resulting from REDD+ implementation, such as land tenure reform or increased community capacity for local governance, in cases where this strengthens local community rights and access to land and resources.

REDD + benefit-sharing refers to "the distribution of both the monetary and the non-monetary benefits generated through the implementation of REDD+ projects" (Thuy et al. 2013:1). A distinction is often made between vertical benefit-sharing between actors at national, regional and local levels versus horizontal benefit-sharing between and within communities and households (IUCN 2009). REDD+ benefit-sharing mechanisms are the "variety of institutional means, governance structures and instruments that distribute finance and other net benefits" (Luttrell et al. 2012:131). The growing literature on REDD+ identifies various benefit-sharing mechanisms that are now being tested in REDD+ projects. These include, for example, PES; community-based forest management (CBFM), and integrated conservation and development projects (ICDP) (IUCN 2009; Costenbader 2011). Benefit-sharing remains one of the most contentious areas of REDD+ (Skutsch 2013), however, and whether benefit-sharing mechanisms, such as PES and ICDP, can deliver both equitable and effective REDD+ outcomes is highly debated in the literature (for example, Pattanayk et al. 2010; Sunderlin and Sills 2012). 
REDD+ benefit-sharing may also be associated with policy processes, such as governance reforms and fiscal incentives (Chagas et al. 2011, Vijge and Gupta 2014). Policy reform may be needed to transform financial incentives that encourage economic activities associated with deforestation, to those that incentivise alternative activities compatible with forest conservation. Benefit-sharing thus also forms part of the current discourse on 'nested' approaches to REDD+, which considers distribution of incentives at different scales of activity, from national to regional and local. Yet, nested approaches to REDD+ pose a key challenge: how to design a hierarchy of complementary incentives or benefit-sharing approaches (Minang and van Noordwijk 2013), and manage potential trade-offs in distributing incentives for behavioural change across different levels (Chagas et al. 2011).

Another dimension of REDD+ benefit-sharing relates to the rationales for it: going beyond incentivising behavioural change that targets drivers, to also ensuring that forest dependent communities benefit from REDD+ on equity grounds. As such, the benefit-sharing literature displays significant divergences between two (potentially competing) rationales, first, an 'effectiveness and efficiency' rationale that focuses on reducing carbon emissions, and second, an 'equity' rationale that focuses on the right of local communities to benefit from REDD+ (Luttrell et al. 2012). While recognising the crucial importance of equity considerations, our primary aim here is to assess whether REDD+ interventions, and the benefits accruing from them, are responsive to the (direct and indirect) drivers of deforestation and forest degradation, as a means to incentivise behavioural change.

\subsubsection{Conceptualising drivers of deforestation and forest degradation}

In addition to benefits and benefit-sharing, the growing REDD+ literature extensively discusses drivers of deforestation and forest degradation (Pacheco et al. 2012; Houghton 2012). As this literature documents, deforestation and forest degradation often result from a complex interplay of both direct drivers (operating at local or regional levels) and indirect drivers (operating at local, regional, national and international levels). Currently, commercial and subsistence agriculture are the direct drivers of more than $70 \%$ of deforestation, and logging and fuelwood extraction are the major direct drivers of forest degradation (Hosonuma et al. 2012). Increasing international trade and commodity flows resulting from economic globalisation are exacerbating this complex relationship (Lambin and Meyfroidt 2011). In light of this, some call for a hybrid approach to addressing drivers, whereby REDD+ projects target local, direct drivers, and national REDD+ policies and strategies target national and indirect drivers (see, for example, Poffenberger 2009). One advantage of such a strategy would be that targeted local interventions that respond well to local drivers would be less likely to result in so-called "leakage" or a shift of unsustainable practices to other locations (Fisher et al. 2011).

With regard to national-level drivers, an important study by Kissinger et al. (2012) provides a first analysis of how such drivers are being addressed (or not) within national REDD+ Readiness Strategies, including through identified benefit-sharing mechanisms. The study found, inter alia, that national REDD+ Readiness Strategies do not yet sufficiently target commercial agriculture and the associated indirect international drivers behind it, even though these are set to become even more important in the future.

In this article, we contribute to this line of analysis by assessing the envisioned benefits accruing from REDD+ projects currently being implemented, and their responsiveness to the direct and indirect drivers of deforestation and forest degradation. Such an analysis allows us to (re)assess key 
claims in the literature regarding this relationship. For example, a study by Blom et al. (2010) found that the rhetoric of several early REDD+ projects closely resembled that of integrated conservation and development projects (ICDPs), although these projects have received considerable criticism for overemphasising the role of poverty as a driver of deforestation (McShane et al. 2011). A more systematic and comprehensive analysis of the envisioned linkages (or lack thereof) between deforestation/degradation drivers and benefit-sharing through REDD+ projects can thus permit assessment of whether this remains the case.

Finally, assessing the (lack of) interlinkages between drivers and benefit-sharing allows also for assessment of whether REDD+ can serve as a catalyst for transformative change in the land-use sector of tropical forested countries. As Furman (2009: 5) states, a 'theory of change' is a "coherent set of ideas that describes: what the change should be, how a change process occurs, what makes it happen, what has to happen for the intended result/ outcome to be reached, who needs to be involved, whose interests are at stake, and what the result/ outcome of a change process should be". Such theories of change remain, however, relatively rare. Putz and Romero (2012: 676) for example, note the need for "....informed and innovative approaches framed by robust and dynamic theories of change that promote linkages among the different players who influence the fates of tropical forested landscapes and resources". Our aim here is thus also to assess if such theories of change are discernible in the multiple scholarly analyses of drivers and/or REDD+ benefit-sharing that we examine.

\subsection{Methodology and Approach: A Meta-Analysis of the State of the Art}

In this section, we outline the procedure and methods we used to select the academic articles and REDD+ project documents that formed the basis for our meta-analysis of the link, if any, being posited between drivers and benefits in REDD+ scholarly analyses and policy practice.

\subsubsection{Selecting and reviewing the scholarly literature}

To select the academic articles we used to assess posited linkages between drivers and REDD+ benefits, we conducted a systematic review of the scholarly literature on REDD+ in November 2013. We identified articles suitable for our analysis as follows: first, we searched for articles in the preceding five years (i.e. from 2009 onwards) with three key words, "REDD+", "driver(s)" and "benefit(s)," using the electronic databases Google Scholar, Scopus and Web of Science. While this approach may have excluded some relevant articles that did not use these keywords, we assume that we have captured the bulk of the relevant scholarly literature through this process. To keep our task manageable, we next excluded from the search results non-peer reviewed articles, reports, grey literature, book chapters, and media reports.

Our search yielded 71 academic articles that mentioned "REDD+", "driver(s)" and "benefit(s)". We classified these into three categories: those providing a general overview of REDD+ (37 articles); those examining REDD+ policy and governance at the national level (15 articles); and those analysing specific REDD+ project interventions, our focus of interest here (19 articles).

These 19 articles, which analysed 21 existing, emerging or potential REDD+ projects, formed the basis for our meta-analysis of the envisaged linkages, if any, being posited in the scholarly literature between drivers and benefits (Table 3.1). As we found very few articles examining existing REDD+ 
projects in-depth, we included in our analysis: pilot REDD+ projects; pre-existing forest projects identified as having the potential to become REDD+ projects; land use studies that identified potential REDD+ project interventions; and landscape areas over which one or more pilot REDD+ projects were being implemented. We hereafter refer to all of these as 'REDD+ projects'. They all aimed, through their interventions, to generate certain benefits, and each thus also identified benefitsharing mechanisms, including PES, community-based forest management (CBFM), or integrated conservation and development projects (ICDP). Most of the 21 projects analysed in these 19 articles were based in Africa (9) (with Tanzania, Ghana and Cameroon featuring in more than one article) and Asia (8) (with Cambodia and the Philippines featuring in two articles), with a smaller number in Latin America (4).

In undertaking our meta-analysis, we systematically reviewed the analyses of the 21 projects in these 19 articles to identify, first, which drivers of deforestation and forest degradation were identified therein; second, the envisioned project interventions and benefits to be generated and shared; and third, the posited links, if any, between identified drivers and REDD+ benefits. As a final step, we considered whether a theory of change, i.e. a description of the change processes required for a REDD+ project to address specific drivers, was advanced in any article. Through this analysis, we aimed to compliment the work already done by Kissinger and colleagues to assess whether drivers and benefits are being considered at the national-level in REDD+ Readiness Strategies (Kissinger et al. 2012).

Table 3.1 Scholarly analyses of REDD+ projects: articles included in the meta-analysis

\begin{tabular}{|l|l|l|}
\hline REDD+ Intervention & Country/ Region & References \\
\hline $\begin{array}{l}\text { Agricultural sustainability approaches with } \\
\text { the potential to become REDD+ projects }\end{array}$ & Asia (1), Africa (1) & Lusiana et al. (2012); Molua (2012) \\
\hline Payment for Ecosystem Services (PES) & $\begin{array}{l}\text { Latin America (1), } \\
\text { Africa (1), Asia (2) }\end{array}$ & $\begin{array}{l}\text { Plumb et al. (2012); Bugalho et al. (2011); } \\
\text { McElwee (2012); Yang et al. (2013) }\end{array}$ \\
\hline $\begin{array}{l}\text { Community-based forest management } \\
\text { (CBFM) }\end{array}$ & $\begin{array}{l}\text { Africa (2), Asia (3), } \\
\text { Latin America (3) }\end{array}$ & $\begin{array}{l}\text { Mustalahti et al. (2012); Karky et al. } \\
\text { (2013); Lasco et al. (2011); Poffenberger } \\
\text { (2009); Cronkleton et al. (2011); Robinson } \\
\text { et al. (2013) }\end{array}$ \\
\hline $\begin{array}{l}\text { Pre-REDD+ participatory projects } \\
\text { identified as having potential to become } \\
\text { REDD+ projects }\end{array}$ & Asia (1), Africa (1) & Bourgoin et al. (2013); Asare et al. (2013) \\
\hline $\begin{array}{l}\text { Projects with a mix of agricultural } \\
\text { sustainability measures, PES, CBFM, } \\
\text { and/or Integrated Conservation and } \\
\text { Development Projects (ICDP) }\end{array}$ & Africa (3), Asia (2) & $\begin{array}{l}\text { Essomba et al. (2013); Fisher et al. (2011); } \\
\text { Ros-Tonen et al. (2013); Lasco et al. } \\
\text { (2013); Ty et al. (2011) }\end{array}$ \\
\hline
\end{tabular}




\subsubsection{Selecting and reviewing REDD+ project design documents}

We also reviewed 28 project design documents (PDDs) to assess, again, the linkages between drivers and benefits in REDD+ pilot projects. In choosing which PDDs to include in our analysis, our selection criteria were: first, that they be Climate, Community and Biodiversity Alliance (CCBA) certified, even if certification had since expired. CCBA certified REDD+ projects are wellestablished and expected to reach a higher standard of performance in terms of positive consequences for climate, community and biodiversity, as compared to other REDD+ projects. While such a selection criterion might introduce a bias into our study, we focused on such projects precisely because of the likelihood that they could catalyse transformative change, given their focus on a broader range of REDD+ benefits beyond carbon. The bias was lessened, however, by the fact that very few of the projects examined in the scholarly analysis (discussed above) concerned CCBA certified projects. Second, we selected projects with an "avoided deforestation" focus, since these were, in our view, more likely to highlight casual relationships between drivers and benefit-sharing, as compared to reforestation projects focusing on replanting areas deforested in the past, where certain drivers may no longer be operating.

In contrast to the projects described in the scholarly literature, the CCBA projects we selected were mostly based in Latin America (17) (with 5 projects in Brazil, 4 in Peru and 2 in Belize), with a smaller number from Africa (7) and Asia (4). As with the meta-analysis of the scholarly literature, we analysed these 28 selected PDDs to assess which direct and indirect drivers operating at international, national and local levels they identified, if any in the context of a given REDD+ project, and the range of benefits (envisioned to be) generated and shared through specific interventions.

We turn next to the results of our meta-analysis of the scholarly literature and the REDD+ project design documents.

\subsection{Findings of the Meta-Analysis}

\subsubsection{Assessing linkages between drivers and benefits: meta-analysis of the scholarly literature}

Our analysis and findings with regard to the meta-analysis of the scholarly literature are captured in Table 3.2. This table shows the number (and percentage) of the 21 projects discussed in the 19 scholarly articles that refer a given driver of deforestation and forest degradation as being relevant in that context, and the benefits (intended to) accrue from specified REDD+ interventions. Of the 21 REDD+ projects, 19 noted the importance in a given context of more than one driver, and 16 covered more than one project intervention and associated benefit.

As Table 3.2 demonstrates, the most frequently noted drivers in the scholarly literature were local or regional direct drivers of deforestation and degradation. In many cases, furthermore, linkages were assumed to exist between such drivers and the benefits deriving from REDD+ interventions. Agriculture was identified as being the most significant direct local or regional driver of deforestation, and it was also (sought to be) targeted by some REDD+ interventions and associated benefitsharing mechanisms. For example, the driver "commercial agriculture" (mentioned in $43 \%$ of the projects) was being, to some extent, targeted by REDD+ interventions and associated benefit- 
sharing relating to "agricultural intensification or support for alternative high value cash crops" (mentioned in 33\% of all analysed projects). Similarly, the driver "conversion for subsistence agriculture" (mentioned in 38\% of projects) was being targeted by "increasing the productivity of subsistence farming" (mentioned in 29\%). However, the direct driver "conversion for livestock farming" (29\%) appeared not to be targeted by REDD+ benefit-sharing mechanisms.

Illegal logging was the most significant local or regional direct driver of degradation (mentioned in $48 \%$ of all analysed projects), which was sought to be targeted in some cases by "community-based forest management" (38\%). Other local direct drivers of degradation also appeared to be targeted, to greater or lesser extent, by REDD+ interventions and associated benefit-sharing, for example, "fuelwood extraction" (38\%), being targeted by "energy efficiency interventions" (19\%); "commercial logging" (29\%), by "forest certification schemes" (19\%); "forest fires" (19\%), by "forest fire management" measures (10\%); and "trade in non-timber forest products" (14\%), by "support for alternative livelihoods" (19\%). To a lesser extent, linkages were also posited between some national-level indirect drivers and REDD+ benefits, for example, the driver "government support for commercial agriculture" $(10 \%)$ or "logging" $(10 \%)$ was being targeted by "land-use planning" (14\%); and the driver "unclear land tenure" (19\%) by "land tenure reform" efforts $(29 \%)$. Interestingly, relatively few project analyses mentioned poverty $(24 \%)$ or a lack of alternative income sources $(24 \%)$ as indirect drivers, although many of projects were being implemented in rural communities with low average incomes. Instead, the analyses largely referred to poverty alleviation as an additional aim (or co-benefit) of REDD+ interventions, rather than as a driver to be addressed.

In terms of developing a 'theory of change', all 19 articles highlighted the stakeholders and interests that would need to be involved to achieve transformative change, yet did not go significantly beyond this. For example, 18 of the 21 projects identified (in some cases, only in vague terms) certain elements of the change process that would need to take place for REDD + project interventions and associated benefit-sharing mechanisms to reduce deforestation and forest degradation. However, the results of such a change process remained largely unassessed and were completely unknown or unpredicted for 11 of the analysed REDD+ projects. Scholarly analyses of six projects that incorporated PES or CBFM schemes that pre-dated REDD+ did propose some expected results, in terms of the extent to which benefit-sharing mechanisms would be likely to reduce deforestation or forest degradation. A further four analyses of potential or pilot REDD+ projects used economic or simulation models to predict the probable impacts of incentives distributed through benefit-sharing mechanisms on the drivers of deforestation or forest degradation. 
Table 3.2 Scholarly analyses of REDD+ projects: targeting drivers through benefits

\begin{tabular}{|c|c|c|c|c|c|c|}
\hline Driver & Scale & Type & $\begin{array}{c}\text { No. } \\
\text { and \% } \\
\text { of } \\
\text { Projects } \\
(n=21)\end{array}$ & $\begin{array}{l}\text { Project Interventions } \\
\text { and Associated } \\
\text { Benefits }\end{array}$ & Scale & $\begin{array}{c}\text { No. } \\
\text { and \% } \\
\text { of } \\
\text { Projects } \\
(n=21)\end{array}$ \\
\hline \multicolumn{7}{|l|}{$\begin{array}{l}\text { Deforestation - } \\
\text { Agricultural } \\
\text { conversion }\end{array}$} \\
\hline $\begin{array}{l}\text { Conversion for } \\
\text { commercial } \\
\text { agriculture }\end{array}$ & $\begin{array}{l}\text { Local / } \\
\text { Regional }\end{array}$ & Direct & $9(43 \%)$ & $\begin{array}{l}\text { Agricultural } \\
\text { intensification or } \\
\text { support for high value } \\
\text { cash crops }\end{array}$ & $\begin{array}{l}\text { Local / } \\
\text { Regional }\end{array}$ & $7(33 \%)$ \\
\hline $\begin{array}{l}\text { Conversion for } \\
\text { subsistence } \\
\text { agriculture }\end{array}$ & Local & Direct & $8(38 \%)$ & $\begin{array}{l}\text { Increasing subsistence } \\
\text { agriculture productivity }\end{array}$ & Local & $6(29 \%)$ \\
\hline $\begin{array}{l}\text { Conversion for } \\
\text { livestock }\end{array}$ & $\begin{array}{l}\text { Local / } \\
\text { Regional }\end{array}$ & Direct & $6(29 \%)$ & & & \\
\hline \multirow{2}{*}{$\begin{array}{l}\text { Government support } \\
\text { for commercial } \\
\text { agriculture }\end{array}$} & National & Indirect & $2(10 \%)$ & Land-use planning & Regional & $3(14 \%)$ \\
\hline & & & & $\begin{array}{l}\text { Creation of Protected } \\
\text { Areas }\end{array}$ & $\begin{array}{l}\text { Local/ } \\
\text { Regional }\end{array}$ & $3(14 \%)$ \\
\hline \multicolumn{7}{|l|}{$\begin{array}{l}\text { Forest Degradation } \\
\text { - Logging }\end{array}$} \\
\hline Illegal logging & $\begin{array}{l}\text { Local / } \\
\text { Regional }\end{array}$ & Direct & $\begin{array}{l}10 \\
(48 \%)\end{array}$ & $\begin{array}{l}\text { Community based } \\
\text { forest management }\end{array}$ & Local & $8(38 \%)$ \\
\hline Commercial logging & $\begin{array}{l}\text { Local / } \\
\text { Regional }\end{array}$ & Direct & $6(29 \%)$ & $\begin{array}{l}\text { Sustainable timber } \\
\text { management / FSC } \\
\text { certification }\end{array}$ & $\begin{array}{l}\text { Local/ } \\
\text { Regional }\end{array}$ & $4(19 \%)$ \\
\hline $\begin{array}{l}\text { Logging for domestic } \\
\text { use }\end{array}$ & Local & Direct & $4(19 \%)$ & $\begin{array}{l}\text { Community based } \\
\text { forest management }\end{array}$ & Local & $8(38 \%)$ \\
\hline $\begin{array}{l}\text { Government support } \\
\text { for commercial } \\
\text { logging }\end{array}$ & National & Indirect & $2(10 \%)$ & Land-use planning & Regional & $3(14 \%)$ \\
\hline $\begin{array}{l}\text { International demand } \\
\text { for timber }\end{array}$ & $\begin{array}{l}\text { Internatio } \\
\text { nal }\end{array}$ & Indirect & $2(10 \%)$ & & & \\
\hline \multicolumn{7}{|l|}{$\begin{array}{l}\text { Forest Degradation } \\
\text { - Other Direct } \\
\text { Drivers }\end{array}$} \\
\hline Fuelwood extraction & $\begin{array}{l}\text { Local / } \\
\text { Regional }\end{array}$ & Direct & $8(38 \%)$ & $\begin{array}{l}\text { Energy efficiency } \\
\text { interventions }\end{array}$ & Local & $4(19 \%)$ \\
\hline
\end{tabular}




\begin{tabular}{|c|c|c|c|c|c|c|}
\hline Forest fires & Local & Direct & $4(19 \%)$ & Forest fire management & $\begin{array}{l}\text { Local/ } \\
\text { Regional }\end{array}$ & $2(10 \%)$ \\
\hline $\begin{array}{l}\text { Trade in non-timber } \\
\text { forest products }\end{array}$ & $\begin{array}{l}\text { Local / } \\
\text { Regional }\end{array}$ & Direct & $3(14 \%)$ & $\begin{array}{l}\text { Support for alternative } \\
\text { livelihoods }\end{array}$ & Local & $4(19 \%)$ \\
\hline \multicolumn{7}{|l|}{$\begin{array}{l}\text { Deforestation and } \\
\text { Forest Degradation } \\
\text { - Other Indirect } \\
\text { Drivers }\end{array}$} \\
\hline Unclear land tenure & National & Indirect & $4(19 \%)$ & Resolving land tenure & $\begin{array}{l}\text { Local / } \\
\text { National }\end{array}$ & $6(29 \%)$ \\
\hline $\begin{array}{l}\text { Increasing } \\
\text { population }\end{array}$ & $\begin{array}{l}\text { Local / } \\
\text { National }\end{array}$ & Indirect & $2(10 \%)$ & & & \\
\hline $\begin{array}{l}\text { Weak law } \\
\text { enforcement }\end{array}$ & $\begin{array}{l}\text { Local / } \\
\text { National }\end{array}$ & Indirect & $2(10 \%)$ & & & \\
\hline Corruption & $\begin{array}{l}\text { Local/ } \\
\text { National }\end{array}$ & Indirect & $2(10 \%)$ & & & \\
\hline Ease of access & Local & Indirect & $2(10 \%)$ & & & \\
\hline $\begin{array}{l}\text { Deforestation and } \\
\text { Degradation } \\
\text { Indirect Driver - } \\
\text { Poverty }\end{array}$ & & & & $\begin{array}{l}\text { Other Interventions } \\
\text { and Associated } \\
\text { Benefits }\end{array}$ & & \\
\hline $\begin{array}{l}\text { Lack of alternative } \\
\text { income sources }\end{array}$ & Local & Indirect & $5(24 \%)$ & Direct payments & $\begin{array}{l}\text { Local/ } \\
\text { Regional }\end{array}$ & $7(33 \%)$ \\
\hline \multirow[t]{4}{*}{ Poverty } & Local & Indirect & $5(24 \%)$ & Ecotourism (income) & Local & $2(10 \%)$ \\
\hline & & & & $\begin{array}{l}\text { Debt alleviation and/or } \\
\text { microcredit schemes }\end{array}$ & Local & $2(10 \%)$ \\
\hline & & & & Provision of education & Local & $2(10 \%)$ \\
\hline & & & & Provision of clean water & Local & $2(10 \%)$ \\
\hline
\end{tabular}

Note: A driver or benefit was not included if it was only mentioned in one of the 21 projects 


\subsubsection{Assessing linkages between drivers and benefits: meta-analysis of REDD+ PDDs}

The results of our analysis of the 28 REDD+ project design documents (PDDs) are shown in Table 3.3. The table captures, as did our Table 3.2, the frequency with which different drivers, and specific REDD+ interventions and associated benefits, are mentioned in the 28 PDDs. All of the REDD+ projects covered by the PDDs mentioned more than one driver, and all but one introduced at least two project interventions with associated benefit-sharing.

Based on the posited linkages between drivers and benefits, as discernible from our review of these 28 PDDs (outlined in Table 3.3), we can discern several similarities in our findings with the scholarly analysis. The PDD analysis also shows some linkages being made between local or regional, direct drivers of deforestation and degradation, and REDD+ interventions and associated benefit-sharing. Conversion to agriculture was again identified as the dominant local, and/or regional, direct driver of deforestation; with "conversion for subsistence agriculture" (identified as a local driver in 57\% of projects) targeted by REDD+ interventions aimed at increasing productivity (64\%); and "conversion for commercial agriculture" (50\%) targeted, but to lesser extent, by "support for high value cash crops and non-timber forest products" (29\%). The PDD analysis also confirmed another finding from our analysis of the scholarly literature: that a significant gap remained in targeting the direct driver "conversion to livestock farming" (57\%). In the PDD documents, this driver was only sought to be targeted in a limited way, for example, through a push to "increase livestock farming sustainability" (21\%).

As envisioned in these PDD documents, REDD+ project interventions also sought to target local or regional drivers of forest degradation. These included, for example, "fuelwood extraction" (mentioned in $36 \%$ of the PDDs) targeted by promotion of "energy efficiency interventions" (32\%); "logging for domestic use" (32\%) by the establishment of "woodlots and tree planting" (39\%); and "forest fires" (25\%) by "forest fire management" (21\%). As with our analysis of the scholarly literature, the meta-analysis of the PDDs also revealed posited linkages between some regional and national-level indirect drivers, and certain types of REDD+ interventions and associated benefits. These included, for example, the national, indirect drivers of "unclear land tenure" (25\%), targeted by efforts to "resolve land tenure" issues (29\%); and "government support for commercial agriculture" (32\%), targeted, to some extent, by "promoting forests in regional plans" (25\%).

Furthermore, a number of national and international indirect drivers were identified that REDD+ project-level interventions were not expected to influence. These included, inter alia, population increase and in-migration to forests; international demand for agricultural commodities and timber; and fluctuations in international commodity prices.

Some differences exist, however, between the results of our analysis of REDD+ projects in the scholarly literature (Table 3.2) and the PDDs (Table 3.3). First, a number of REDD+ project-related benefits identified in the PDDs, such as provision of education (57\%) and healthcare $(50 \%)$ appeared to be disproportionately high, compared to the number of projects in which poverty $(25 \%)$ was mentioned as a driver. An explanation could be that such activities are being conceptualised as co-benefits flowing from a REDD+ intervention in PDD documents, rather than as an attempt to address poverty as a driver (as we found with our analysis of the scholarly literature). A second difference was that more drivers and benefits were identified in the PDD analysis. This could be the result of the larger overall number of PDD documents (and associated REDD+ projects) that we analysed and the greater level of detail about each intervention contained therein (compared to the scholarly analyses of REDD+ projects). One difference between the two was that a large number of 
CCBA projects stated their intention to improve "law enforcement" (75\%), as compared to analyses of the REDD+ projects in the scholarly literature, which did not highlight this issue. The PDD documents also highlighted efforts being made in CCBA-certified pilot projects to address the local driver of "small-scale mining" through efforts to increase sustainability $(11 \%)$. Furthermore,

"conversion for livestock" was the most frequently mentioned local or regional direct driver in the PDD analysis, referred to in $57 \%$ of projects, compared to only $27 \%$ of projects described in the scholarly analysis. These differences may reflect the higher percentage of CCBA projects based in Latin America, where, for example, livestock farming in tropical forest regions is more prevalent. 
Table 3.3 Analysis of REDD+ PDDs: targeting drivers through benefits

\begin{tabular}{|c|c|c|c|c|c|c|}
\hline Driver & Scale & Type & $\begin{array}{l}\text { No. and } \\
\% \text { of } \\
\text { Projects } \\
(n=28)\end{array}$ & $\begin{array}{l}\text { Project } \\
\text { Interventions and } \\
\text { Associated } \\
\text { Benefits }\end{array}$ & Scale & $\begin{array}{l}\text { No. and } \\
\% \text { of } \\
\text { Projects } \\
(n=28)\end{array}$ \\
\hline \multicolumn{7}{|l|}{$\begin{array}{l}\text { Deforestation - } \\
\text { Agricultural } \\
\text { Conversion }\end{array}$} \\
\hline $\begin{array}{l}\text { Conversion for } \\
\text { livestock }\end{array}$ & $\begin{array}{l}\text { Local / } \\
\text { Regional }\end{array}$ & Direct & $16(57 \%)$ & $\begin{array}{l}\text { Increasing livestock } \\
\text { farming } \\
\text { sustainability }\end{array}$ & $\begin{array}{l}\text { Local/ } \\
\text { Regional }\end{array}$ & $6(21 \%)$ \\
\hline $\begin{array}{l}\text { Conversion for } \\
\text { subsistence agriculture }\end{array}$ & Local & Direct & $16(57 \%)$ & $\begin{array}{l}\text { Increasing } \\
\text { subsistence } \\
\text { agriculture } \\
\text { productivity }\end{array}$ & Local & $18(64 \%)$ \\
\hline $\begin{array}{l}\text { Conversion for } \\
\text { commercial agriculture }\end{array}$ & $\begin{array}{l}\text { Local / } \\
\text { Regional }\end{array}$ & Direct & $14(50 \%)$ & $\begin{array}{l}\text { Support for high } \\
\text { value high value } \\
\text { cash crops and non- } \\
\text { timber forest } \\
\text { products }\end{array}$ & $\begin{array}{l}\text { Local / } \\
\text { Regional }\end{array}$ & $8(29 \%)$ \\
\hline $\begin{array}{l}\text { Government support } \\
\text { for commercial } \\
\text { agriculture }\end{array}$ & National & Indirect & $9(32 \%)$ & $\begin{array}{l}\text { Promoting forests in } \\
\text { regional plans }\end{array}$ & Regional & $7(25 \%)$ \\
\hline $\begin{array}{l}\text { International demand } \\
\text { for agricultural } \\
\text { commodities }\end{array}$ & $\begin{array}{l}\text { Internation } \\
\text { al }\end{array}$ & Indirect & $5(18 \%)$ & & & \\
\hline $\begin{array}{l}\text { Fluctuations in } \\
\text { commodity prices }\end{array}$ & $\begin{array}{l}\text { Internation } \\
\text { al }\end{array}$ & Indirect & $5(18 \%)$ & & & \\
\hline $\begin{array}{l}\text { National demand for } \\
\text { agricultural } \\
\text { commodities }\end{array}$ & National & Indirect & $2(7 \%)$ & & & \\
\hline \multicolumn{7}{|l|}{$\begin{array}{l}\text { Forest Degradation } \\
\text { - Logging }\end{array}$} \\
\hline Illegal logging & $\begin{array}{l}\text { Local / } \\
\text { Regional }\end{array}$ & Direct & $13(46 \%)$ & Law enforcement & $\begin{array}{l}\text { Local / } \\
\text { Regional }\end{array}$ & $21(75 \%)$ \\
\hline Commercial logging & $\begin{array}{l}\text { Local / } \\
\text { Regional }\end{array}$ & Direct & $11(39 \%)$ & $\begin{array}{l}\text { Sustainable timber } \\
\text { management and } \\
\text { FSC certification }\end{array}$ & $\begin{array}{l}\text { Local / } \\
\text { Regional }\end{array}$ & $10(36 \%)$ \\
\hline $\begin{array}{l}\text { Logging for domestic } \\
\text { use }\end{array}$ & Local & Direct & $9(32 \%)$ & $\begin{array}{l}\text { Woodlots and tree } \\
\text { planting }\end{array}$ & Local & $11(39 \%)$ \\
\hline $\begin{array}{l}\text { Local demand for } \\
\text { timber }\end{array}$ & Local & Indirect & $4(14 \%)$ & $\begin{array}{l}\text { Woodlots and tree } \\
\text { planting }\end{array}$ & Local & $11(39 \%)$ \\
\hline
\end{tabular}




\begin{tabular}{|c|c|c|c|c|c|c|}
\hline $\begin{array}{l}\text { Government support } \\
\text { for commercial } \\
\text { logging }\end{array}$ & National & Indirect & $7(25 \%)$ & $\begin{array}{l}\text { Promoting forests in } \\
\text { regional plans }\end{array}$ & Regional & $7(25 \%)$ \\
\hline $\begin{array}{l}\text { International demand } \\
\text { for timber }\end{array}$ & $\begin{array}{l}\text { Internation } \\
\text { al }\end{array}$ & Indirect & $4(14 \%)$ & & & \\
\hline \multicolumn{7}{|l|}{$\begin{array}{l}\text { Forest Degradation } \\
\text { - Fuelwood }\end{array}$} \\
\hline Fuelwood extraction & $\begin{array}{l}\text { Local / } \\
\text { Regional }\end{array}$ & Direct & $10(36 \%)$ & $\begin{array}{l}\text { Energy efficiency } \\
\text { interventions }\end{array}$ & Local & $9(32 \%)$ \\
\hline \multicolumn{7}{|l|}{$\begin{array}{l}\text { Deforestation - } \\
\text { Roads and } \\
\text { Infrastructure }\end{array}$} \\
\hline Road building & $\begin{array}{l}\text { Local / } \\
\text { National }\end{array}$ & Direct & $8(29 \%)$ & Land-use planning & Regional & $7(25 \%)$ \\
\hline $\begin{array}{l}\text { Government support } \\
\text { for infrastructure }\end{array}$ & National & Indirect & $5(18 \%)$ & $\begin{array}{l}\text { Promoting forests in } \\
\text { regional plans }\end{array}$ & Regional & $7(25 \%)$ \\
\hline \multicolumn{7}{|l|}{$\begin{array}{l}\text { Forest Degradation - } \\
\text { Mining }\end{array}$} \\
\hline Small-scale mining & Local & Direct & $6(21 \%)$ & $\begin{array}{l}\text { Increasing } \\
\text { sustainability of } \\
\text { small-scale mining }\end{array}$ & Local & $3(11 \%)$ \\
\hline $\begin{array}{l}\text { Government support } \\
\text { for mining }\end{array}$ & National & Indirect & $2(7 \%)$ & $\begin{array}{l}\text { Promoting forests in } \\
\text { regional plans }\end{array}$ & Regional & $7(25 \%)$ \\
\hline \multicolumn{7}{|l|}{$\begin{array}{l}\text { Forest Degradation } \\
\text { - Fire }\end{array}$} \\
\hline Forest fires & Local & Direct & $7(25 \%)$ & $\begin{array}{l}\text { Forest fire } \\
\text { management }\end{array}$ & $\begin{array}{l}\text { Local / } \\
\text { Regional }\end{array}$ & $6(21 \%)$ \\
\hline \multicolumn{7}{|l|}{$\begin{array}{l}\text { Deforestation and } \\
\text { Degradation } \\
\text { Indirect Drivers - } \\
\text { Land Tenure and } \\
\text { Ownership }\end{array}$} \\
\hline Increasing population & $\begin{array}{l}\text { Local / } \\
\text { National }\end{array}$ & Indirect & $9(32 \%)$ & & & \\
\hline Unclear land tenure & National & Indirect & $7(25 \%)$ & $\begin{array}{l}\text { Resolving land } \\
\text { tenure }\end{array}$ & $\begin{array}{l}\text { Local / } \\
\text { National }\end{array}$ & $8(29 \%)$ \\
\hline In-migration & $\begin{array}{l}\text { Local / } \\
\text { Regional }\end{array}$ & Indirect & $6(21 \%)$ & & & \\
\hline $\begin{array}{l}\text { Clearance to claim } \\
\text { ownership }\end{array}$ & Local & Direct & $6(21 \%)$ & $\begin{array}{l}\text { Resolving land } \\
\text { tenure }\end{array}$ & $\begin{array}{l}\text { Local / } \\
\text { National }\end{array}$ & $8(29 \%)$ \\
\hline $\begin{array}{l}\text { Conversion for } \\
\text { settlements }\end{array}$ & Local & Direct & $5(18 \%)$ & Law enforcement & $\begin{array}{l}\text { Local / } \\
\text { Regional }\end{array}$ & $21(75 \%)$ \\
\hline
\end{tabular}




\begin{tabular}{|c|c|c|c|c|c|c|}
\hline Land speculation & $\begin{array}{l}\text { Local / } \\
\text { National }\end{array}$ & Indirect & $3(11 \%)$ & & & \\
\hline $\begin{array}{l}\text { Weak landowner } \\
\text { presence }\end{array}$ & Local & Indirect & $2(7 \%)$ & Law enforcement & $\begin{array}{l}\text { Local / } \\
\text { Regional }\end{array}$ & $21(75 \%)$ \\
\hline \multicolumn{7}{|l|}{$\begin{array}{l}\text { Deforestation and } \\
\text { Degradation } \\
\text { Indirect Driver - } \\
\text { Poverty }\end{array}$} \\
\hline \multirow[t]{4}{*}{$\begin{array}{l}\text { Lack of alternative } \\
\text { income sources }\end{array}$} & Local & Indirect & $7(25 \%)$ & $\begin{array}{l}\text { Support for } \\
\text { alternative } \\
\text { livelihoods }\end{array}$ & Local & $15(54 \%)$ \\
\hline & & & & $\begin{array}{l}\text { New employment } \\
\text { opportunities }\end{array}$ & $\begin{array}{l}\text { Local / } \\
\text { Regional }\end{array}$ & $14(50 \%)$ \\
\hline & & & & Direct payments & $\begin{array}{l}\text { Local / } \\
\text { Regional }\end{array}$ & $7(25 \%)$ \\
\hline & & & & Ecotourism & Local & $5(18 \%)$ \\
\hline \multirow[t]{7}{*}{$\begin{array}{l}\text { Poverty and/or } \\
\text { indebtedness }\end{array}$} & Local & Indirect & $7(25 \%)$ & $\begin{array}{l}\text { Provision of } \\
\text { education }\end{array}$ & Local & $16(57 \%)$ \\
\hline & & & & $\begin{array}{l}\text { Provision of } \\
\text { healthcare }\end{array}$ & Local & $14(50 \%)$ \\
\hline & & & & $\begin{array}{l}\text { Community trust } \\
\text { funds }\end{array}$ & Local & $6(21 \%)$ \\
\hline & & & & $\begin{array}{l}\text { Provision of clean } \\
\text { water }\end{array}$ & Local & $6(21 \%)$ \\
\hline & & & & Microcredit schemes & Local & $5(18 \%)$ \\
\hline & & & & $\begin{array}{l}\text { Provision of local } \\
\text { infrastructure }\end{array}$ & Local & $4(14 \%)$ \\
\hline & & & & Provision of housing & Local & $2(7 \%)$ \\
\hline \multicolumn{7}{|l|}{$\begin{array}{l}\text { Other Indirect } \\
\text { Drivers of } \\
\text { Deforestation and } \\
\text { Degradation - }\end{array}$} \\
\hline \multirow[t]{2}{*}{ Weak law enforcement } & $\begin{array}{l}\text { Local / } \\
\text { National }\end{array}$ & Indirect & $9(32 \%)$ & Law enforcement & $\begin{array}{l}\text { Local / } \\
\text { Regional }\end{array}$ & $21(75 \%)$ \\
\hline & & & & $\begin{array}{l}\text { Community capacity } \\
\text { building }\end{array}$ & Local & $11(39 \%)$ \\
\hline Corruption & $\begin{array}{l}\text { Local/ } \\
\text { National }\end{array}$ & Indirect & $7(25 \%)$ & Law enforcement & $\begin{array}{l}\text { Local / } \\
\text { Regional }\end{array}$ & $21(75 \%)$ \\
\hline $\begin{array}{l}\text { Lack of environmental } \\
\text { awareness }\end{array}$ & Local & Indirect & $3(11 \%)$ & $\begin{array}{l}\text { Environmental } \\
\text { education }\end{array}$ & Local & $5(18 \%)$ \\
\hline
\end{tabular}

Note: A driver or benefit was not included if it was only mentioned in one of the 28 PDDs. 


\subsection{Discussion: (How) are REDD+ Projects Addressing Drivers?}

The findings of our meta-analysis show that the ability of REDD+ projects to tackle drivers through project interventions and associated benefit-sharing remains variable at best, with some (local, regional and direct) drivers more easily targeted than others.

First, our analysis has highlighted that the benefits and benefit-sharing mechanisms currently envisioned within REDD+ projects are responsive to certain local direct drivers of forest degradation, such as fuelwood collection, forest fires and illegal logging, and some local direct drivers of deforestation, particularly clearance for subsistence agriculture. Many projects have sought, for example, to increase the sustainability and productivity of subsistence agricultural systems, as revealed both through the scholarly analysis and PDD documents. Furthermore, our analysis also suggests that REDD+ projects are going beyond ICDP approaches in that they are providing benefits for communities such as education and healthcare. This is not because they necessarily assume that poverty is a main driver of deforestation, but rather because they aim to achieve poverty alleviation goals as an additional co-benefit for local communities, for reasons of equity and legitimacy.

Second, and related to the above, our analysis also reveals that REDD+ benefit-sharing mechanisms are also going beyond ICDP approaches to target drivers operating at regional and national levels, by providing direct payments via PES schemes and by attempting to reform policies in relation to improved land tenure and land-use planning. Although such interventions, especially land tenure reform and the beneficiaries thereof, remain much debated and contested (Rival 2013; Resosudarmo et al. 2013; Larson et al. 2013; Naughton-Treves and Wendland, 2014), they do signal an attempt within REDD+ projects to target drivers operating beyond the local level in certain instances.

Third, REDD+ projects seem to target, to some extent, clearing of forest for commercial agriculture as a major local or regional direct driver of deforestation, with certain projects seeking to assist with agricultural intensification or the introduction of alternative cash crops. However, very few projects target the driver "conversion of livestock farming", despite the fact that this is frequently mentioned as a local or regional direct driver of deforestation. In some cases, livestock producers are seen as being targeted through direct payments shared through PES schemes, but for the most part, they are not being widely targeted by REDD+ interventions and associated benefit-sharing.

This implies a need for policy reforms in the context of a national REDD+ strategy to address this specific driver. Yet, as revealed in earlier analyses of such national strategies, only $29 \%$ of them are advocating livestock management interventions (Kissinger et al. 2012:19). Other REDD+ research has concluded that cattle ranching should be targeted as a priority for REDD+ interventions, for example, given that its expansion threatens forests in many locations (Müller et al. 2011). Our metaanalysis thus supports calls made by some for REDD+ interventions that target agricultural expansion (Nepstad, Irawan et al. 2013) through policy reforms, and with a particular focus on livestock producers.

Fourth, although our analysis highlights that REDD+ project interventions and associated benefitsharing are at least targeting some indirect national or regional-level drivers, such as unclear land tenure and government support for logging or agricultural expansion, it also shows that various 
indirect drivers, such as corruption or population increases, including through in-migration, are not being targeted by REDD+ interventions. Unsurprisingly, as also demonstrated by the analysis of national REDD+ Readiness Strategies by others, governments are not intending to tackle these difficult and sensitive issues through their national REDD+ strategies either (Kissinger et al. 2012).

Fifth, our analysis confirms that currently envisaged REDD+ interventions and associated benefitsharing are unable to respond to drivers relating to high and increasing international demand for timber and agricultural commodities. Our findings in this regard are likely to be an underestimate, moreover, as indirect international drivers are often not even identified as relevant by REDD+ project documents. Kissinger et al. (2012) found that REDD+ national strategies were also failing to identify and respond to such international drivers. This is increasingly a concern highlighted in the REDD+ literature, which points to conflicting policy agendas and government support for activities that stimulate international demand for commodities, notably agriculture, logging, infrastructure developments, and mining (Larson and Petkova 2011; Corbera and Schroeder 2011; Murdiyarso et al. 2012; and Vatn and Vedeld 2013) as a key hurdle for transformative change through REDD+.

Where the impetus and responsibility for change in this context should lie remains a contested and challenging issue. In particular, there appears to be little pressure emanating from the international level to address these drivers, particularly if the advent of REDD+ is seen as a transfer of responsibility for tackling deforestation to developing countries and local forest communities. The decision on drivers in the context of methodological guidance on REDD+ within the UNFCCC, as agreed at the Conference of the Parties in Warsaw in 2013, is telling in not explicitly referring to international drivers. Instead, it reinforces somewhat the view that forest communities are primary agents of deforestation, insofar as the decision states that "...livelihoods may be dependent on activities related to drivers of deforestation and forest degradation” (UNFCCC 2013b).

Our analysis thus also highlights the need to explore how an evolving global REDD + architecture can address international demand-side drivers, if at all; and/or whether REDD+ should be complimented by other initiatives. Lessons from the EU's Forest Law Enforcement Governance and Trade (FLEGT) mechanism can be instructive here, in providing an approach to tackle indirect international drivers that could be complementary to REDD+ projects and national strategies (Broekhoven and Wit, 2014; EU FLEGT Facility 2015).

\subsection{Conclusions and a Future Research Agenda}

Despite the vast reams of academic writing on REDD+, our meta-analysis of both the scholarly literature and REDD+ PDDs reveals a lack of systematic consideration of the precise links between drivers of deforestation and REDD+ interventions and associated benefit-sharing. While some economic studies have reviewed the potential impacts of payment for ecosystem services schemes on drivers by using economic models and cost benefit analysis to predict expected outcomes, such analyses remain largely conjectural (Plumb et al. 2012; Busch et al. 2012). The limited research done to date to analyse the transformative potential of REDD+ projects on the ground to address drivers is partially explainable by the fact that REDD+ is still being negotiated within the UNFCCC and only now being operationalised (Visseren-Hamakers, Gupta et al 2012). As such, many studies of the 
effectiveness of REDD+ project interventions to address drivers remain inconclusive or else are highly dependent on local conditions, for example, in relation to PES (McElwee 2012; Pham et al. 2014) or agricultural intensification (Phelps et al. 2013).

In addition, very few scholarly analyses articulate a theory of change as a tool for evaluating impacts of REDD+, as advocated, for example, by Putz and Romero (2012). In our review of the scholarly literature, we were only able to discern the tentative outlines of such theories of change. These included the identification of stakeholders to be targeted in a change process, or expected outcomes based on lessons learnt from earlier PES schemes (e.g., Yang et al. 2013; McElwee 2012), or from community-based forest management (CBFM) (e.g., Cronkleton et al. 2011; Robinson et al. 2013). Broader theories of change with regard to complex international-national-local linkages driving degradation and deforestation are largely absent. In concluding, our analysis reveals a remaining need for greater theoretical and empirical understanding of the causal relationships between the complex web of drivers of deforestation and forest degradation operating at different levels, and the impacts of benefit-sharing, as part of the range of nested interventions being developed through REDD+. 


\section{An Ecological Landscape Approach to REDD+ in Madagascar: Promise and Limitations??}

\subsection{Introduction}

Reducing emissions from deforestation and forest degradation $(\mathrm{REDD}+)^{10}$ is a mechanism being developed under the UNFCCC that financially compensates developing countries for reducing greenhouse gas emissions from deforestation and forest degradation, conserving and sustainably managing forests and enhancing forest carbon stocks (UNFCCC 2011). Over the last decade, pilot REDD+ projects have proliferated in a multitude of developing countries, resulting in a patchy coverage of forest-sector projects that appear inadequate to deal with many of the drivers of deforestation and forest degradation, especially those operating beyond the local level (WeatherleySingh and Gupta, 2015). Although many countries are now in the process of developing national REDD+ strategies, implementation of such strategies is in its infancy, and a key challenge remains their ability to respond to drivers, most of which originate outside the forest sector (Salvini et al. 2014; Kissinger et al. 2012), including agricultural drivers.

In recent years, sub-national REDD+ initiatives have therefore been explored and are gaining traction, including landscape approaches (Bernard et al., 2013; Pacheco et al., 2011). A landscape approach to REDD+ is ostensibly intended to address drivers outside of the forest sector, as compared to project-level forest-sector focused REDD+ interventions. In particular, efforts labelled landscape REDD+ include involving and incentivising agricultural producers to reduce land-based greenhouse gas emissions, thereby tackling agricultural expansion as one of the main drivers of deforestation (Nepstad, Irawan et al. 2013). It is assumed that landscape-oriented REDD+ initiatives can complement the ongoing development and implementation of local-level projects and nationallevel REDD+ strategies, within a nested hierarchy of approaches to REDD+. However, the assumption that landscape approaches to REDD+ addresses drivers remains largely untested, and challenges remain in the development and design of such programmes (Bastos-Lima 2017, Minang and van Noordwijk, 2013), including incorporating sub-national activities into national-level frameworks (Bernard et al. 2014). Landscape approaches to REDD+ are a relatively recent addition to the burgeoning academic literature in this field, with few in-depth inquiries into how and why particular landscape approaches are emerging, and whether they are better able to address deforestation and degradation drivers.

Madagascar is one country where landscape approaches to REDD+ are being explored, but presents a challenging context for their development and implementation. The agricultural sector is mainly subsistence and small-scale (Conservation International 2014), making it difficult to engage the private sector. The country is also characterised by extremely high levels of poverty, especially in rural areas (World Bank 2010). Furthermore, despite past efforts at decentralisation, the governance structure remains extremely centralised, with weak governance capacities at regional and local

\footnotetext{
${ }^{9}$ This chapter has been published as: Weatherley-Singh, J., and A. Gupta. 2017. “An Ecological Landscape Approach to REDD + in Madagascar: Promise and Limitations?” Forest Policy and Economics 85. https://doi.org/10.1016/j.forpol.2017.08.008

${ }^{10}$ REDD + stands for: reducing emissions from deforestation and forest degradation in developing countries; and the role of conservation, sustainable management of forests and enhancement of forest carbon stocks in developing countries
} 
administrative levels (Vaillancourt 2008). Madagascar was initially a forerunner in the development and implementation of REDD+, with several early local-level REDD+ projects (Ferguson 2009). These early projects benefited from the long-standing interest and engagement of scientists and international donors in the country's unique and outstanding biodiversity (Myers et al. 2000), which is threatened by deforestation (Harper et al. 2007). One of the earliest examples of these REDD+ projects is the Makira project located in northeast Madagascar, which began as a pilot carbon mitigation project in 2001. Due to the area's remoteness, the principal drivers of deforestation and forest degradation here are small-scale. The Makira project's long history of involving local communities in reducing deforestation and generating co-benefits make it an interesting case to study activities to combat local direct drivers. The Makira project continued to develop with the beginning of carbon credit sales in 2013, even as a political crisis stalled the development of REDD+ at the national level. With other REDD+ projects and national REDD+ discussions recommencing, it is timely to analyse Madagascar's experiments with REDD+ and the recent interest in landscape approaches.

This article has a two-fold aim. First, we analyse how landscape approaches to REDD + are being conceptualised in the academic and policy literature, and develop a typology of different conceptualisations; and second, we assess which approach to REDD+ landscapes may be emerging in Madagascar, if any, and whether it is able to address both direct and indirect drivers of deforestation and forest degradation. We proceed as follows: Section 2 assesses diverse conceptualisations of landscape approaches to REDD+ in the literature. We identify here a typology of such approaches, which we characterise as economic, political and ecological. Section 3 then discusses the political context for the emergence of REDD+ in Madagascar, and identifies the emergence herein of an ecological landscapes approach to REDD+. Section 4 then discusses whether an ecological landscape approach to REDD+ is well-positioned in this context to address indirect drivers of deforestation and forest degradation. Section 5 undertakes a similar analysis for direct drivers. Here we also draw on empirical analysis of the REDD+ Makira project and its prospects of addressing direct, small-scale local drivers, viewing it as an example of the kind of project that could be scaled up in implementing an ecological landscape approach to REDD+ in Madagascar.

Our analysis is based on a field visit to Madagascar, including to the Makira REDD+ project, in December 2014. We draw on semi-structured interviews with 28 Makira project beneficiaries (from the communities of Ambodivoany, Marovovonana and Ambalamahogo) from 5 to 7 December 2014, and an additional 20 semi-structured interviews with stakeholders informed of REDD+ developments at the national-level in Madagascar. These were conducted from December 2014 to December 2015, in person and by skype and phone. The national-level stakeholders interviewed included representatives of 4 NGOs, 3 government ministries or agencies, 3 private companies, 3 research institutes or universities, and 4 international donors (see Appendix 3 for a list of nationallevel interviewees). 


\subsection{Conceptualising Landscape Approaches to REDD+: A Typology}

Greater emphasis is now being given to REDD+ in UNFCCC discussions, particularly in Article 5 of the Paris Agreement negotiated during the $21^{\text {st }}$ COP in 2015, which highlights the importance of conserving and enhancing forests. Although the UNFCCC does not refer specifically to landscape approaches to REDD+ (Turnhout et al. 2016), there is a general understanding within the REDD+ community that a landscape approach considers the carbon storage potential of the wider landscape, rather than just the forest, given that most deforestation drivers originate outside of the forest sector (Vanderhaegen et al. 2015). The development of landscape approaches is therefore often cited as a way of addressing drivers beyond the forest sector (Bernard et al. 2013; Pirad and Belna 2012). With the inclusion of REDD+ within the Paris Agreement, and the growing interest in landscape approaches as a means of REDD+ implementation, it is timely to examine what such approaches entail, their innovative elements, and assumptions regarding their prospects to address drivers of deforestation and forest degradation.

From a review of the academic literature, it is possible to discern a number of key elements, which are increasingly associated with a landscape approach to REDD+. First, the notion of "jurisdictional REDD+" is now being used to refer to politically-determined administrative areas within which local government administrations lead on REDD+ initiatives (Gari, 2013) and as a way of linking REDD+ projects to sub-national or national-level strategies (Fischer et al. 2016). A related notion is that of a sub-national jurisdictional approach which emphasises an economic conceptualisation of REDD+ landscapes to include land-based production systems or commodity production areas as appropriate scales at which to work with large agricultural producers to incentivise change (Nepstad, Irawan et al. 2013). An ecological understanding of a landscape approach to REDD+ is also now discernible as a system of landscape planning that incorporates a range of ecosystems that can store carbon and mitigate climate change, in addition to forests (Rival 2013). Most recently, research from a development perspective is calling for REDD+ to include the concept of 'territory' based on land users rights, in identifying REDD+ landscapes (McCall 2016). Drawing on these diverse conceptualisations, we identify and discuss here, a typology of landscape approaches to REDD+ which we characterise as economic, political and ecological (see Figure 4.1). 


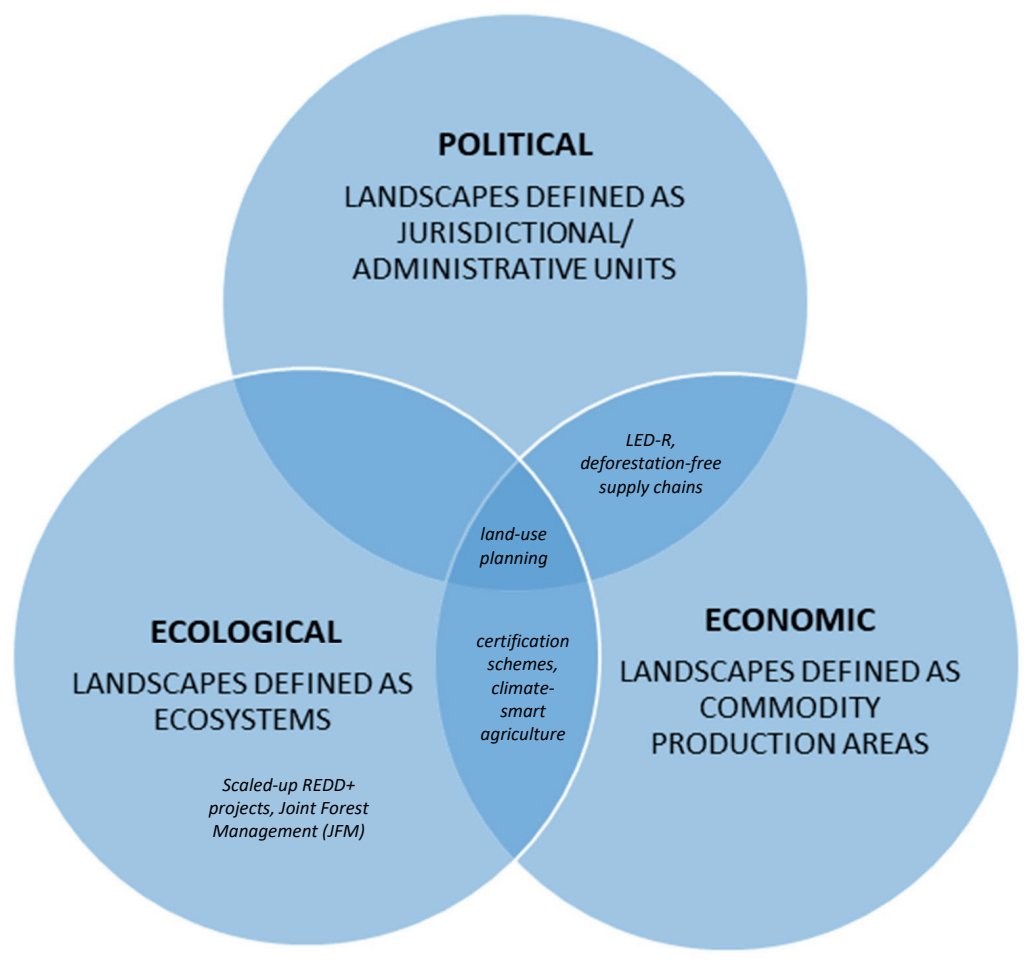

Figure 4.1 Conceptualisations of landscape approaches to REDD+

Economic landscape approaches: Much of the discussion about landscape REDD+ in the academic literature is based on the experiences of Indonesia and Brazil (for example, Fishbein and Lee 2015), two countries that are leading the development of REDD+ activities (Cerbu et al. 2011). In both the Indonesian and Brazilian context, there is a need to address the expansion of industrial agriculture because it is the major driver of deforestation. Companies have therefore been incentivised, partly in response to public pressure (Tollefson 2015), to reduce their negative impacts on forests through engagement in initiatives such as deforestation-free supply chains, sustainable commodity roundtables and certification schemes across their commodity production areas, an approach we term 'economic'. This landscape approach to REDD+ has also developed to some extent out of a need to engage agricultural companies in the development of Nationally Appropriate Mitigation Actions (NAMAs) in order to reduce land based emissions (van Noordwijk et al. 2014). In sum, the economic approach to landscapes is being driven by large agribusiness companies, in collaboration with governments.

Political landscape approaches: The advent of NAMAs under the UNFCCC is also influencing conceptualisations of REDD+ landscape approaches from what we define as a 'political' perspective. Some provincial governments are attempting to deliver emissions reductions as part of a 
nested approach to achieving overall emission reductions through NAMAs at the national level (Minang et al. 2015). Such efforts often link to the concept of Low Emission Rural Development (LED-R), and the need to decrease all land-based emissions within a particular political jurisdiction, as is emerging under 'jurisdictional' REDD+ (Dewi et al., 2013; Nepstad et al., 2012). There is considerable overlap between political and economic conceptualisations of landscape REDD+ (as illustrated in Figure 4.1), and several scholars are advocating for jurisdictional REDD+ to more closely integrate with voluntary initiatives led by large agricultural companies to reduce their impact on deforestation and decrease their emissions across commodity production areas (Nepstad, Irawan et al. 2013; Boucher and Elias 2013). Notwithstanding overlaps with economic approaches, however, the political-administrative approach to landscapes is more carbon-centric and driven by provincial and national governments acting in collaboration to meet emission reduction targets.

Ecological landscape approaches: Finally, we identify the emergence of what we term an 'ecological' conceptualisation of REDD+ landscapes, deriving from a conservation science discourse that mainly defines landscapes on the basis of shared ecological or biological characteristics. The Secretariat of the Convention on Biological Diversity (CBD 2011) refers, for example, to an ecological approach to REDD+ landscapes, as being concerned with incorporating conservation of different ecosystems, including forests. Such an approach attempts to find a balance between different land uses (Molua 2012:83), and is mainly promoted by those interested in REDD+ from a forest conservation perspective and its potential to deliver co-benefits, especially for biodiversity (for example, Potts et al. 2013). Yet, as Sayer et al. (2013) report, there are also differences in the conceptualisation of ecological landscapes, from those that exclusively focus on biogeographical characteristics to more recent perspectives that aim to reconcile conservation and development trade-offs (see, for example, Leventon et al. 2014, and Bastos-Lima et al (2017a) for an analysis of synergies between REDD+ and the Sustainable Development Goals). Given that there are unlikely to be significant overlaps between political jurisdictions and ecosystem boundaries, ecologicallybased landscape approaches necessarily involve a complex web of actors rather than a dominance of formal state administrations (van Oosten 2013). But ecologically based areas may overlap with economically-defined commodity production areas (Thompson, 2015), thus the agricultural private sector may be involved in ecological landscape approaches, for example initiatives relating to climate-smart agriculture (Salvini et al. 2016) or sustainable agriculture (Harvey et al. 2013), as shown in Figure 4.1. In conclusion, the ecologically-based conceptualisation is mainly being driven by proponents of forest conservation, with the involvement of agricultural producers in some cases. Implementation of such a landscape approach and its responsiveness to both direct and indirect drivers is important to assess, given that it has received less attention in the REDD+ literature to date than economic and politically oriented approaches.

\subsection{Deforestation, Forest Degradation and an Emerging Ecological Landscape Approach to REDD+ in Madagascar}

Madagascar has suffered from high rates of deforestation in recent decades with an estimated decrease in forest cover of $40 \%$ from the 1950's to 2000 (Harper et al. 2007). Competing narratives are well documented concerning the historical extent of deforestation in Madagascar and the primary causes (Pollini 2010). While the role of proximate, direct drivers is not marginal, given the expansion of slash and burn agriculture by local communities (Vieilledent and Grinand 2013; Desbureaux and Brimont 2015), some analysts point to indirect drivers of deforestation as being 
more important, especially the role of state actors, governance and policy failures (Horning 2012; Seagle 2010). More recently, attention has turned to the high profile illegal rosewood trade, leading to forest degradation, which is fuelled by international drivers but also by weak domestic oversight and corruption (Randriamalala and Liu, 2010).

The high levels of deforestation combined with the outstanding and unique biodiversity harboured by Madagascar's forest habitats (Myers et al. 2000) has led to high international interest in conserving remaining forest areas. International conservation NGOs and donors have therefore played an unusually prominent role in the development of the country's environmental policy (Duffy 2006), which has been further enhanced by the limited capacity of the Malagasy state due to budgetary limitations, low technical capacity and political instability (Hrabanski et al. 2013). Creating and managing protected areas (including forests) has been a high priority of the government and international donors since the 2003 World Parks Congress when Madagascar reiterated its commitment to tripling its coverage of protected areas, (Gardner et al. 2013). The high interest in forest conservation and protected areas in Madagascar also led to it becoming a forerunner in the development of REDD+, as noted earlier. As a result, it had several well-established local-level projects earlier than most other African countries (Ferguson 2009) but progress in the development and implementation of REDD+ stalled between 2009 and 2014 due to a political crisis that led to a withdrawal in donor funding. Since 2014, however, the development of a REDD+ national strategy has recommenced and the government's REDD+ Readiness Preparation Proposal was approved for funding from the World Bank's Forest Carbon Partnership Facility (FCPF) in May 2015. Alongside this process, there is now increasing interest in developing appropriate sub-national REDD+ interventions, including experimenting with landscape approaches.

The international attention given to conserving forests in Madagascar in recent decades has influenced the emergence of a landscape approach to REDD+. Stakeholders largely discuss and define landscapes in ecological terms, together with an emphasis on ensuring that it results in cobenefits for biodiversity and local communities. Such an 'ecological approach' can be discerned by the nature of the REDD+ related activities being pursued. For example, sub-national consultations related to the development of Madagascar's Readiness Preparation Proposal for the FCPF were conducted at an eco-regional level to represent all forest ecosystem areas (Ministere de l'Environnement 2014) and the government and other partners launched the World Bank funded Eco-regional REDD+ Project in March 2014. ${ }^{11}$ Interviews with stakeholders involved in the development and implementation of REDD+ in Madagascar reveal the high level of interest in and technical expertise in forest conservation from a biodiversity conservation perspective. ${ }^{12}$ Numerous forest conservation initiatives have already been implemented over the years (Erdmann 2010) with ecological landscapes at their centre, such as USAID's Eco-regional Initiatives Program (DAI 2009). These are important precursors to REDD+ landscape approaches.

The ecological landscape conceptualisation is enhanced by Madagascar's natural environment and political and economic context. Topography, geology and highly localised climatic conditions have led to distinctive biogeographic zones at the sub-national level that harbour different biodiversity

\footnotetext{
11 As reported by Etc Terra, one of the project partners, at: http://www.etcterra.org/fr/projets/perrfh (accessed November 2015)

${ }_{12}$ Nine author interviews (with two government representatives, three NGO members, three donor representatives, and one academic researcher) all emphasised this focus on biodiversity conservation. Four of these interviews took place on location in Madagascar, 9-10 December 2014; and five were conducted by telephone in the period June - August 2015
} 
(Lowry et al. 1997). These distinctive ecological regions harbour different forest types that are reported to vary in the threats they face, their ability to sequester carbon, and the attention they receive from donors (Conservation International 2014), thereby requiring regionally-adapted, distinctive landscape-oriented responses. Furthermore, in contrast to countries with advanced REDD+ initiatives at landscape scale, the agricultural private sector in Madagascar is small with limited capacity, and it has not been incentivised to engage in REDD+ because of little perceived added value in doing so. ${ }^{13}$ In addition, Madagascar's centralised governance structure, limited technical capacity and limited regional government engagement, makes it difficult to implement jurisdictional (i.e. aligned with political administrative boundaries) REDD + approaches, as has been attempted elsewhere.

In sum, developments relating to REDD+ in Madagascar, including those seeking to embed REDD+ in a broader land use context, reflect most closely what we term an ecological landscape approach here. Yet its implementation, and its potential to address indirect and proximate drivers in a manner that brings value-added to already long-standing forest conservation efforts underway, remains little analysed. We turn next to assessing current practice and the prospects for an ecological landscape approach REDD+ in Madagascar to address direct (local) and indirect drivers of deforestation and forest degradation, in order to draw conclusions about of the promise and limitations of this newest rendition of forest conversation initiatives in the region.

\subsection{An Ecological Landscape Approach to REDD+ in Madagascar: Tackling Indirect Drivers?}

As mentioned previously, competing narratives exist concerning the primary drivers of deforestation in Madagascar. While some emphasise the activities of local communities, notably the expansion of subsistence agriculture, others note indirect drivers related to poor governance, corruption and insecure land tenure, as well as international influences. These issues have been long debated in Madagascar, with recent research highlighting that the long history of forest conservation efforts has failed to successfully tackle deforestation drivers (Waeber et al, 2016). The REDD+ process in Madagascar builds on previous forest conservation efforts and has also been expert-dominated, with considerable attention given thus far to establishing baselines and monitoring, reporting and verification (MRV) mechanisms to generate forest-carbon related information. The political impact of focusing resources and attention on development of such MRV systems remains, however, little analysed, in this and other REDD+ contexts (Gupta et al. 2014; Gupta et al. 2012). With a focus on technical MRV systems, less attention has been given to addressing wider governance issues that underlie indirect deforestation drivers. This is also linked to lack of strong national government leadership and limited attempts to build political support across government ministries for REDD+, beyond the Ministry of Environment. A lack of inter-sectoral coordination at the governmental level is widely seen as a major constraint to REDD+ implementation, with a shared recognition that more needs to be done to raise the profile of REDD+ politically. ${ }^{14}$ This is not unique to Madagascar, with lack of inter-sectoral coordination and limited involvement of relevant government ministries

\footnotetext{
${ }^{13}$ Interviews with two representatives from the private sector and one researcher, in interviews conducted by phone, on the 12 June, 5 December and 5 August 2015 respectively

${ }^{14}$ Eight interviews by a government representative, three NGO representatives, one researcher and three international donors. Two interviews in Madagascar, 9 - 10 December 2014 and six interviews by telephone, May - August 2015
} 
highlighted as impediments to REDD+ implementation across a number of developing countries, including in Africa (see, for example, Somorin et al. 2014, Brickell et al. 2012 and Korhonen-Kurki et al. 2014).

Landscape-level and jurisdictional initiatives are therefore being promoted in a number of countries (Boucher and Elias 2013) as a way for REDD+ to overcome problems relating to a lack of intersectoral coordination at the national level. Nonetheless, the Madagascan case demonstrates the difficulties of implementing an ecologically-based landscape approach to REDD+ that seeks to balance competing land use sectors (e.g. mining, agriculture and conservation) in a context in which land use decisions are being taken at the national, rather than sub-national level. Key indirect drivers of deforestation and forest degradation, such as mining, are not receiving sufficient attention within national REDD+ discussions in Madagascar (World Bank 2010), even as local conflicts with forest protection are reported (Blanc-Pamard 2009) with implications for landscape approaches. As one Malagasy researcher put it, "Madagascar is divided in eco-regions, but the mining sector uses different types of zoning depending on where mineral deposits are found, leading to potential conflict". ${ }^{15}$ In the same way, large-scale agriculture has also received little attention to date as a driver, despite reports of increased foreign investment and attempted land-grabs by international agribusiness companies. ${ }^{16}$ Furthermore, the potential for private sector engagement is seen as limited to financial support for local REDD+ projects, rather than focusing on reducing the negative impacts of their activities. ${ }^{17}$

The absence of a strong agribusiness sector interested in engagement also limits the potential to shape REDD+ landscapes around commodity production areas and implement initiatives such as deforestation-free supply chains, as attempted elsewhere. Some recognition of commercial agriculture as an indirect driver can be seen from government perspectives that note, for example, that "we need to increase agricultural productivity", ${ }^{18}$ with an NGO representative stating that "more could be done nationally to promote large-scale agricultural production away from forest areas". ${ }^{19}$ Private sector representatives also see the promise in engaging agricultural companies in the development of agroforestry initiatives in partnership with communities to act as an appropriate buffer zone around protected forest areas. ${ }^{20}$ This is aligned with research from elsewhere that highlights the potential for agroforestry initiatives to serve as a strategic approach for REDD+ in Africa because of social and environmental co-benefits, such as improving food security for poor farmers and improving soil fertility (Mbow et al. 2014) while reducing pressure on forests, decreasing deforestation and contributing to biodiversity conservation (Minang, Duguma et al. 2014). However, such approaches, focusing on intensifying agricultural production and developing agroforestry projects are by no means new in Madagascar (Erdmann 2010) and may simply replicate previous forest conservation efforts.

\footnotetext{
15 Author interview with a researcher, by telephone, 4 August 2015

${ }^{16}$ Author interviews with one NGO representative, a researcher and one private sector company representative stating that they know of reports of land grabs by foreign agricultural companies. One interview in Madagascar, 10 December 2014, and two interviews by telephone, 12 June 2015 and 5 August 2015

${ }^{17}$ Interviews with two government representatives and a donor. One interview in Madagascar, 10 December 2014 and two interviews by telephone, 15 May 2015, 7 July 2015

${ }^{18}$ Interview with government representative, by telephone, 26 July 2015

${ }^{19}$ Interview with NGO representative, by telephone, 2 June 2015

${ }^{20}$ Interview with private sector representative, by telephone, 12 June 2015
} 
Insecure land tenure is another indirect driver of deforestation that REDD+ initiatives, including landscape approaches, are ill-equipped to address (Wehkamp et al. 2015). ${ }^{21}$ In the Malagasy context, this exacerbates the impacts of other drivers, such as small-scale illegal mining, in-migration and land-grabbing. As long recognised in Madagascar, an attempt to address this issue via land tenure reforms at the national level can backfire, because of tensions between the formal national system and local customary systems (Evers et al. 2006) and the potential for increasing elite capture and further undermining community land rights and access (Eilenberg 2015). An alternative, promoted by some ${ }^{22}$ is to encourage the government to develop an ecological landscape approach to REDD+ based on land zoning initiatives that seek to balance competing land uses (Molua 2012) and address the "jurisdictions of land-use sectors" (Denier et al. 2014:28) as a more pragmatic approach to the politically contested and largely unattainable aim of national land tenure reform. Again, such a suggestion is not new, yet a landscape perspective on REDD+ could, in theory, revitalise and give new impetus to it. As it is currently implemented, however, such approaches to addressing indirect drivers are not yet being given serious consideration within the REDD+ discussions in Madagascar. ${ }^{23}$

In sum, what we have identified as an ecological conceptualisation of a landscape approach in this context appears to reinforce the perception of REDD+ as a niche environmental issue subservient to increasing economic pressures on land, such as commercial agriculture and mining. As currently constituted, the range of stakeholders involved does not represent the inter-sectoral collaboration required to deliver the assumed benefits of a landscape approach. Instead of presenting a new hoped-for solution to tackling indirect drivers, the approach taken appears to be stymied by the same weaknesses as previous forest conservation efforts, insofar as the focus is on changing the behaviour of local communities assumed to be the primary drivers of deforestation (Seagle 2010), without also tackling indirect drivers (national and international) that lie outside of the forest sector.

\subsection{An Ecological Landscape Approach to REDD+ in Madagascar: Tackling Direct Drivers?}

Notwithstanding the importance of targeting indirect drivers, it is important to consider if REDD+ landscape approaches are succeeding in targeting small-scale direct drivers in the Malagasy context. These might be related to the activities of local communities, such as the expansion of slash and burn agriculture (known as tavy) mainly for subsistence, small-scale mining, logging, fuelwood consumption and grazing (Ministere de l'Environnement 2014). To examine this question, we interviewed stakeholders involved in REDD+ discussions at the national level, as well as 28 community members and beneficiaries involved in the Makira project in northeast Madagascar. The Makira project is an interesting case to consider in terms of the impact of REDD+ approaches on reducing local direct drivers. It is one of the world's first forest carbon mitigation projects, and its

\footnotetext{
${ }^{21}$ Seven interviews, with three NGO representatives, two donors, a private sector representative and one researcher. Three interviews in Madagascar, 9 - 10 December 2014 and four interviews by telephone, June August 2015

${ }^{22}$ Interview with an NGO representative in Madagascar, 10 December 2014 and a government representative, by telephone, 7 July 2015

${ }^{23}$ Interview with an NGO representative in Madagascar, 10 December 2014 and a government representative, by telephone, 7 July 2015
} 
remote location within the largest remaining block of rainforest in the country (Tondrasoa, 2007), as shown in Figure 4.2, implies that the primary drivers are likely to be local, with limited external influences, with the potential to scale-up activities with communities.

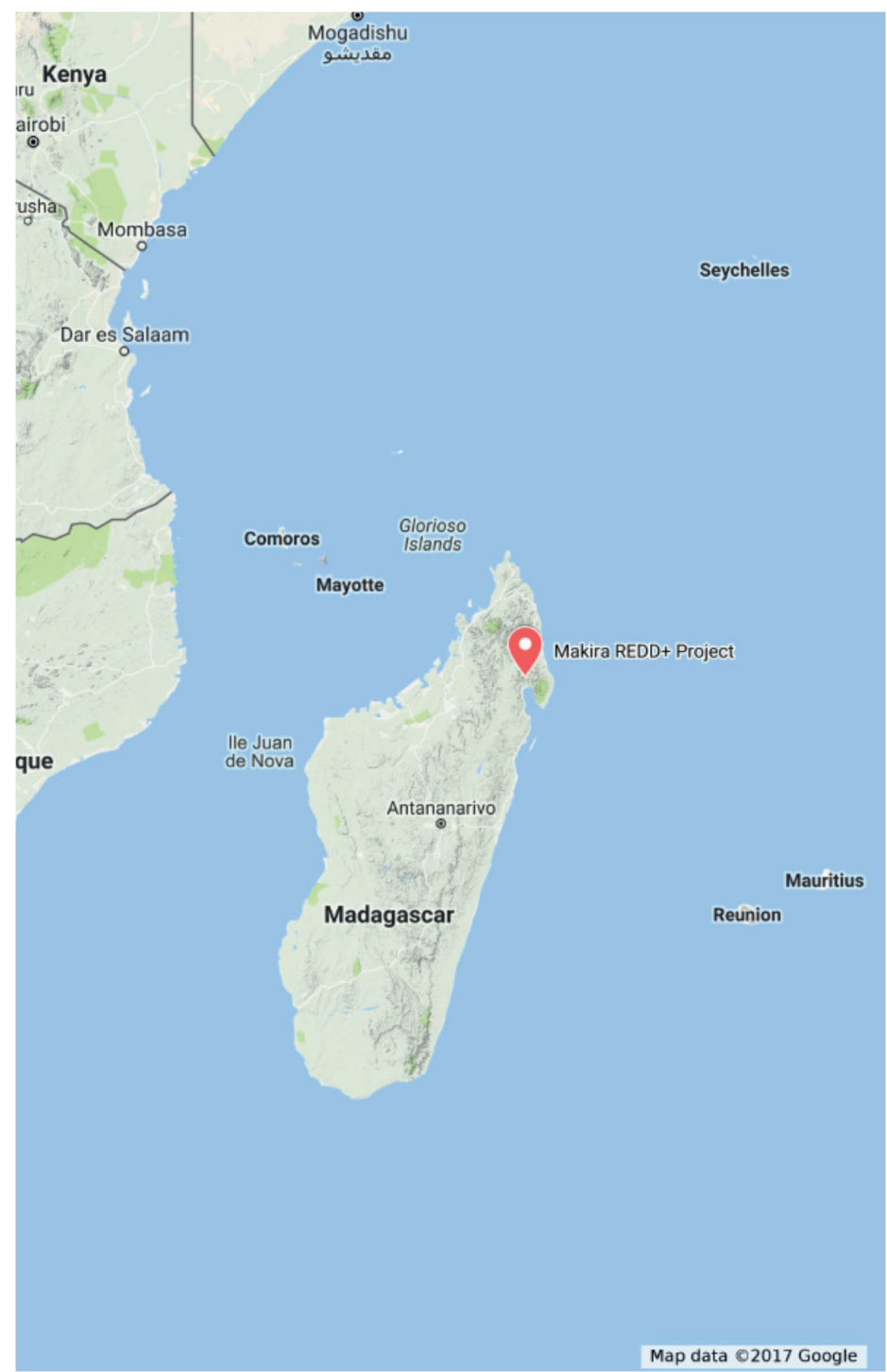

Figure 4.2 Location of the Makira REDD+ project 
Our interviews with national-level stakeholders revealed a dominant view that the overriding aim of REDD+ in such a highly biodiverse but very poor country should be on achieving co-benefits for biodiversity and communities, rather than on reducing land-based carbon emissions from forests and other ecosystems. This becomes an important context within which to assess the promise of landscape approaches to REDD+ to address small-scale direct drivers. As one NGO stakeholder stated, "a big outcome for Madagascar would be getting such a high proportion of benefits out to the local communities". ${ }^{24}$ This view is also reflected in Malagasy government policy documents stating that REDD+ should result in multiple benefits and that communities should receive $50 \%$ of the benefits accruing from projects and programmes (Ministere de l'Environnement 2015). A view held by many stakeholders ${ }^{25}$ is that the implementation of a landscape approach should thus involve the scaling-up of local REDD+ projects, as way to ensure that individuals outside of protected or forested areas also benefit from REDD+. In some cases, this is viewed as sufficient justification for REDD + to extend beyond the forest, regardless of impact on land-based emissions. As one NGO representative categorically stated, “... emissions in Madagascar are very minimal compared to other countries, so the reason why REDD + is important is for poverty alleviation and biodiversity conservation and not so much because of climate". ${ }^{26}$ If so, a compelling question becomes whether a specifically ecological approach to REDD+ landscapes is well placed to deliver this.

An ecologically-based approach to landscape REDD+, as conceptualised in the Malagasy context, includes the scaling-up of REDD+ projects to deliver further co-benefits to communities. In practice, however, there are limited opportunities for engagement by communities in national and sub-national REDD+ discussions ${ }^{27}$ which results in legitimacy deficits particularly if initiatives are to be scaled-up (Chhatre et al., 2012; Kashwan \& Holahan, 2014; Vijge and Gupta 2014). The complexities and difficulties of developing equitable benefit-sharing mechanisms are well documented in the REDD+ literature (for example, Luttrell et al. 2012 and Skutsch 2013) and are exacerbated in the Madagascan context by a lack of sufficient and sustained financing to guarantee community co-benefits via existing REDD+ projects. Previous research undertaken at another REDD+ project in Madagascar has shown that although conservation agreements being implemented in partnership with local communities have had some positive impacts linked to devolving management control to local communities (Bertrand et al., 2014), the project was not able to adequately compensate communities for the true costs (including social and cultural costs) associated with the behavioural changes required for forest conservation efforts (Brimont and Karsenty, 2015). Projects that attempt to deliver both community and biodiversity co-benefits face the additional complication of reconciling these two objectives in contexts where trade-offs are more common than win-win outcomes (McShane et al. 2011).

Communities living within the geographical scope of the Makira project are poor and marginalised, even by Malagasy standards, with, for example, a 40\% illiteracy rate (Tondrasoa, 2007). Although much of the forest remains intact, our interviews with community members highlighted some of the pressures it continues to face from local deforestation and forest degradation drivers, notably the practice of tavy to make way for rice cultivation, and tree cutting for a wide range of household uses

\footnotetext{
24 Author interview with NGO representative, in Madagascar, 10 December 2015

25 Seven author interviews, with: one government representative, three NGO representatives, two donors and one private sector representative. Two interviews in Madagascar, 9 - 10 December 2014 and five interviews by telephone, May - July 2015

26 Author interview with NGO representative, by telephone, 3 July 2015

${ }_{27}$ Noted in two author interviews by telephone: with an NGO representative, 2 June 2015 and a researcher 5 August 2015
} 
including building houses, boats, furniture, fences and for fuelwood.$^{28}$ Much of the decision-making related to forest management has been devolved to local communities under the 1996 'Gestion Locale Sécurisée' or so-called GELOSE law, who are being supported to implement REDD+ project activities and are benefiting from the sale of carbon credits. ${ }^{29}$

Our interviews with Makira REDD+ project beneficiaries found a range of perspectives in relation to perceived project benefits. Many cited non-monetary benefits provided via the project very positively, for example the provision of a school ${ }^{30}$ and a water supply. ${ }^{31} \mathrm{~A}$ couple of beneficiaries, however, were not in favour of the restrictions on cutting trees. ${ }^{32}$ Several beneficiaries expressed frustration that they had kept their side of the bargain and stopped deforesting, but that the expected financial benefits had not been forthcoming. ${ }^{33}$ Beneficiaries clearly saw, however, the links between the project and forest protection and were in unanimous agreement that the project had reduced deforestation. ${ }^{34}$ Some of the project benefits community members had received were noted to be directly linked to drivers, for example, rice irrigation was provided as a means of intensifying agriculture ${ }^{35}$ and tree nurseries were set up to establish agroforestry projects, ${ }^{36}$ both to take pressure of the existing forest. This supports other research that indicates that REDD+ projects may have the potential to go beyond previous integrated conservation and development projects (ICDPs) (Atela et al. 2015) which faced a range of criticisms such as weak links between conservation and development outcomes (Blom et al, 2010). This notwithstanding, interviewees who were in favour of the project were at pains to emphasise that they did not necessarily engage in activities that provide an alternative to deforestation because of benefits from the REDD+ project, but because of a desire to protect the forest that was disappearing. ${ }^{37}$ It was evident that some project beneficiaries value the forest and want to prevent further deforestation, but at the same time are frustrated by the perceived unfairness that they are not receiving adequate compensation and the hoped for benefits. There is potential for REDD+ projects, such as Makira, to be scaled-up and go beyond previous forest conservation efforts in terms of more directly linking development interventions and conservation outcomes and preventing deforestation (the linchpin of an ecological landscape approach). At the same time, without long-term sustained financial support for REDD+ interventions and involvement of community members in the political decision-making pertaining to REDD +, there is a risk that community members will be unlikely to be motivated to 'keep their side of the bargain' and engage in alternatives to deforestation that come at a cost despite their interest in reducing deforestation.

In sum, the expectation amongst many stakeholders is that landscape REDD+ in Madagascar should be implemented via the scaling-up of REDD+ projects such as the Makira project, because of the potential co-benefits for communities and biodiversity. Our analysis suggests, however, that

\footnotetext{
2824 project beneficiaries in interviews in Madagascar, 15 - 17 Dec 2014

${ }^{29}$ Press statement on carbon credit sales for Makira: https://newsroom.wcs.org/News-

Releases/articleType/ArticleView/articleId/6601/Feb-20--Carbon-Credits-for-Madagascars-Makira-NaturalPark-Now-Available-Online-Through-Stand-for-Trees-Campaign.aspx

3019 project beneficiaries in interviews in Madagascar, 15 - 17 Dec 2014

3110 project beneficiaries in interviews in Madagascar, 15 - 17 Dec 2014

322 project beneficiaries in interviews in Madagascar, 15 - 17 Dec 2014

338 project beneficiaries in interviews in Madagascar, 15 - 17 Dec 2014

3428 project beneficiaries in interviews in Madagascar, 15 - 17 Dec 2014

3510 beneficiaries in interviews in Madagascar, 15 - 17 Dec 2014

363 beneficiaries in interviews in Madagascar, 15 - 17 Dec 2014

3710 beneficiaries in interviews in Madagascar, 15 - 17 Dec 2014
} 
although there is potential for such an approach in this context, the prospects of generating benefits and addressing local drivers is still limited, given inter alia that communities have limited input into the REDD+ decision making process at national and sub-national levels, and that the financing available for such projects is far short of what is needed. As such, scaling-up REDD+ projects as currently conceived in an (ecological) landscape approach may result in some co-benefits and address small-scale drivers, but is unlikely to go beyond the challenges and opportunities already encountered within longstanding forest conservation efforts.

\subsection{Conclusion}

In this paper, we distilled a typology of landscape approaches to REDD+ in the academic literature and policy practice, consisting of economic, political and ecological approaches. We also assessed how and why an ecological landscape approach to REDD+ is emerging in Madagascar, and whether it is able to address direct and indirect drivers of deforestation and forest degradation. We draw some lessons from our analysis here for the applicability of an ecological approach to REDD+ landscapes in other REDD+ countries.

As we have argued, the dominant discourse on sub-national and jurisdictional (mainly economic and political) approaches to REDD+ has grown out of particular national contexts (including Indonesia and Brazil). These tend to be characterised by powerful economic and political actors, strong regional governments, and influential agribusiness sectors, where the main driver of deforestation is the expansion of commercial agriculture. However, this approach is not necessarily emerging in those developing country contexts where the private sector and sub-national governments do not play such dominant roles. Instead an ecological approach to REDD+, based on a forest conservation rationale, is emerging in the Malagasy context.

Our analysis reveals the significant challenges that still constrain the development and implementation of an ecological landscape approach to REDD + in this context, as well as its ability to tackle drivers beyond the forest sector. Despite a novel sounding landscape conceptualisation that is expected to bring new political impetus and financing, REDD + is still being treated as a niche environmental issue in Madagascar. Although landscape approaches to REDD+ are expected in both academic literature and policy practice to tackle drivers outside the forest sector and thereby overcome deficiencies in national REDD+ strategies and local projects, in practice such an approach is not yet stimulating discursive or institutional change. Rather than being able to overcome the challenges of a lack of intersectoral integration in REDD+ discussions at the national level, landscape approaches appear to be hindered by the same problem.

Our analysis does, however, suggest that the landscape approach has potential to address local, direct drivers and bring some benefits to communities, for example, by involving communities and small-scale agricultural enterprises in scaled-up REDD+ projects and agroforestry initiatives, particularly in remote forest areas with limited external influences. Furthermore, the sharing of benefits generated from such projects appears to go beyond previous ICDP efforts, by demonstrating a clearer link between development interventions and forest conservation outcomes and achieving a decrease in deforestation. However, although scaling-up REDD+ projects (and framing this as an ecological landscape approach) might be perceived as an innovative new forest conservation strategy, the long-term sustainable sources of funding at the scale needed to bring about transformational change are still lacking, and legitimacy is undermined by a lack of community 
engagement and representation at multiple political scales of decision-making. Furthermore, landscape-approaches to REDD+ are currently unable to counter competing interests for land and insecure land tenure, thereby reducing hope that such new approaches to REDD+ will be better placed to tackle, in particular, indirect drivers.

We conclude, therefore, that although an ecological approach to REDD+ landscapes is emerging in Madagascar, the challenges facing its implementation are not different from those facing more longstanding forest conservation efforts. In order to address deforestation and forest degradation drivers more effectively than has been achieved in the pre-REDD+ era, further progress is needed to: achieve inter-sectoral coordination at the national and also at the international, donor-level (Gupta et al., 2016); secure sufficient and sustainable sources of REDD+ finance; and ensure meaningful community engagement and representation at political levels (both national and subnational). Such conditions are relevant to other REDD+ countries as well, such as Democratic Republic of the Congo or Papua New Guinea, which are now exploring landscape approaches to REDD+ and share some or all of Madagascar's characteristics, such as high biodiversity and poverty levels, a centralised governance structure, and a small-scale private sector. While ecological landscape approaches may be best suited to such contexts, additional research is needed to determine whether and under what conditions such approaches can address drivers of deforestation and forest degradation, and deliver the hoped-for new impetus to REDD+. 


\section{5 'Embodied Deforestation' as a New EU Policy Debate to Tackle Tropical Forest Loss: Assessing Implications for REDD+ Performance ${ }^{38}$}

\subsection{Introduction}

The need to tackle drivers of deforestation and forest degradation operating at the international level has long been recognised (e.g., Lambin et al., 2001) but has thus far largely been overlooked by national environmental policy-makers (Henders et al. 2018). However, the issue is now beginning to be actively taken up in policy debates, including within the EU, as global trade in agricultural products becomes a more prominent driver of deforestation (Meyfroidt et al., 2013). More than half of all deforestation and forest degradation worldwide is now estimated to be due to the conversion of forestland for commercial agriculture to meet global demand for food, fuel and fibre (Lawson et al. 2014). Global demand for commodities is a major driver of deforestation in Latin America and Asia in particular, and a significant component of this global demand originates from within the EU (Rautner et al., 2013). How developed countries contribute to deforestation in tropical countries, particularly through importing agricultural commodities, is thus garnering increased attention, including within the EU.

A study produced for the European Commission (2013:p.iv) estimated, for example, that the EU is responsible for $10 \%$ of global 'embodied deforestation', i.e. deforestation as an externality in the production, trade or consumption of a good, commodity or service. Recent declarations at the international level to reduce or end deforestation, such as the 2014 UN New York Declaration on Forests, and the Amsterdam Declaration by a number of European governments, as well as commitments by multinational companies to promote deforestation-free supply chains and certification schemes, such as the Roundtable on Sustainable Palm Oil (RSPO), are giving further impetus to policymakers seeking to tackle international consumption patterns that fuel tropical deforestation. Arguably, one of the first attempts by the EU to decrease the negative impacts of its consumption on tropical forests was through its 2009 Renewable Energy Directive, which required the introduction of sustainability criteria (Bicalho et al. 2016) to ensure biofuel production did not impact biodiverse primary forests (European Commission 2009). The development of EU sustainability criteria was influenced by voluntary certification schemes, such as the RSPO (Harnesk et al. 2017), but both have been criticised for their limited ability to achieve sustainability in practice (De Man and German 2017; Oliveira et al. 2017). These efforts are now increasing, most recently with the adoption of a European Parliament resolution in 2017, which advocated restrictions on palm oil imports because of their negative environmental impacts, including adverse impacts on forests (European Parliament 2017).

While the sustainability of commodity supply chains is increasingly the focus of both academic and policy scrutiny, our article analyses how these issues land within an increasingly fragmented global and EU-level forest governance architecture, with a wide array of initiatives spearheaded by both state and non-state actors to address tropical deforestation. Another, highly visible, such initiative

\footnotetext{
38 This chapter has been published as: Weatherley-Singh, J., and A. Gupta. 2018. "Embodied Deforestation" as a new EU Policy Debate to Tackle Forest Loss: Assessing Implications for REDD+ Performance Forests 9 (12) 751. https://doi.org/10.3390/f9120751
} 
is REDD $+{ }^{39}$ under the UNFCCC, which financially compensates developing countries for reducing greenhouse gas emissions associated with deforestation and forest degradation (Reinecke et al. 2014). REDD+ has been understood and implemented in a variety of ways by a range of state and non-state actors (Gupta et al., 2016; Turnhout et al., 2016). These include project-level initiatives aiming to deliver co-benefits for biodiversity and communities in specific local contexts (Blom et al., 2010); performance-based carbon payments (Corbera 2012; Limberg et al. 2009); and more recently, sustainable landscape approaches that often involve the private sector (Boucher and Elias 2013; Fishbein and Lee 2015).

REDD+ projects and sub-national initiatives have been shown to be responsive to some drivers operating at local and national levels, but are largely unable to tackle drivers of tropical forest loss operating at the international level (Kissinger et al. 2012; Weatherley-Singh and Gupta 2015). particularly those linked to agricultural production (Soto Golchur et al. 2018). In addition to its focus on local as opposed to national or international drivers, REDD+ has also been criticised because of negative socio-economic impacts, such as fuelling inequality through restrictions on access to forests and the commodification of carbon (Hunsberger et al. 2017; Dawson et al. 2018). In general, commentators see REDD+ as having failed to live up to the initial high expectations following its introduction in international climate change policy discussions in 2005 , especially in terms of finance flowing to developing countries to combat tropical deforestation (Turnhout et al. 2016). Notwithstanding such criticisms, recent research points to a reconceptualisation of REDD+ in which it is viewed as a conservation and development measure, with more realistic expectations with regard to its performance, rather than being seen as "the" answer to tropical deforestation (Lund et al. 2017; Duchelle et al 2018; Massarella et al. 2018). Furthermore, there is also an expectation in both policy circles and academic literature that newer REDD+ landscape approaches, particularly those that involve the agri-business sector, will be better able to tackle drivers of deforestation linked to the expansion of large-scale agricultural commodities for export (Nepstad, Irawan et al. 2013), even if their impact on drivers operating at the global level is limited (Weatherley-Singh and Gupta 2017). The new interest in tackling international drivers linked to consumption in developed countries (i.e., the concept of embodied deforestation), combined with newly emerging REDD+ initiatives involving the private sector, may thus signal a new and more integrated approach to combating tropical forest loss, one that prioritises tackling drivers of deforestation and forest degradation operating at the international level.

Yet whether this potential is being realised remains little analysed. The concept of embodied deforestation has not yet been discussed in the scholarly literature, given its very recent emergence within the EU policy arena. How the concept is understood, and the extent to which it is gaining traction from policy-makers, requires further examination. It is also unclear what role, if any, is foreseen for REDD+ by those engaged in this new discussion. Will a focus on embodied deforestation marginalise REDD+ or give it fresh relevance? How is REDD+ performance, particularly in relation to tackling international drivers, related to this new approach, if at all? And finally, will tackling embodied deforestation become one of many initiatives aiming to address tropical deforestation within the EU, contributing to further fragmentation, or it will facilitate a more integrated approach?

\footnotetext{
${ }^{39} \mathrm{REDD}+$ stands for: Reducing emissions from deforestation and forest degradation in developing countries; and the role of conservation, sustainable management of forests and enhancement of forest carbon stocks in developing countries
} 
This article analyses these timely questions. We proceed as follows: Section 2 reviews the concepts of fragmented and networked forest governance architectures, as the conceptual lens through which we analyse the nature and implications of the new notion of embodied deforestation. Section 3 outlines our methodology and methods of data generation and analysis. Section 4 maps the existing fragmented approach to forest policy-making in the EU, and how the embodied deforestation debate is emerging within this policy context. Section 5 presents our analysis of whether and how this new notion is being translated into EU policy. We conclude by considering whether it represents a move towards a more fragmented or integrated forest policy, and with what implications for REDD+.

\subsection{From Fragmented to Networked Forest Governance: A Conceptual Shift}

Forest governance arrangements, both globally and within the EU, have long been considered fragmented, insofar as multiple sites of governance authority co-exist. In recent years, there has been a shift from analysing causes and consequences of fragmentation to analysing the networked nature of forest governance (for example, Reinecke et al., 2014; Gallemore 2017). Networked forest governance involves bringing together a wide range of actors representing different interests from the private and public spheres (Jedd, 2015), with coordination and negotiation between independent stakeholders interacting horizontally (rather than vertically) (Schulz et al., 2016). In this context, forest governance by formal political administrative structures is replaced by diffuse and complex networks that involve a wide range of actors (Jedd and Bixler, 2015), including from the private sector (Pistorius and Freiberg, 2014). Although networked forest governance scenarios often describe a retreating of the state to make way for other actors, recent studies highlight that the state still imposes limits on the involvement of other actors (Schulz et al., 2016) and often continues to exert considerable influence over the policy process (Arts 2014).

As production and consumption of forest and agricultural products becomes increasingly globalised, with complex supply chains, it becomes increasingly difficult for states to regulate and govern the sustainability of production, leading to an emergence of hybrid forms of state and private governance (Bush et al. 2015). Within globalised commodity chains, highly complex horizontal and vertical chains and networks emerge, with interactions between actors at different points of transactions. As such, networked governance can be "...conceived as a mosaic of both formal and informal networks, interconnecting production practices in the space of place to the space of flows of global trade" (Bush and Oosterveer 2007:390). In terms of action to tackle deforestation drivers linked to global commodity chains, the intervention points in such networked contexts are thus often located in developed countries (such as the EU), and therefore outside the sphere of policy action that can be taken by governments in developing countries. The globalisation of commodity chains is also impacting the effectiveness of REDD+ implementation, which is being adopted in a fragmented manner at sub-national or national levels (Well and Carrapatoso 2017). This has meant, in some cases, a displacement of deforestation from early to late adopters of REDD+ (Ingalls et al. 2018).

It has been observed, however, that governance of some global value chains is also becoming more coordinated between concerned public and private actors at different scales (Milligan and O'Keeffe 2018). Few studies, however, have analysed diverse EU forest policies from a networked forest governance perspective, with little analysis of the implications of emerging and new policy 
discourses for future EU action on, inter alia, REDD+. Some forest governance studies have been conducted in relation to the EU Forest Law Enforcement Governance and Trade (FLEGT) initiative (van Heeswijk and Turnhout 2013), but these have tended to focus on its impacts in partner (i.e. developing) countries (for example, Springate-Baginski et al. 2014; Lesniewska and McDermott 2014). Studies have also been undertaken with regard to regional European forest policy, which indicate a long-recognised lack of policy integration within the EU itself (Winkel and Sotirov 2016), and an increasing trend of influence by economic state interests over environmental interests (Giessen et al., 2014). It is therefore timely to analyse whether the emerging EU 'embodied deforestation' debate represents an actual shift in responsibility to address deforestation drivers from developing countries (via supply-side measures) to developed countries (via demand-side measures), whether it signals a shift from a fragmented to a more integrated approach, and what the implications are for REDD+.

\subsection{Methodology and Methods of Analysis}

This analysis relies on qualitative methodologies of document analysis and interviews. Given that there is little published secondary literature on the concept of embodied deforestation, our sources of data have been almost exclusively primary documents, as well as semi-structured interviews with those involved in this very new, emerging debate. Our analysis is thus based on detailed primary document analysis of 55 recent policy documents (generated during the period January 2014 to December 2017) developed by or for the EU, which we identified as being of relevance to EU tropical forest policy (for a complete list of analysed documents, see Appendix 2). We selected these according to the following procedure: with regard to European Parliament documents, a search was conducted on the Parliament website for documents containing a reference to the word 'forest'. Any documents found were then included in the analysis, if they concerned global or tropical forests (as opposed to only being concerned with European forests). No equivalent search function exists on the European Commission website, so documents were instead searched for on the webpages of relevant Directorate-Generals covering policy areas considered to be relevant to the issue of international tropical forest policy, namely: climate change, energy, trade, sustainable development, agriculture, foreign policy, environment, development, and the general future direction of EU strategy and budget. Again, documents were only included in the analysis if they referred to forests globally or outside of the EU (with the exception being a few overarching documents that set out the general direction of future EU policies, which were included for their relevance to all EU policy areas).

Once the documents had been selected, the document analysis consisted of mining these documents to distil answers to a number of questions, through close reading of each. The questions related to, inter alia, what new policy measures were being proposed/advocated; what drivers of deforestation or forest degradation were sought to be addressed, if any; whether the emphasis was on tackling consumption in the EU, or on support for measures in developing countries; whether REDD+ was mentioned and if so, how; and whether new policies or funding for REDD+ implementation were being proposed, also in conjunction with efforts to tackle international drivers.

In addition to the document analysis, 15 semi-structured interviews were conducted with stakeholders and policy-makers involved in discussions on embodied deforestation in the EU, during the period February - August 2018. These were intended to verify the findings of the 
document analysis. Stakeholders were mainly selected based on their participation in two conferences organised by the European Commission on tropical deforestation in 2014 and $2017^{40}$ and because they were known to be actively involved in EU tropical forest policy debates. A stakeholder mapping was undertaken to select a range of participants working in different organisations. There was, however, a lower response rate from those working in EU institutions and national governments than from those working for NGOs and research institutes. A list of interviewees is provided in Appendix 4 and includes five policy-makers from EU institutions and national governments, five representatives of environmental NGOs, four independent experts and researchers, and one staff member from a UN agency. The questions posed included: Whether stakeholders saw the embodied deforestation concept as useful and why; whether they saw a change in the balance between EU support for demand-side measures (to be implemented by the EU) versus supply-side measures (to be undertaken by developing countries) to tackle tropical deforestation; what outcomes they hoped for; and what role they envisaged for REDD + in evolving EU policies targeting deforestation.

\subsection{Mapping the Fragmented Evolution of EU Tropical Forest Policy}

Since there is no single international treaty dealing with tropical deforestation, the issue has been dealt with globally in a fragmented manner, through a range of diverse policy instruments and agreements on related topics, such as biodiversity or climate change (Pistorius 2012). EU policy instruments dealing with tropical forests have generally developed in response to participation in such international UN conventions and agreements. Thus, tropical forests have been dealt with across a range of EU policy instruments, mirroring the situation at global-level where forests are addressed within international agreements on biodiversity, trade in endangered species, climate change, etc. EU forest policy is thus spread across various EU-level institutions, such as Directorates-General for climate change, development cooperation, environment and trade. Each of these have their own perspectives on forest issues, with a similar situation prevailing at the level of individual EU Member States as well, where different dimensions of forest policy, whether climate, trade or biodiversity related, are usually addressed by different national-level ministries (Pirlot et al., 2018).

External EU policy-making on forests has been largely aligned with the goals of specific, existing UN Conventions and international agreements. Thus, policies on biodiversity have sought to find a balance between biodiversity conservation and its sustainable economic use (Morgera 2012), with a stated aim of achieving and supporting sustainable forest management in this context (Pirlot et al, 2018). The EU Biodiversity Strategy (European Commission, 2011) sets out actions to implement the UN Convention on Biological Diversity (CBD) and promote the conservation and sustainable use of biodiversity, including forests. Similarly, EU wildlife trade legislation (European Commission, 1996) was adopted to implement rules under the Convention on the International Trade in Endangered Species (CITES) in order to protect species (including timber species) threatened by international trade. The EU also participates in the UN International Tropical Timber Organisation (ITTO), that was established from a commercial viewpoint to reconcile sustainable forest management with expansion of the tropical timber trade (United Nations, 2006), and the UN Forum

\footnotetext{
${ }^{40}$ DG Environment. 2017. Available online: http://ec.europa.eu/environment/forests/deforestation.htm (accessed on 12 September 2018)
} 
on Forests (UNFF), which emphasises the need to combat deforestation through expansion of sustainable forest management (SFM) (Rautner et al., 2013). Arguably the EU policy instrument that has gained the most traction, political attention and funding in relation to tropical forests is its Forest Law, Enforcement, Governance and Trade (FLEGT) initiative developed in the context of the 2002 World Summit on Sustainable Development (European Commission, 2003). FLEGT aims to reduce imports of illegally logged timber into the EU, including by supporting action in developing countries to strengthen sustainable forest management and improve governance (Denier et al. 2014).

The EU and its Member States are also parties to the UNFCCC and have together contributed about $30 \%$ of global finance for REDD+. A large proportion of this has, however, been in the form of bilateral aid from Germany and the UK.. ${ }^{41}$ The EU established its REDD facility in 2010, but has also donated to existing multilateral initiatives, such as the World Bank Forest Carbon Partnership Facility (FCPF) and UN-REDD programme (Norman and Nakhooda 2015), rather than choosing to become a major player in its own right within global REDD+ discussions. The introduction of REDD+ in the UNFCCC discussions in 2005 represented a significant shift in the objectives of international forest policies, including at EU level (UNFCCC 2005), with the focus on reducing carbon emissions from deforestation and forest degradation (Buizer et al., 2013). This new focus on carbon as the main service provided by forests contrasted to previous approaches (McDermott, 2014) that aimed to find a balance between biodiversity conservation and logging for timber. The development of REDD+ was highly influenced by a growing narrative on PES (Pistorius et al., 2012), which explored new funding sources for the conservation of ecosystems based on their utilitarian socio-economic values (for example, Costanza et al. 1997; Millennium Ecosystem Assessment, 2005). The PES approach was also promoted by EU policy-makers who, for example, funded ecosystem valuation studies (such as TEEB, 2009). Although widely endorsed within policy, the PES approach has also drawn criticism from those who highlighted concerns about the commodification of forests for their carbon values, and the potentially negative ecological (Muradian et al. 2013; Redford and Adams 2009) and social (Brown 2013; Chhatre et al., 2012) impacts of this shift in focus.

Concerns have also been expressed that REDD+ unfairly burdens developing countries, with some suggesting it has been used as a distraction to cover up the lack of action by developed countries to tackle their own greenhouse gas emissions (Dooley and Okereke 2010). In terms of external forest policy, EU policy processes have, like other international policymaking fora, historically focused more on supply-side rather than demand-side measures. They have done so by supporting actions taking place in partner (developing) countries, including through REDD + . The evolution of FLEGT, however, did signal a recognition that the EU needed both supply and demand-side measures to tackle illegal timber imports. Thus, the EU has been working to reduce the negative impacts of its tropical timber imports through engagement in the ITTO and CITES and the adoption of its FLEGT Action Plan on combating illegal logging. It is now also beginning to develop policies to decrease the wider environmental impacts of consumption patterns, and its greenhouse gas emissions, and has adopted a Circular Economy Action Plan in 2015 to help

${ }^{41}$ European Commission. Forests, Climate and People: EU Support to Combat Tropical Deforestation (REDD+) 2006 - 2014. Available online: https://ec.europa.eu/clima/sites/clima/files/docs/reddplus_2014_en.pdf (accessed on 30 November 2018) 
transition to a sustainable, low carbon, resource efficient and competitive economy (European Commision 2015).

Similarly, there has been an apparent shift in the implementation of development aid policies and programmes, with developed countries moving away from simply acting as donors to also committing to change their own policies. The adoption of the UN SDGs in 2015, for example, represented a significant change in focus from their predecessor, the Millennium Development Goals (MDGs), due to their universal applicability, with goals applying to both developed and developing countries. The European Commission is also considering whether to propose an EU Action Plan to Combat Tropical Deforestation, and in 2018 published a study (COWI 2018) outlining the feasibility of policy options to tackle the drivers of tropical deforestation linked to EU imports of so-called "forest-risk" commodities, a new term gaining traction within this policy debate, which appears to refer to globally traded agricultural commodities that are associated with significant tropical deforestation. However, the European Commission has not yet decided which, if any, option to pursue. We turn next to whether this emerging discussion represents a real shift in EU policies dealing with tropical forests, by presenting the findings from our document analysis and interviews.

\subsection{Tackling EU Embodied Deforestation: A New Approach to Addressing Drivers?}

This section addresses whether and how the new debate on embodied deforestation is poised to address demand-side, international deforestation drivers, through specific adjustments to EU forest policy. It does so by analysing three aspects of this broad question: first, how the notion of embodied deforestation is conceptualised, and what new policy measures, if any, are advocated by policy-makers and stakeholders to tackle it; second, whether these debates and developments signal a real shift towards tackling deforestation drivers linked to EU consumption (i.e. demand side drivers); and third, whether these new debates and developments signal a move towards a less fragmented and more integrated approach to EU forest policy, and what role remains for REDD+ herein.

\subsubsection{Conceptualising embodied deforestation: emerging policy narratives}

Our study of EU policy documents reveals a high level of EU support for implementing the SDGs (a central focus of 20 of the policy documents we analysed) and, to a lesser extent, climate action (a central focus of 10 documents), as illustrated in Table 5.1. EU policies across a range of subject areas are being shaped to reflect the aims of the SDGs. Those relating to climate, energy and environment are all being tailored to tackle climate change, relating both to the EU's own emissions and to supporting actions in developing countries. In accordance with a realignment of its development policies to reflect the SDGs, the EU increasingly views its role less as a donor and more as a partner with developing countries. For example, the European Consensus document sets out the EU's development aid priorities, but also includes action on EU consumption patterns. The 
EU is also now encouraging other countries to address their own consumption patterns to become more sustainable, for example, through the EU-funded Switch Asia programme. ${ }^{42}$

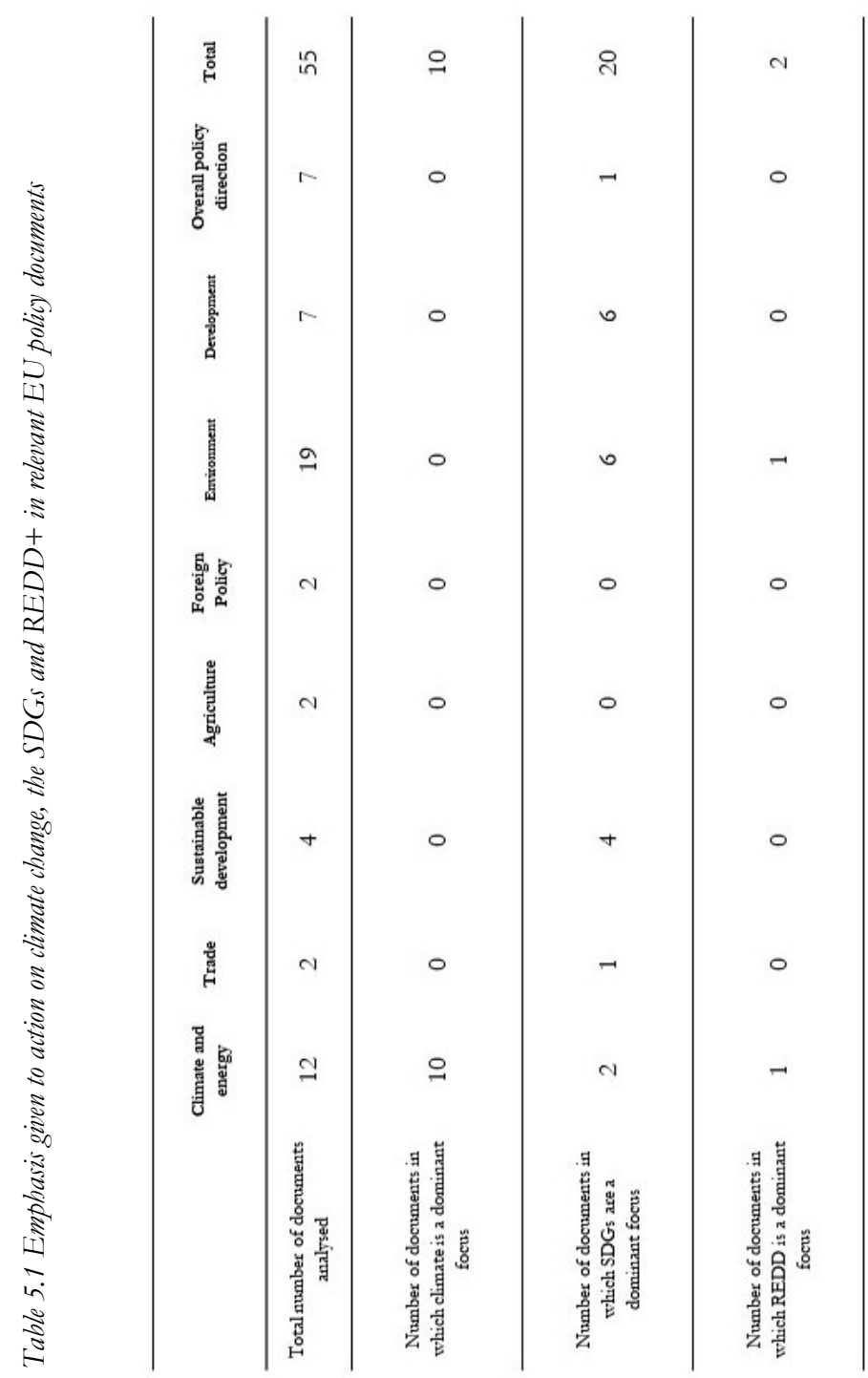

\footnotetext{
${ }^{42}$ Switch Asia is an EU funding programme to support sustainable production and consumption in Asia, http://www.switch-asia.eu/
} 
Somewhat surprisingly, however, tackling global deforestation and REDD+ are low priorities within wider policy discussions on climate and the SDGs, and the relevance of forests and land use, in particular, to the climate debate is largely missed. Instead, EU climate action appears to focus more on tackling EU greenhouse gas emissions and how this can lead to innovation and new jobs within the EU, rather than on reducing negative environmental impacts elsewhere, caused by EU consumption. The Eurostat report on monitoring EU action to achieving the SDGs demonstrates the strong shift towards supporting action within the EU rather than in developing countries. Although the need to halt global deforestation is mentioned (Eurostat 2017: P299), the proposed indicators to monitor progress only cover forests in the EU. A key finding of our analysis is that REDD+, in particular, has a very low profile within analysed policy documents. It is the dominant theme of only two EU policy documents, both of which are reports on EU activities undertaken in the past. Of the 55 policy documents we analysed, only 16 mention REDD+ in passing. Even reports and documents that are very supportive of policy measures to conserve tropical forests, such as the European Parliament report calling for EU action for sustainability (which highlights the need to address deforestation drivers and expresses support for afforestation for mitigation), do not mention REDD+ specifically.

Whilst some support was expressed for 'embodied deforestation' as a conceptual approach in our stakeholder interviews, it is unclear whether sufficient momentum is behind it to signal a change of approach in external EU forest policy. Around half of those interviewed consider the 'embodied deforestation' concept to signal a useful approach, whilst identifying a number of limitations. ${ }^{43}$ Interviewees noted, for example, that various terms are being used to express similar concepts, which is confusing. For example, the French government refers to 'imported deforestation', ${ }^{4}$ Sweden refers to reducing its ecological footprint ${ }^{45}$ and the recent European Commission feasibility study refers to 'embedded deforestation' (COWI 2018:31). Second, it was observed that the term has to be explained each time it is used, which limits its usage to policy-makers rather than being broadly understandable to a wider public. Others noted that all imports of a particular commodity are treated, within this simplified concept, as having the same deforestation impacts, which limits its accuracy. One interviewee commented that alternative concepts such as 'sustainable supply chains', are more likely to be understood and supported by a wider audience. ${ }^{46}$ Despite the limitations of the approach, we next turn to considering whether the EU is moving towards greater emphasis on demand-side measures to be adopted by developed countries, thereby sharing responsibility for tackling deforestation drivers more evenly than previous initiatives focusing on supply-side actions by developing countries.

\footnotetext{
${ }^{43}$ Interviews with: EU policy-maker in Brussels,1 February 2018; NGO representative by skype, 16 March 2018; EU agency representative by skype, 12 April 2018; independent expert by skype, 18 April 2018; researcher in Brussels, 26 April 2018; NGO representative by skype, 18 May 2018; EU policy-maker in Brussels, 24 May 2018; independent expert by skype, 17 August 2018

${ }^{44}$ http://www.mightyearth.org/france-announces-new-five-year-climate-plan-that-puts-end-to-importeddeforestation-of-products-like-palm-oil-and-soy/

${ }^{45}$ Interview with UN agency staff member by skype, 2 February 2018

${ }^{46}$ Interview with EU policy-maker in Brussels, 1 February 2018
} 


\subsubsection{Shifting responsibility from South to North: targeting demand?}

In terms of whether there has been a shift in the balance of responsibility for tackling deforestation drivers from developing to developing countries, with a corresponding shift in the balance between demand and supply-side measures in EU external forest policy, there appears to be a shift in rhetoric, at least. This is demonstrated, for example, by the European Parliament report on palm oil (European Parliament 2017), which advocates restricting imports of palm oil to the EU to prevent deforestation. It should be noted, however, that this is just a policy recommendation by the European Parliament, with no proposals from the Commission to implement it, partly because this report was met with strong political opposition from Indonesia and Malaysia who want to protect their export markets, as widely reported in the media. ${ }^{47}$ More generally, in our analysis of policy documents, we identified various supply-side and demand-side measures being advocated within EU policies relevant to forests (see Table 5.2 for the list of suggested new policy measures), with a higher number of actions relating to the demand-side. As in the case of palm oil, however, very few of the suggested demand-side measures are mentioned in official policy documents. Instead, they are mainly mentioned in the draft of a feasibility study undertaken by consultants for the European Commission. If enacted, however, these suggested new policy measures would help to address a number of international drivers of deforestation and forest degradation. These include illegal logging and the international trade in timber (building on existing EU efforts under FLEGT and the EUTR), agricultural conversion linked to the global export of commodities and imports, as well as international financial transfers associated with deforestation.

\footnotetext{
${ }^{47}$ Jakarta Post, 2018. Available online: http://www.thejakartapost.com/academia/2018/07/06/the-eus-waron-palm-oil-will-continue.html (accessed on 12 September 2018)
} 
Table 5.2 New suggested policy measures to combat tropical deforestation within documents published by or for EU policy-makers

\begin{tabular}{|c|c|c|c|}
\hline $\begin{array}{l}\text { Suggested new supply- } \\
\text { side measures }\end{array}$ & $\begin{array}{c}\text { Suggested new } \\
\text { demand-side measures }\end{array}$ & $\begin{array}{c}\text { Suggested measures } \\
\text { mentioning REDD+ }\end{array}$ & $\begin{array}{l}\text { Direct and indirect } \\
\text { drivers of deforestation } \\
\text { and forest degraded that } \\
\text { would be impacted }\end{array}$ \\
\hline $\begin{array}{l}\text { Climate change and } \\
\text { energy } \\
\text {-Measures to reduce } \\
\text { impact of biofuels \& } \\
\text { indirect land-use change } \\
\text { (ILUC) } \\
\text { Trade } \\
\text { - Support the } \\
\text { conservation and } \\
\text { sustainable use of natural } \\
\text { resources } \\
\text {-Support reductions in } \\
\text { illegal logging } \\
\text { Sustainable } \\
\text { development } \\
\text {-Financial support to } \\
\text { partner countries } \\
\text { Environment } \\
\text {-Increased support to } \\
\text { partner countries to } \\
\text { protect forests, including } \\
\text { for FLEGT } \\
\text {-Incentives for } \\
\text { Sustainable Forest } \\
\text { Management (SFM) } \\
\text {-Support synergies } \\
\text { between REDD and } \\
\text { FLEGT } \\
\text {-Request for finance for } \\
\text { global biodiversity } \\
\text {-Support to reduce timber } \\
\text { trafficking } \\
\text {-Support to smallholder } \\
\text { producers } \\
\text {-Support to jurisdictions } \\
\text { to prepare for REDD+ }\end{array}$ & $\begin{array}{l}\text { Trade } \\
\text {-Increase supply chain } \\
\text { transparency and due } \\
\text { diligence } \\
\text { Sustainable } \\
\text { development } \\
\text {-Measures to reduce } \\
\text { consumption impacts on } \\
\text { tropical forests } \\
\text {-Improve sustainability of } \\
\text { global supply chains } \\
\text { Agriculture } \\
\text {-Promote use of local } \\
\text { rather than } \\
\text { internationally-sourced } \\
\text { timber } \\
\text { Environment } \\
\text {-Restrictions on oil palm } \\
\text { imports } \\
\text {-Support for commodity } \\
\text { certification schemes } \\
\text {-Support local rather than } \\
\text { internationally-sourced } \\
\text { biofuels } \\
\text {-Certification schemes for } \\
\text { commodity imports } \\
\text {-Encourage China to } \\
\text { adopt FLEGT-type } \\
\text { measures } \\
\text {-Demand-side measures } \\
\text { to reduce illegal timber } \\
\text { imports } \\
\text {-Reduce consumption } \\
\text { impacts on global } \\
\text { biodiversity } \\
\text { - }\end{array}$ & $\begin{array}{l}\text { Environment } \\
\text {-Support synergies } \\
\text { between REDD and } \\
\text { FLEGT } \\
\text {-Support to } \\
\text { jurisdictions to prepare } \\
\text { for REDD+ } \\
\text { Development } \\
\text {-EU support for } \\
\text { REDD+ in Key } \\
\text { Landscape Areas }\end{array}$ & $\begin{array}{l}\text { Climate change and } \\
\text { energy } \\
\text {-Conversion for biofuels } \\
\text { or ILUC } \\
\text { Trade } \\
\text {-Illegal logging } \\
\text {-Conversion for global } \\
\text { commodity imports } \\
\text { Sustainable } \\
\text { development } \\
\text {-Conversion for global } \\
\text { commodity imports } \\
\text {-Lack of finance in partner } \\
\text { countries } \\
\text { Agriculture } \\
\text {-Unsustainable timber } \\
\text { logging } \\
\text { Environment } \\
\text {-Conversion for oil palm } \\
\text {-Lack of finance in partner } \\
\text { countries } \\
\text {-Illegal logging and timber } \\
\text { trafficking } \\
\text {-Conversion for biofuels } \\
\text { or ILUC } \\
\text {-Unsustainable forest } \\
\text { management } \\
\text {-Conversion for } \\
\text { smallholder agriculture } \\
\text {-Lack of capacity at } \\
\text { jurisdictional level } \\
\text {-Lack of market incentives } \\
\text { for sustainably produced } \\
\text { commodities }\end{array}$ \\
\hline
\end{tabular}




\begin{tabular}{|c|c|c|}
\hline $\begin{array}{l}\text {-Incentives for } \\
\text { sustainably produced } \\
\text { commodities } \\
\text { Development } \\
\text {-EU support for REDD+ } \\
\text { in Key Landscape Areas }\end{array}$ & $\begin{array}{l}\text {-Reduce impact of } \\
\text { biofuel production on } \\
\text { forests e.g. through } \\
\text { sustainability criteria } \\
\text {-Include sustainable } \\
\text { forest trade in free trade } \\
\text { agreements (FTAs) } \\
\text {-Closure of EU markets } \\
\text { to products linked to } \\
\text { deforestation } \\
\text {-Due diligence for forest } \\
\text { risk commodities } \\
\text {-Transparency initiatives } \\
\text { and consumer } \\
\text { information on } \\
\text { agricultural commodities } \\
\text {-Disclosure of financial } \\
\text { information for forest } \\
\text { risk commodities } \\
\text {-Promotion of } \\
\text { sustainable finance }\end{array}$ & $\begin{array}{l}\text { Development } \\
\text {-Lack of finance for } \\
\text { REDD+ }\end{array}$ \\
\hline
\end{tabular}

Interviewees expressed strong support for the EU Timber Regulation (EUTR) as a model for tackling demand, despite well documented implementation challenges (Pirlot et al 2018; McDermott and Sotirov 2018). At least six interviewees noted that the EU needs to take a regulatory approach to tackling deforestation, along the lines of an EUTR for agricultural commodities. ${ }^{48}$ Two of the interviewees also stated that the EU should develop a policy instrument that provides transparency in financial reporting by companies on deforestation risks. ${ }^{49}$ The only recent EU legislative proposal to actually tackle a driver of tropical deforestation or forest degradation is a proposal from the European Commission to decrease competition for land between biofuels, agriculture and forests through changes to the Renewable Energy Directive. This was developed in response to considerable criticism of the EU's biofuels policy (see, for example, Fast and McCormick 2012). As revealed in one of our interviews, however, the proposal was watered down considerably in early 2018 before being adopted. ${ }^{50}$ Therefore, despite the rhetoric and the growing number of new suggested policy measures to tackle embodied deforestation, there is very little in the way of actual new legal or policy proposals to address EU consumption impacts. As summed up by one of our interviewees, in general the European Commission is mostly interested in developing voluntary

\footnotetext{
${ }^{48}$ Interviews with: EU policy-maker in Brussels, 1 February 2018; NGO representative by skype, 23 February 2018; and NGO representative by skype, 16 March 2018; an EU agency member by skype, 12 April 2018; independent expert by skype 15 April 2018; independent expert by skype, 17 August 2018

${ }^{49}$ Interviews with an EU policy-maker in Brussels, 1 February 2018; an NGO representative by skype 12 April 2018

${ }^{50}$ Interview with EU policy advisor in Brussels, 28 June 2018
} 
rather than regulatory measures to tackle demand and "expects more from partner countries than they are willing to do themselves". ${ }^{51}$

Our interviews with stakeholders involved in the EU policy debate also reveal differing views as to whether the EU should go beyond achieving legality to also mandating sustainability standards that imports should meet or aim for 'zero deforestation' targets for commodity imports. This emerging discussion is building on experiences in relation to FLEGT, which currently only covers legality but could, in theory, be expanded to include sustainability criteria (van Heeswijk and Turnhout 2013; Lesniewska and McDermott 2014). Four of the interviewees ${ }^{52}$ consider that a new policy tool to deal with deforestation should be based on sustainability rather than legality standards, although they recognised the challenges this posed in terms of gaining acceptance from partner, developing countries, and expressed concern that the EU would be imposing its sustainability standards and governing beyond its borders. Differing views were also expressed as to whether partner countries have adequate legal frameworks in place through which to implement a sustainability approach, or whether these would need to be updated or developed first.

\subsubsection{From fragmentation to integration in networked EU forest governance: what role for REDD+?}

Currently, EU external forest policy-making is highly fragmented, inconsistently applied and contains gaps, or as one interviewee put it "efforts are all over the place so an overarching approach is needed" ${ }^{33}$ Another interviewee outlined the challenges as including contradictory policies proposed by different Commission Directorate-Generals; a lack of coherent planning as to how the EU will achieve its international forest policy commitments; and no standardised EU definition or understanding of key concepts, such as Sustainable Forest Management (SFM), REDD+, or even forests. ${ }^{54}$ As pointed out by one interviewee, "the EU needs a deforestation policy and a REDD+ policy as it's not clear what it's trying to achieve in either sphere" and "the Member States all have divergent views", 55 thereby demonstrating a challenge of multilevel governance.

These views are reflected in a report from the EU REDD+ facility that outlines the REDD+ activities the EU is now supporting to address tropical deforestation, which includes several initiatives that are not generally thought of as being 'REDD+' such as, for example, demand-side measures. This could either be interpreted as REDD+ evolving into a new conceptual approach or becoming increasingly irrelevant or side-lined in funding priorities. Those we interviewed gave differing views regarding the potential of REDD+ and its performance, also in terms of addressing deforestation drivers. One interviewee noted that "REDD+ has got so complex it's stuck and should go back to being an offsetting mechanism", ${ }^{56}$ whereas another was of the opposite view that "REDD+ is an umbrella which also encompasses sustainable supply chain approaches". ${ }^{77}$

\footnotetext{
${ }^{51}$ Interview with an NGO representative by skype, 23 February 2018

52 Interviews with an EU policy-maker in Brussels, 1 February 2018; an NGO representative by skype, 16

March 2018; an NGO representative by skype,12 April 2018; independent expert by skype, 17 August 2018

${ }^{53}$ Interview with EU policy-maker in Brussels, 1 February 2018

${ }^{54}$ Interview with NGO representative by skype, 18 May 2018

${ }^{55}$ Interview with an EU agency staff member by skype, 12 April 2018

${ }^{56}$ Interview with NGO representative by skype, 15 February 2018

${ }^{57}$ Interview with EU agency staff member by skype, 12 April 2018
} 
Looking ahead, as shown in Table 5.2, very little is actually suggested within documents published by or for EU policy-makers in relation to new REDD+ policies or funding. Divergent views were expressed in our interviews regarding the continuing role of the EU as a donor to REDD+. In theory, the EU target of $20 \%$ of budgetary spending for climate objectives (with a proposed increase to $25 \%$ in the European Commission's proposal for the new EU budget post-2020) ${ }^{58}$ should make way for significant funding to be made available for REDD + . Large-scale European Commission funding has not been forthcoming in practice, however, although some individual EU countries, such as Germany and the UK, have provided substantial bilateral support for REDD+ (Norman and Nakhooda 2015). Three interviewees ${ }^{59}$ were of the view that REDD+ finance from donors, such as the EU, has been helpful in creating enabling conditions to combat deforestation, even as the readiness process has created expectations within partner (developing) countries of continued finance (as also mentioned by Hein et al. 2018). This would need to be followed through, for example, by funding REDD+ landscape/jurisdictional approaches, yet our analysis suggests that such increasing funding is not necessarily envisioned.

Scepticism was also expressed regarding the proper establishment of a functioning carbon market and the lack of interest in this by the private sector, who seem to be more attracted to the idea of sustainable supply chains ${ }^{60}$ although it was also noted that international aviation carbon offsets schemes could provide a new way forward (as also commented by Golub et al. 2018). A Commission-funded study published in March 2018 outlines potential EU policy options for tackling tropical deforestation and includes a recommendation for the EU to support "jurisdictional REDD+ projects to promote sustainable and deforestation-free agriculture production" (COWI 2017:75) which, if implemented, could provide a new way forward for EU support for REDD+ initiatives that combines jurisdictional REDD+ with supply chain approaches. Furthermore, EU development aid policies are increasingly looking to partner with the private sector to deliver policy goals through public-private-partnerships (PPPs), which may open new opportunities and lead to novel networked forest governance arrangements in partner developing countries (European Commission 2016), but also risks watering down forest conservation objectives.

Several interviewees mentioned the need for the EU to contribute to global dialogues on REDD+ or other multilateral processes that can link demand and supply-side measures, and suggested that the SDGs could provide a helpful framework for this process (potential synergies between REDD+ and the SDGs have also been noted by others, such as Bastos Lima et al. 2017a). However, it was noted that there is no obvious existing UN fora where such a dialogue could take place, with little confidence expressed in the UNFF (in line with previous criticism, for example, Dimitrov 2005). It was therefore suggested that in practice it may be more workable for the EU to encourage further

\footnotetext{
${ }^{58}$ European Commission 2018, A Modern Budget for a Union that Protects, Empowers and Defends the Multiannual Financial Framework for 2021-2027, COM/2018/321 finalhttps://eur-lex.europa.eu/legalcontent/EN/TXT/?uri=COM $\% 3 \mathrm{~A} 2018 \% 3 \mathrm{~A} 321 \% 3 \mathrm{AFIN}$

${ }^{59}$ Interview with UN agency staff member by skype, 2 February 2018; NGO representative by skype, 15

February 2018; EU agency staff member by skype, 12 April 2018

${ }^{60}$ Interviews with UN staff member by skype, 2 February 2018; NGO representative by skype, 15 February

2018; NGO representative by skype, on16 March 2018; and EU agency staff member by skype, 12 April 2018
} 
dialogue on this issue.$^{61}$ One interviewee noted that the UNFCCC is now turning its attention to decreasing greenhouse gas emissions linked to agriculture. This could be an area in which the EU could envisage playing a leading role, both by tackling emissions linked to its own domestic agriculture as well as through promoting sustainable supply chains and responsible consumption, partially through existing REDD+ approaches. Others note, however, that there is limited potential to build synergies between accounting for land use, land use change and forestry (LULUCF) and REDD+ (see, for example, Pistorius et al., 2017) and from the perspective of one interviewee, the EU's own rules on LULUCF accounting lack credibility and environmental integrity. ${ }^{62}$

Our analysis reveals, furthermore, several calls from different stakeholders for an EU Action Plan to Combat Tropical Deforestation (mentioned in five documents from the European Parliament and one from a research agency), and in two interviews. ${ }^{63}$ An Action Plan could provide a new comprehensive approach to external EU forest policy, with an overarching policy framework that includes both demand-side and supply-side measures. It could also place current support for REDD+ within a more integrated approach, as one of a number of measures to tackle deforestation rather than as the sole solution to tackling tropical deforestation. EU action plans can be effective tools for increasing political and financial support to tackle an issue. The publication of the EU FLEGT Action Plan in 2003, for example, garnered significant support for preventing the imports of illegal logged timber into the EU (Dooley and Ozinga 2011), thereby tackling one important driver of forest degradation. The publication of an EU Action Plan against Wildlife Trafficking in 2016 similarly gave considerable impetus to addressing wildlife trafficking. Action plans can, however, also remain weak, non-binding documents if they do not include legislative proposals. Thus, they may fail to achieve inter-sectoral integration, as was reportedly the case for the EU's domestic forest strategy and associated action plan (Winkel and Sotirov 2016; Aggestam and Pülzl 2018). So far, the European Commission is yet to come forward with a proposal for an action plan in relation to tropical deforestation.

\subsection{Conclusion}

Our analysis has shown that there is growing momentum within the EU to implement the SDGs and act on climate change, but tackling tropical deforestation or supporting REDD+ remain relatively low priorities for policy-makers within these wider debates. There has been a genuine shift in emphasis within policy debates towards addressing greenhouse gas emissions and negative impacts of consumption at the EU level. However, a gap remains between such rhetoric and specific policy measures being proposed to tackle EU consumption in relation to tropical deforestation. Despite several calls for an EU Action Plan against Tropical Deforestation that contains regulatory measures on EU imports of forest-risk commodities, and suggested new policy measures included in several documents, the European Commission has not yet acted. This may be because economic interests are now dominating strongly over environmental ones, as has happened in the case of

\footnotetext{
${ }^{61}$ Interviews with UN staff member by skype 2 February 2018, NGO representative by skype, 15 February 2018, NGO representative by skype, 23 February 2018 and EU agency staff member by skype, 12 April 2018

${ }^{62}$ Interview with an EU agency staff member by skype, 12 April 2018

${ }^{63}$ Interview with NGO representative by skype, 16 March 2018 and independent expert by skype, 18 April 2018
} 
domestic EU forest policies (Juerges and Newig 2015) although there are indications that some private companies are actually supportive of greater EU action on tropical forests (COWI 2018).

With regard to REDD+, very little is being proposed in terms of new policies or funding. This could be because of the perception that the private sector is more interested in 'sustainable supply chain' approaches, despite limited evidence that they can deliver on social sustainability objectives and reduce deforestation (Newton and Benzeev 2018; Meijer 2015). It is currently unclear whether supply-chain approaches will give further impetus to jurisdictional REDD+, whether they will replace or be a substitute for REDD+ initiatives, or whether new networked governance arrangements will emerge with partner (developing) countries. If the European Commission does decide to develop an overarching action plan that includes both demand- and supply-side measures, this could indeed signal a new integrated EU approach to tackling deforestation, which replaces the current range of fragmented approaches. Under this scenario, REDD+ could become one of a number of linked policy approaches, rather than being burdened with the expectation that it can solve tropical deforestation (and all associated issues) on its own. This would also spread the burden of responsibility more evenly between developed and developing countries. Embedding REDD+ within the framework of an initiative such as an EU Action Plan could also contribute to overcoming two major challenges, namely the lack of REDD+ finance and the need to address international drivers of deforestation and forest degradation (Hein et al. 2018). However, in the absence of actual EU legislative proposals to tackle drivers linked to global consumption and new commitments to REDD+ finance, the interest in tackling embodied deforestation is unlikely to signify major policy change, with the burden of responsibility to combat deforestation continuing to fall on developing countries. 


\section{Conclusion}

This thesis examines the transformational potential of REDD+. It uses a networked governance lens through which to analyse whether diverse conceptualisations and operationalisations of REDD + are addressing direct and indirect drivers of deforestation and forest degradation. It also examines whether this represents a shift from a fragmented to a more integrative approach to multilevel forest governance and, if so, how this is impacting the ability of REDD+ to deliver transformational change. This concluding chapter begins by summarising the findings of each of the four preceding chapters (section 6.1). It then discusses how, taken together, these findings answer the two central research questions of this thesis (section 6.2). The following section discusses the external validity of these findings and how they contribute more widely to scientific knowledge of environmental governance (section 6.3). The chapter ends by identifying promising areas of future research (section 6.4).

\subsection{Synthesis of the Research Findings}

The preceding four chapters of this thesis set out to answer different components of the central questions of this thesis. Before attempting to answer these questions holistically, a summary is provided here of the main findings in each of the individual four preceding chapters.

Chapter 2 analysed the evolution of REDD+ from its advent in 2005 within global climate change negotiations and the wide array of expectations that are coming to be associated with it. Three consecutive conceptualisations were identified: carbon-centred, where REDD+ is primarily a climate mitigation strategy; co-benefits-centred, where REDD+ becomes a triple win solution for climate, biodiversity and communities; and landscape-centred, where REDD+ activities are embedded in integrated sustainable land-use approaches. In assessing the expectations relating to climate change mitigation, carbon financing and co-benefits, associated with each of these conceptualisations against existing REDD+ experiences, a mixed picture emerged. Some expectations, specifically relating to forest carbon financing for climate change mitigation, were not being adequately met, although others, notably the delivery of co-benefits, hold out more promise. Yet this also highlighted a potential paradox facing REDD + . While there is growing recognition that co-benefit generation is key to the success of REDD+, and that piece-meal, forest-carbon focused REDD+ interventions are unlikely to address the complex direct and indirect causes of tropical forest loss, a focus on forest carbon is still being foregrounded in measuring and reporting on REDD+ performance, and in generating results-based payments (even as these aspects remain challenging). This implies, however, that the future of REDD+ may lie not in one conceptualisation coming to dominate, but rather in coexistence of heterogeneous practices. REDD + may therefore end up as a patchwork of projects and practices with different foci and financing mechanisms. Although this cannot prevent trade-offs, such a heterodox REDD+ may provide building blocks for the polycentric governance of the world's remaining tropical forests. 
Chapter 3 analysed the co-benefit approach to REDD+ in more detail. A meta- analysis was undertaken to identify the links, if any, between multiple and diverse drivers of deforestation operating at different levels, and the benefits accruing from and being shared through REDD+ projects, as a way of assessing whether or not REDD+ projects are directly addressing these drivers of deforestation and forest degradation. The nature of this link was assessed through examining (a) scholarly analyses, through an in-depth analysis of the posited relationships between drivers and REDD+ benefit-sharing through discussions of REDD+ projects in the peer-reviewed literature; and (b) in policy practice, through analysing how this link is conceptualised and operationalised, if at all, in REDD+ project design documents. This meta-analysis suggested that while some local, direct drivers and a few regional indirect drivers of deforestation and forest degradation are being targeted by specific REDD+ interventions and associated benefit-sharing mechanisms at the project-level, most national and international indirect drivers are not. The chapter concludes that the growing academic analyses of REDD+ projects do not (as yet) advance viable theories of change, i.e. there is currently little focus on how REDD+ benefits could play a transformative role in catalysing action on drivers.

Chapter 4 provides a detailed examination of the REDD+ landscape conceptualisation, taking Madagascar as a case study. Landscape approaches to REDD+ are assumed to be better able to tackle direct and indirect drivers of deforestation, particularly those that lie outside the forest sector, but this assumption had not been fully assessed. The first finding of this chapter was that diverse understandings of "landscape" approaches to REDD+ are discernible in a growing body of academic literature and policy practice. In assessing the expectation that such approaches can better tackle drivers, this chapter had a two-fold objective: first, to develop a typology of landscape approaches to REDD+ discernible in the literature; and second, to assess which approach might be ascendant in the particular context of Madagascar, and whether it has the potential to address direct and indirect drivers of deforestation and forest degradation here. The analysis of the burgeoning REDD+ landscape literature yielded a typology of landscape approaches, which are characterised as economic, political and ecological. In assessing which of these approaches is discernible in Madagascar, it was found that an ecological conceptualisation had emerged. While such an approach showed some promise in addressing drivers, in comparison to previous ICDP that pre-date REDD+, it was nonetheless still limited in its ability to do so. Hurdles included a lack of intersectoral coordination and national-level political support for combating deforestation, as well as a lack of community engagement in multilevel political processes. The conclusion highlighted the promise and limitations of pursuing a landscape approach to REDD+ in Madagascar, and the relevance of this analysis for other REDD+ countries wherein an ecological landscape approach might be considered.

Chapter 5 analysed the latest emerging debate in the forest governance literature, around the concept of 'embodied deforestation' and the implications of this for REDD+. This debate has mainly arisen amongst policy-makers working in the EU, and aims to target EU agricultural commodity imports as drivers of deforestation. The notion of embodied deforestation views deforestation as an externality generated by EU imports associated with tropical deforestation. This chapter examined whether this concept represents a shift in tackling international-level drivers of tropical deforestation within EU policy. It also examined, from a networked governance perspective, whether this new debate fuels further fragmentation or rather a move towards a more integrated approach to combating tropical 
forest loss within EU policy, and what the implications are for other initiatives, most notably REDD+. The analysis drew on an extensive analysis of EU policy documents and semi-structured interviews with stakeholders and EU decision-makers. It found that, despite growing debate around the concept of embodied deforestation, policy measures necessary to reduce the impact of EU consumption of agricultural commodities associated with tropical deforestation have not yet been developed. In conclusion, "embodied deforestation" remains more an idea than reality within EU policy to date, with the burden of responsibility for addressing international drivers still largely remaining on developing (or exporting) countries. There is still potential, however, for this debate to lead to a more integrated approach to tackling tropical deforestation within EU policy, if it comes to be seen, together with REDD+, as one of a number of linked approaches to EU efforts to combat tropical deforestation.

I turn next to discuss the combined results of the four preceding chapters and how, when considered together, they answer the two central research questions of this thesis: namely, whether the various evolving conceptualisations of REDD+ can effectively tackle drivers of deforestation and forest degradation; and, the extent to which REDD+ is becoming integrated with other policy domains and the impact of this on its ability to achieve transformational change.

\subsection{Answering the Research Questions}

\subsubsection{Conceptualisations of REDD+ and ability to tackle drivers}

This section draws on the findings of all chapters to answer the first central question of this thesis: 'To what extent have evolving conceptualisations of REDD+ effectively tackled direct and indirect drivers of deforestation and forest degradation, operating at different levels?'

To answer this question, I first draw on thesis findings to outline the evolving conceptualisations of REDD+ in policy and practice over time, before discussing whether, and to what extent, these diverse variants are able to address drivers. The diverse conceptualisations of REDD+, as identified in this thesis, are illustrated in Figure 6.1, which also highlights the main proponents of each conceptual approach, and the specific thesis chapter in which they are discussed. As the figure illustrates, in the first phase of its development, REDD+ was characterised by two main conceptual approaches: carbon-centric and co-benefit. In a carbon-centric approach, REDD+ is understood as having a focus on efficiently and effectively reducing or avoiding forest-related carbon emissions to mitigate climate change, while at the same time conserving forests. A finding of this thesis is that while the carbon-centric approach is discussed at length in the literature, it has not been widely implemented, in contrast to the co-benefit approach. Although it is discussed in chapter 2, a detailed analysis is therefore not undertaken of the carbon-centric approach in this thesis. In a co-benefit focused approach, REDD+ is understood to go beyond climate change mitigation and forest conservation to deliver additional environmental and social benefits, such as contributing to livelihoods, sustainable development, enhanced governance, and biodiversity conservation. This approach gained the most traction in the early stages of REDD+ and was often implemented through REDD+ projects led by conservation organisations interested in achieving biodiversity cobenefits. This approach was analysed in detail in chapter 3 . 


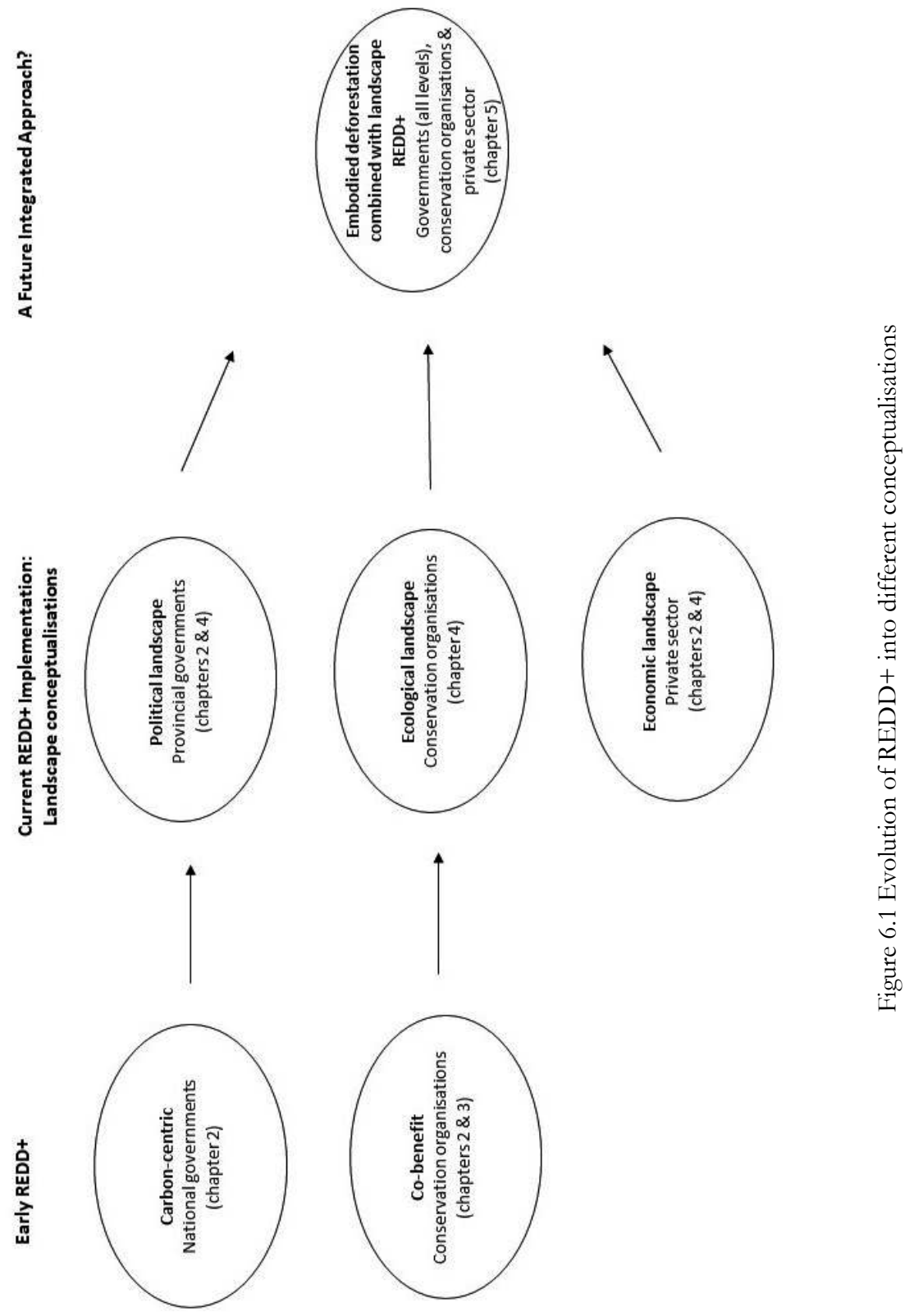


The next phase in the evolution of REDD+ was the introduction of the landscape-level conceptual approach, which is still in the relatively early stages of implementation, termed the 'current implementation phase' in Figure 6.1. In the broadest terms, the landscape approach involves linkages between forests and other forms of land use, particularly agriculture, with concurrent extensive focus on engaging relevant stakeholders beyond traditional forest-related multilevel decision-making arrangements. This landscape approach can be further subdivided into three main conceptualisations, political, ecological and economic.

A political approach to landscape REDD+, mainly defines and conceptualises landscapes on the basis of administrative or jurisdictional boundaries. It involves integrating REDD+ with efforts by provincial governments to decrease land-based emissions. This often involves contributing to the implementation of NAMAs within a particular political jurisdiction and may be linked to Low Emission Rural Development (LEDR) programmes. It can therefore be viewed as an evolution of the carbon-centric conceptual approach described in early REDD+. In contrast, an ecological conceptual approach mainly defines and conceptualises landscapes on the basis of ecological or biological characteristics. In this scenario, REDD + combines forest conservation and climate mitigation with efforts to conserve other ecosystems by attempting to find a balance between different land uses and development. It can therefore be viewed as a development of the co-benefit approach in early REDD + . It is strongly influenced by conservation organisations interested in scaling-up REDD+ projects and forest conservation efforts for biodiversity co-benefits. The ecological landscape approach was the least examined in the REDD+ literature, and was the focus of analysis in chapter 4 .

This new involvement by the private sector, who was not involved in the early phase of REDD+, brought an additional conceptual framing to landscape REDD+. As a finding of this thesis, this is termed an economic landscape approach. In this scenario, landscapes are defined and conceptualised on the basis of commodity production in areas where industrial agriculture is a major driver of deforestation. This has resulted in REDD+ becoming integrated with large-scale private sector initiatives to reduce land-use emissions and tackle deforestation, such as deforestation-free supply chains, sustainable commodity roundtables and certification schemes. This approach is dominant in the conceptualisation and operationalisation of landscape REDD+, led by initiatives in Indonesia and Brazil. It often overlaps with political landscape approaches, in which there is collaboration between provincial governments acting to meet emission reduction targets and private sector actors interested in meeting zero deforestation commitments. It may also overlap with ecological landscape approaches, for example, through climate-smart agriculture and land-use planning initiatives.

The newest conceptual approach now being introduced is that of the embodied deforestation discourse emerging at the international policy level. It is mainly developing out of EU tropical forest policy discussions, rather than directly from the REDD+ policy space, but is having an impact upon how REDD+ is further conceptualised, as discussed in chapter 5. Embodied deforestation views tropical deforestation and degradation as an externality in the production, trade or consumption of a good, commodity, or service, and therefore introduces a shared responsibility for tackling such deforestation between those involved not only in its production, but also in its trade and consumption. This new conceptualisation has recently entered the international policy discourse, but for the most part is not yet being implemented. There is potential for new policy instruments to 
emerge from such a new discourse, however, which could be combined with REDD+ landscape approaches or even supersede them. This scenario is therefore labelled as 'A Future Integrated Approach?', in Figure 6.1, as it is being proposed by a combination of stakeholders from governments, conservation organisations and the private sector, thereby bringing together the main stakeholder groups involved in REDD+.

Following these findings relating to the diverse conceptualisations of REDD + as discussed above, I now turn to address the second part of the first research question: to what extent have these various conceptualisations been able to tackle the drivers of deforestation and forest degradation in practice? The findings of the thesis relating to this part of the question, synthesising across all four empirical chapters, are summarised in Table 6.1. To provide a comprehensive answer to this question, Table 6.1 also includes information on the ability of other REDD+ conceptualisations to tackle drivers, namely economic and political landscape approaches, and national REDD+ strategies and plans. These conceptualisations were discussed in this thesis but not analysed in detail, as they were already well covered by other researchers, as referenced in the table. 
Table 6.1 Diverse conceptualisations of REDD + and their impact on drivers: overview of findings

\begin{tabular}{|c|c|c|c|c|c|}
\hline $\begin{array}{l}\text { Governance } \\
\text { level and type } \\
\text { of REDD+ } \\
\text { intervention }\end{array}$ & $\begin{array}{c}\begin{array}{c}\text { Local co- } \\
\text { benefit } \\
\text { projects }\end{array} \\
\text { (co-benefit } \\
\text { approach) }\end{array}$ & $\begin{array}{c}\text { Landscape } \\
\text { level }\end{array}$ & $\begin{array}{c}\text { Landscape } \\
\text { level }\end{array}$ & $\begin{array}{l}\text { National } \\
\text { strategies } \\
\text { and plans }\end{array}$ & $\begin{array}{c}\begin{array}{c}\text { International } \\
\text { forest policy } \\
\text { interventions }\end{array} \\
\text { (embodied } \\
\text { deforestation) }\end{array}$ \\
\hline $\begin{array}{l}\text { Source / } \\
\text { Reference }\end{array}$ & $\begin{array}{c}\text { Chapters } 2 \\
\text { and } 3\end{array}$ & $\begin{array}{c}\text { Chapters } 2 \\
\text { and } 4\end{array}$ & $\begin{array}{l}\text { Chapter } 2 \\
\text { Fishbein and } \\
\text { Lee (2015) } \\
\text { and Boucher } \\
\text { and Elias } \\
(2013)\end{array}$ & $\begin{array}{l}\text { Kissinger } \\
\text { et al. } \\
\text { (2012) and } \\
\text { Salvini et } \\
\text { al. (2014) }\end{array}$ & Chapter 5 \\
\hline $\begin{array}{l}\text { REDD+ } \\
\text { impact on local } \\
\text { or regional } \\
\text { direct drivers of } \\
\text { deforestation } \\
\text { and forest } \\
\text { degradation }\end{array}$ & & i & & & \\
\hline $\begin{array}{l}\text { REDD+ } \\
\text { impact on } \\
\text { national } \\
\text { indirect drivers } \\
\text { of deforestation } \\
\text { and forest } \\
\text { degradation }\end{array}$ & & i & & & i \\
\hline $\begin{array}{l}\text { REDD+ } \\
\text { impact on } \\
\text { international } \\
\text { indirect drivers } \\
\text { of deforestation } \\
\text { and forest } \\
\text { degradation }\end{array}$ & & & $\mathbf{i}$ & & \\
\hline
\end{tabular}

Explanation of symbols used:

Positive impact

$\uparrow$ Limited positive impact
A) Potential for positive impact but not implemented

i Potential for limited positive impact but not implemented

No discernible impact 
Table 6.1 shows that local REDD+ projects implementing a co-benefit approach to REDD+ have generally had a positive impact on, and been able to tackle, many local direct and indirect drivers of deforestation and forest degradation. The one major exception to this is the direct driver of livestock farming, which is a major cause of deforestation in Latin America in particular, which REDD+ projects seem unable to tackle. Furthermore, although such projects are being implemented at the local level, they are also having an impact on a limited number of indirect drivers operating at the national level, referred to as a 'limited positive impact' in Table 6.1.

In the case of landscape-focused REDD+ interventions, there is an expectation that integrating REDD + more strongly with stakeholders closely involved with agricultural production systems, will help to tackle deforestation linked to the expansion of commercial agriculture - a major driver of deforestation. Much of the academic and grey literature has focused on political and economic understandings of landscape REDD+, which are often combined (as shown in Table 6.1). This literature reports that such approaches hold considerable promise to stimulate new configurations of stakeholders that influence land-use decision-making, particularly from agribusiness companies and provincial governments (Fishbein and Lee 2015). Integrating REDD+ with initiatives such as deforestation-free supply chains also enhances its potential to be linked to efforts to tackle indirect international drivers (Boucher and Elias 2013). There remains, however, a disconnect between the theory and practice with considerable hurdles still to be overcome before such an approach can be implemented. It is thus depicted in Table 6.1 as having potential for positive impact. Table 6.1 also presents the findings for the ecological landscape approach to REDD+ and its potential to tackle drivers, as discussed in detail in chapter 4 . It shows that such an approach appears to have less potential to address drivers than more localised REDD+ projects. It only has potential to have a positive impact on a limited number of local direct and indirect drivers of deforestation and forest degradation, and some national indirect drivers, if fully implemented. Understandably, neither local projects taking a co-benefit approach to REDD+ implementation nor landscape approaches are able to effectively tackle indirect drivers operating at the national or international level.

Although a nested approach to REDD+ should mean that indirect drivers operating at the national level will be tackled through national level REDD+ strategies and readiness plans, studies by other researchers found that in fact such national strategies also tended to focus on direct drivers operating at the local level (Kissinger et al. 2012) or predominately on drivers associated with forest degradation rather than deforestation (Salvini et al. 2014). Activities targeting national indirect drivers are therefore a major implementation gap for REDD+. Whilst local drivers are therefore being targeted with some success, the weak point in the REDD+ networked governance system appears to be at national level, where efforts to achieve cross-sectoral policy integration have been largely unsuccessful. This finding is echoed by other researchers, for example, Somorin et al. (2014) and Korhonen-Kurki et al. (2014). This is likely to be the point at which REDD+ comes up against powerful economic vested interests that are largely resistant to change. Table 6.1 thus shows that, as currently conceptualised and operationalised, REDD+ is unable to tackle indirect, international drivers of deforestation and forest degradation.

Building upon this finding, the examination of the newly emerging 'embodied deforestation' discussion at the international forest policy level in chapter 5 is important and timely. It shows that, if well implemented, this approach may indeed have the potential to tackle indirect drivers operating 
at the international level, especially relating to trade and consumption of agricultural commodities that are linked to tropical deforestation. This would also have a positive impact on some drivers operating at the national level. Although such discussions are still at an early stage and have not yet been implemented (except through a national strategy on imported deforestation published by the government of France in November 2018) ${ }^{64}$, they appear to hold promise to tackle such drivers if implemented.

\subsubsection{Is REDD+ bringing transformational change through policy integration?}

In light of the above findings, and the answer to the first research question, I turn next to the second overarching research question of this thesis: "From a networked governance perspective, to what extent is REDD+ becoming integrated across diverse policy domains and how is this impacting its ability to deliver transformational change?"

The first step in answering this question requires synthesising the findings of this thesis regarding the extent to which REDD+ is becoming integrated across policy domains. As the preceding analysis has shown, REDD+ generated a lot of interest across a diverse array of policy domains, given its status as the first international environmental policy mechanism to be developed at the interface of the climate change and forest policy domains (as illustrated in Figure 1.3, section 1.3.3). As REDD+ began to be implemented, and the importance of clearance for agricultural commodity production became recognised as a major driver of deforestation it also became integrated with agricultural policies (Soto Golcher and Visseren-Hamakers 2018). However, integration with this new policy area beyond the scope of environmental governance, has only been weakly achieved (as shown in Figure 1.4, section 1.3.3).

Although REDD+ can thus be described as initially situated at the forest-climate nexus and then at the forest-climate-agriculture nexus, this thesis indicates that its situation at the nexus of diverse policy domains is now becoming ever more complex. As the importance of indirect international drivers of deforestation and forest degradation has become more widely recognised (e.g., Curtis et al. 2018), led by the increasingly globalised trade in agricultural commodities and timber, efforts are now being made to link REDD+ to new policies being developed to increase the sustainability of production and consumption. This includes the EU FLEGT policy for timber imports linked to forest degradation, as well as new policies relating to the EU embodied deforestation discussions in relation to agricultural commodities linked to deforestation, as described in chapter 5 . This engagement with sustainable production and consumption issues has also begun to indirectly link REDD + to the trade policy discourse, going beyond the environmental domain. This increasingly complex situation is illustrated in Figure 6.2. It shows that REDD+ is becoming integrated with other policies within the environmental domain, but also increasingly with other policy domains beyond environment, namely trade and agriculture, although links here are weaker. REDD+ can thus now be described as being increasingly situated at the forest-climate-agriculture-trade policy nexus.

${ }^{64}$ As reported by the government of France at the following link: https://www.gouvernement.fr/en/endingdeforestation-caused-by-importing-unsustainable-products (accessed 13 May 2019) 


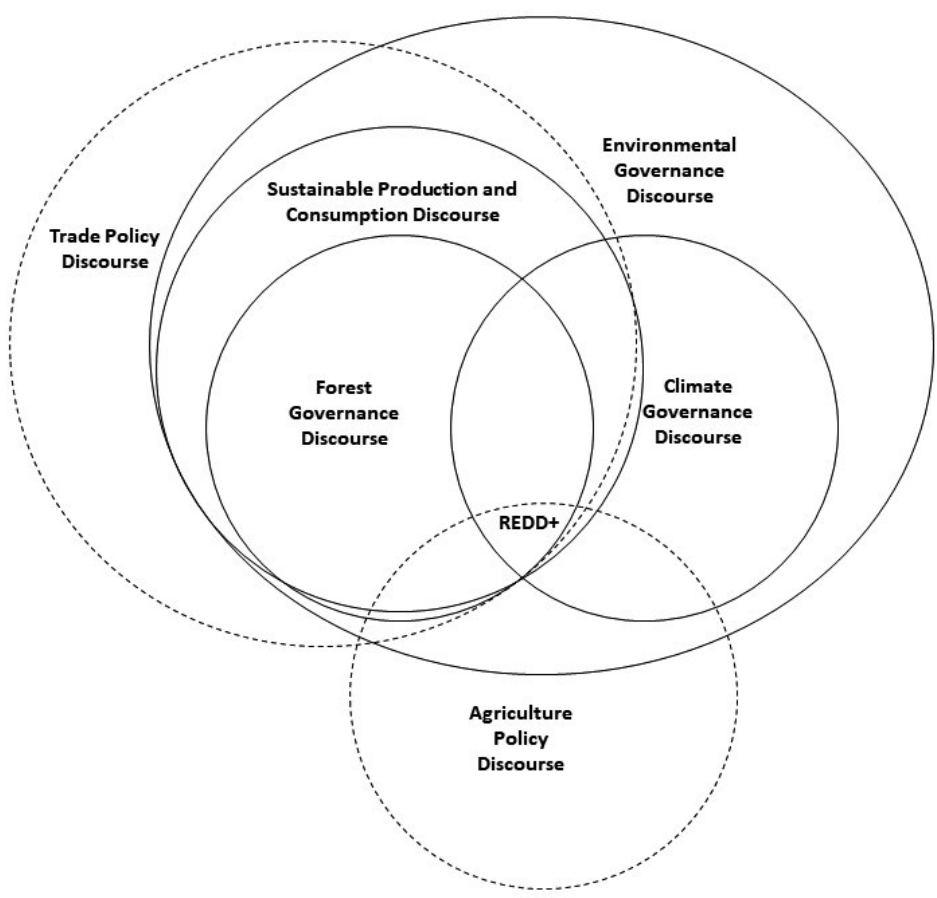

Figure 6.2 REDD+ at the nexus of policy domains within and beyond the environment

As seen above, REDD+ can therefore indeed be viewed as an example of networked governance, not least because it is becoming more integrated with other policy domains. In light of this, I consider next how this growing integration is impacting upon its ability to deliver transformational change. Transformational change involves disruptional change that triggers shifts from degraded to functional socio-ecological systems at multiple scales (Chaffin et al. 2016) and requires new governance at the policy nexus to help convert trade-offs into synergies (as described in section 1.3.1). In the context of global deforestation and forest degradation, transformational change can therefore be discerned through the ability to address indirect drivers operating at the international level, particularly those associated with growing global trade in commodities linked to deforestation. As concluded in the preceding section (section 6.2.1), as previously conceptualised and operationalised, REDD + has been unable to tackle indirect, international drivers of deforestation and forest degradation. Addressing them will therefore require a new, transformational approach, at this new emerging nexus of diverse policy domains.

The new, emerging policy discussions at the international level on 'embodied deforestation' (as described in chapter 5), therefore present an interesting new opportunity to achieve transformational change. It has thus far been difficult for REDD+ to become strongly integrated with policies 
outside of the environmental governance arena, namely agriculture and trade policies, given that they are more concerned with promoting economic interests. Greater success has been achieved in terms of integrating REDD+ with other environmental policies that share similar overarching aims. The embodied deforestation discourse, however, seems to present a new potential for REDD+ to become more deeply embedded within environmental policies being developed within consumer countries to address sustainable production and consumption. This can bring together diverse interest groups at different points along the supply chain.

This thesis finds, therefore, that these newly emerging policy initiatives at the international level, which are bringing together new configurations of stakeholders in informal decision-making structures (as described in chapter 5), may be able to 'leapfrog' over some of the political inertia at national level. As discussed, it has been harder for REDD+ to promote innovative approaches and incentivise change at national level in the face of entrenched economic interests. Economic and political approaches to landscape REDD +, however, appear to represent the major point in the policy nexus at which actors from the agricultural sector are already becoming involved. This is the case at least from the private sector, if not from agricultural ministries, and is resulting in newer, more informal forms of governance at the landscape level. A new integrative approach could, therefore, link efforts by consumer countries to economic and political landscape REDD+ initiatives in developing country contexts. If consumer countries actually take responsibility for tackling indirect international drivers linked to their consumption patterns, and link this to new coalitions of stakeholders that are already emerging at the landscape level within producer countries, new informal governance structures may emerge that could lead to transformational change. The risk for REDD+ of these new structures, however, is that it may be superseded and replaced by new, alternative policy mechanisms.

\subsection{Contribution to Knowledge and External Validity}

This thesis has taken an overarching approach to assessing the ability of REDD+ to tackle the drivers of deforestation and forest degradation, and stimulate transformational change through new integrative approaches. The findings are therefore widely applicable to REDD + in its different incarnations, but also provide a basis for generating insights into similar emerging discussions in other areas of environmental governance.

With regard to the insights pertaining to REDD+, this analysis has drawn on a range of primary information sources about REDD+ with a wide geographic coverage, in order to present results with global relevance (see, for example, Table 1.2, section 1.5.3). In the case of local REDD+ projects analysed in chapter 2 , a quarter of the projects analysed were located in Asia, one third in Africa, and the rest in Latin America. The thesis also contains a range of perspectives on REDD+ through the stakeholder interviews conducted. Around a quarter of individuals interviewed for this thesis provided an international perspective, a third gave a national perspective and the remainder provided a local perspective. Following preliminary stakeholder mapping exercises, interviewees were also selected to represent a range of backgrounds and types of organisations involved in REDD+ discussions. Again, this gave access to a wide range of perspectives, ensuring that the findings are widely applicable (as shown in Table 1.2, section 1.5.3). 
The case study examining landscape REDD+ in Madagascar provided a somewhat atypical example of REDD+ landscape approaches, as it did not share key characteristics of countries, such as Indonesia and Brazil, in which landscape level REDD+ initiatives have gained most prominence thus far. It was therefore able to shed new light on a broader set of dynamics within those developing countries where a more ecological REDD+ might become relevant in the future. Thus, the focus on Madagascar, whilst atypical, provided an opportunity to study a previously unexamined example of landscape REDD+. The findings in this chapter are applicable to other countries that share some of its characteristics, including high poverty, high biodiversity, a centralised rather than regionalised governance structure, and an underdeveloped agricultural sector. Such countries include, for example, the Democratic Republic of the Congo or Papua New Guinea.

I turn next to drawing out implications of the analysis relating to the conceptual evolution of REDD+ over time for other environmental policy domains. As a policy tool that is becoming more integrated into other policy areas over time, it is striking how the evolution of REDD+ reflects wider conceptual debates and empirical developments within the environmental governance arena over time. Figure 6.3 illustrates how REDD+ has evolved both conceptually and operationally over time, and how this evolution reflects wider conceptual debates within the environmental governance arena and beyond. 
Increasing policy integration over time

\begin{tabular}{|c|c|c|c|c|c|}
\hline Policy Nexus & $\begin{array}{l}\text { Environment } \\
\text { (biodiversity) } \\
\text { - forests }\end{array}$ & $\begin{array}{l}\text { Environment } \\
\text {-forests- } \\
\text { climate }\end{array}$ & $\begin{array}{l}\text { Environment- } \\
\text { forests-climate- } \\
\text { agriculture }\end{array}$ & $\begin{array}{l}\text { Environment- } \\
\text { forests-climate- } \\
\text { agriculture-trade }\end{array}$ & $\begin{array}{l}\text { Environment } \\
\text {-forests- } \\
\text { climate- } \\
\text { agriculture- } \\
\text { trade-SDGs }\end{array}$ \\
\hline $\begin{array}{l}\text { REDD+ } \\
\text { conceptualisations }\end{array}$ & Co-benefit & $\begin{array}{l}\text { Carbon- } \\
\text { centric, } \\
\text { alongside } \\
\text { co-benefit }\end{array}$ & $\begin{array}{c}\text { Political, economic } \\
\text { and ecological } \\
\text { conceptualisations } \\
\text { of landscape }\end{array}$ & $\begin{array}{c}\text { Evolving } \\
\text { conceptualisations } \\
\text { of landscape } \\
\text { REDD+ }\end{array}$ & $\begin{array}{c}\text { Embodied } \\
\text { deforestation } \\
\text { and landscape } \\
\text { REDD+ }\end{array}$ \\
\hline $\begin{array}{l}\text { REDD+ } \\
\text { Implementation }\end{array}$ & $\begin{array}{c}\text { Forest } \\
\text { conservation, } \\
\text { sustainable } \\
\text { forest } \\
\text { management }\end{array}$ & $\begin{array}{l}\text { Payments for } \\
\text { carbon, } \\
\text { REDD+ } \\
\text { projects }\end{array}$ & $\begin{array}{c}\text { Landscape and } \\
\text { jurisdictional } \\
\text { REDD+ }\end{array}$ & $\begin{array}{l}\text { Sustainable supply } \\
\text { chains, } \\
\text { deforestation-free } \\
\text { commodity } \\
\text { production }\end{array}$ & $\begin{array}{c}\text { New } \\
\text { international } \\
\text { policies } \\
\text { combined } \\
\text { with } \\
\text { landscape } \\
\text { REDD+? }\end{array}$ \\
\hline $\begin{array}{l}\text { Concepts in the } \\
\text { environmental } \\
\text { governance } \\
\text { discourse }\end{array}$ & $\begin{array}{c}\text { Balance } \\
\text { between } \\
\text { biodiversity } \\
\text { and economic } \\
\text { use }\end{array}$ & $\begin{array}{c}\text { PES, market- } \\
\text { based } \\
\text { discourse }\end{array}$ & $\begin{array}{l}\text { Agricultural policy } \\
\text { discourse }\end{array}$ & $\begin{array}{c}\text { Sustainable } \\
\text { production and } \\
\text { consumption }\end{array}$ & SDGs, IEG \\
\hline
\end{tabular}

Figure 6.3 How evolution of REDD+ in policy and practice reflects wider debates and developments in environmental and sustainability governance

As Figure 6.3 illustrates, when REDD+ was first introduced, forest policies were often linked to biodiversity policies, for example, through the CBD, (shown in Figure 6.3 as the 'pre-REDD+ era'). Forest governance was heavily influenced by a conceptual understanding that applied to many environmental policies at the time, i.e. the need to find a balance between conservation and economic use. This influenced the advent of early REDD+ and the co-benefits approach. As forest policies were integrated within the climate change governance framework in early REDD+, discussions focused on performance-based payments for forest carbon storage. This phase reflected the predominance of PES approaches in the environmental governance discourse at the time, and the interest in finding market-based solutions to environmental challenges. As REDD+ has subsequently become integrated (albeit weakly) with governance approaches linked to the agricultural policy domain, various conceptualisations of landscape-scale REDD+ have appeared. 
This phase has been further impacted by the introduction into the wider REDD+ context of the increasingly dominant sustainable production and consumption policy discourse, which has emphasised newer forms of REDD + engagement with issues such as sustainable supply chains and deforestation-free commodity production, although their implementation still remains nascent in practice.

Finally, the last column in Figure 6.3 illustrates the most recent discursive and empirical developments towards an even more highly integrated approach to environmental governance, influenced by the holistic and universal approach taken in adopting the SDGs and academic discourses such as Integrative Environmental Governance (IEG). These new developments hold out potential for REDD+ to become integrated with new policies now being considered by consumer countries to tackle 'embodied deforestation'. It is unclear what the implications for REDD+ will be in such an emerging scenario, and whether REDD+ even has a future. It remains possible that such a complex policy nexus, involving diverse stakeholders with competing interests and different conceptual approaches, is causing REDD + to evolve into a new and different policy mechanism and is thereby possibly heralding the start of a new 'post-REDD+ era' in international forest governance.

The evolution of REDD+ described above and captured in Figure 6.3, thus has multiple implications for evolving conceptual and empirical debates in environmental and sustainability governance. It is particularly relevant in the context of the current momentum for the development of global overarching environmental policies, as shown by the adoption of the SDGs and the newly proposed UN Global Pact for the Environment. I therefore next turn to discuss some of the insights this analysis provides for other emerging environmental policy mechanisms.

First, the analysis shows that, whilst progress has been made to integrate REDD+ with other environmental policy areas, and new informal structures have been developed at this more complex policy nexus in response, integration with non-environmental policy areas has been much more difficult to achieve. It may be the case that other attempts to develop integrated international environmental approaches (such as the SDGs), also manage to create more coherence and integration with other environmental policies, but do so to a lesser extent with other (nonenvironmental) policy areas. The increasing prominence of the sustainable production and consumption discourse within the environmental policy arena does, however, provide an entry point for addressing negative environmental impacts associated with global trade, and the potential to link the environmental policy domain to others, such as trade and agriculture. SDG target 12, for example, encourages countries to develop national action plans for sustainable consumption and production and to mainstream it as a priority into other national policies. ${ }^{65}$ This type of approach could, for example, be relevant for the current discussion under the CBD concerning new internationally agreed global targets for biodiversity post 2020. Linking more closely with policy actions to increase the sustainability of consumption and production could stimulate the development of new coalitions of actors at the policy nexus and thereby hold promise for incentivising transformative change in addressing global biodiversity loss.

\footnotetext{
${ }^{65}$ As mentioned in SDG target 12, indicator 12.1.1, published online at: https://sustainabledevelopment.un.org/sdg12 (accessed 29 June 2019)
} 
Second, although REDD+ was supposed to provide a nested approach with complementary actions at different levels, a disproportionally strong focus has continued on tackling local drivers and incentivising behaviour change amongst local communities and individuals. REDD + has been criticised by some researchers for creating a new form of neo-colonialism (for example, Cabello and Gilbertson 2012) because incentivising local communities to change their behaviour is viewed as an easier option than challenging more powerful economic interest groups through the creation of transformative REDD+ governance structures at the national level. Whilst perhaps reinforcing this view, the research findings in this thesis also indicate that the advent of new policy approaches within consumer countries linked to sustainable production and consumption processes, may provide a way of linking the local or landscape level impacts to the actions and choices of overseas consumers, thereby sharing the responsibility for behaviour change with global consumers. Such an approach may provide a mechanism that can 'leapfrog' policy inertia at the national level.

This finding is applicable to other sustainability-orientated policy mechanisms that consumer countries are now beginning to consider. France, for example, adopted new legislation in $2017^{66}$ that sets obligations of due diligence on companies, requiring them to take action to reduce and mitigate negative social and environmental impacts caused by their regular suppliers operating in producer countries. Governments in other consumer countries, such as the UK and Switzerland, are also considering the potential for similar due diligence instruments (European Coalition for Corporate Justice, 2018). In a similar vein, the European Commission published draft legislative proposals on sustainable finance in May 2018, which aim to increase transparency in the area of environmental and social impacts of European financial investments, including in partner countries ${ }^{67}$. As with REDD+, while these approaches hold promise, it is important to ensure that they do lead to a fairer sharing of the burden of responsibility between producing and consuming countries, and do not undermine the sovereignty of national governments in producer countries.

Third, as shown in Figure 6.3, as REDD+ has become increasingly integrated with other policies, it is now potentially so transformed that it no longer resembles REDD+. It could even be described as being superseded by new initiatives, thus bringing us to the point where we may be entering a postREDD + era in international forest policy. REDD + in its earliest renditions was unable to live up to the very high and unrealistic expectations originally placed on it, due in part to a lack of hoped-for market-based finance and a reluctance by national implementing governments to achieve necessary cross-sectoral integration. This early 'failure' no doubt caused some key stakeholders to lose interest in it. However, REDD+ has continually evolved, in policy and practice, in response. This notwithstanding, it appears that REDD+ has faced a 'double-edged sword' of increasing environmental policy integration. While some integration across policy domains might be beneficial to avoid unintentional trade-offs and conflicts, such integration might also transform a policy initiative beyond recognition or may cause them to become so overloaded and diluted by different perspectives and expectations that they evolve beyond all recognition. Rather than viewing REDD+ as a failed policy initiative that is now being superseded, however, such an eventuality can also be

\footnotetext{
${ }^{66}$ As published online by the French government: http://www.assemblee-nationale.fr/14/ta/ta0924.asp (webpage accessed 17 May 2019)

${ }^{67}$ Commission legislative proposals on sustainable finance published online at: https://ec.europa.eu/info/publications/180524-proposal-sustainable-finance en (accessed 29 June 2019)
} 
viewed more positively. Thus, a more evolved and integrated REDD+ might well provide an essential stepping stone to the development of much needed innovative environmental policy mechanisms at the international level that have the potential to tackle the ongoing problem of deforestation and forest degradation and achieve transformational change.

\subsection{Areas of Future Research}

With regard to the ability of REDD+ to continue to address drivers of deforestation and forest degradation, it remains to be seen whether this indeed requires entering a 'post-REDD+' era. It is possible that landscape level approaches are combined with new international policies emerging at the international level, including to tackle embodied deforestation, and this enhances the prospects for lasting change. Or, alternatively, it is possible that REDD+ continues to be implemented through both local projects and landscape-scale activities, as one of a number of linked policy approaches that together tackle deforestation and forest degradation. A highly integrated, networked forest governance approach, in which REDD+ is merely one of a number of approaches (including relating to embodied deforestation), could provide a positive way forward for tackling deforestation drivers. This could even signal the end of the currently highly fragmented approach to international forest governance. If a more integrated forest policy approach moves forward, however, further research will be needed to examine how the embodied deforestation approach is evolving and being conceptualised in practice. If and when it is implemented, it will be necessary to analyse whether it is it living up to its promise of tackling the indirect international drivers of deforestation and forest degradation.

Moving beyond REDD+ to the wider environmental governance research agenda, there are still many open questions relating to the impact of increasing integration of policy areas, including integration with non-environmental policies, and the ability of these to stimulate transformational change. It is important to examine the policy nexus of other environmental policies beyond REDD+ to identify whether and how these are shifting as a result of further integration, and if so, whether this is stimulating new formal and/or informal governance arrangements that involve new configurations of actors. Particularly significant is the need to examine the implementation of policies to reach environmental targets developed under the SDGs. The recently published, and widely publicised, Intergovernmental Science-Policy Platform on Biodiversity and Ecosystem Services (IPBES) assessment report on global biodiversity loss, showed, for example, that progress towards achieving the environmental SDGs is impossible without transformational change requiring cross-sectoral approaches and innovative governance (Diaz et al. 2019). Further questions relate more specifically to whether the growing importance of sustainable consumption and production policies within the wider environmental policy discourse is indeed stimulating further policy integration and thereby reducing the negative impacts of globalised trade across a number of environmental policy areas.

Another set of questions relates to the development of new policies by consumer countries, such as the EU Member States, in response to public concern relating to the social and environmental impacts of companies operating in developing countries. This includes, for example, the new due 
diligence legislation being developed and implemented in France and elsewhere, and new EU legislative proposals relating to sustainable financial investments. It is important to examine whether such policies do indeed lead to a fairer sharing of the burden of responsibility for environmental degradation between consuming and producing countries, and whether they shift. away from placing the burden of responsibility for behavioural change on local communities in developing countries. If new international policies are developed and implemented to effectively tackle embodied deforestation, which take seriously the need for a fairer sharing of responsibility between consumer and producer countries, this would indeed be a cause for optimism for tackling global environmental problems, such as tropical deforestation and forest degradation, and for achieving the environmental SDGs. 


\section{References}

Achard, F., Beuchle, R., Mayaux, P., Stibig, H-J., Bodart, C., Brink, A., Carboni, S. et al. 2014. "Determination of Tropical Deforestation Rates and Related Carbon Losses from 1990 to 2010." Global Change Biology 20: 2540-54. https://doi.org/10.1111/gcb.12605.

Aggestam, F., Pülzl, H., 2018. "Coordinating the Uncoordinated: The EU Forest Strategy.” Forests 9 (3): 1-20. https://doi.org/10.3390/f9030125.

Arts, B. 2014. “Assessing Forest Governance from a 'Triple G’ Perspective: Government, Governance, Governmentality*." Forest Policy and Economics 49: 17-22. https://doi.org/10.1016/j.forpol.2014.05.008.

Asare, R., Kyei, A., Mason, J.J., 2013. “The Community Resource Management Area Mechanism: A Strategy to Manage African Forest Resources for REDD+." Philosophical Transactions of the Royal Society of London. Series B, Biological Sciences 368 (1625): 20120311.

Ashford, N.A., Hall, R.P., 2018. “Achieving Global Climate and Environmental Goals by Governmental Regulatory Targeting." Ecological Economics 152 (April): 246-59. https://doi.org/10.1016/j.ecolecon.2018.06.002.

Atela, J.O., Quinn, C.H., Minang, P.A., Duguma, L.A., 2015. "Implementing REDD+ in view of Integrated Conservation and Development Projects: Leveraging Empirical Lessons." Land Use Policy 48: 329-40. https://doi.org/10.1016/j.landusepol.2015.06.011.

Austin, K. G., González-Roglich, M., Schaffer-Smith, D., Schwantes, A.M., Swenson, J.J., 2017. "Trends in Size of Tropical Deforestation Events Signal Increasing Dominance of IndustrialScale Drivers." Environmental Research Letters 12 (5). https://doi.org/10.1088/17489326/aa6a88.

Balderas Torres, A., and Skutsch, M., 2012. "Splitting the Difference: A Proposal for Benefit Sharing in Reduced Emissions from Deforestation and Forest Degradation (REDD+)." Forests 3 (4): 137-54. https://doi.org/10.3390/f3010137.

Ballesteros, A., Nakhooda, S., Werksman J., Kaija, W., Kumar, S., 2010. "Power, Responsibility and Accountability: Re-Thinking the Legitimacy of Institutions for Climate Finance." World Resources Institute. Washington D.C. https://heinonline.org/hol-cgibin/get_pdf.cgi?handle=hein.journals/climatla1\&section $=13$.

Bastos Lima, M.G., Kissinger, G., Visseren-Hamakers, I.J., Braña-Varela, J., Gupta, A., 2017a. “The Sustainable Development Goals and REDD+: Assessing Institutional Interactions and the Pursuit of Synergies." International Environmental Agreements: Politics, Law and Economics 17 (4): 589-606. https://doi.org/10.1007/s10784-017-9366-9.

Bastos Lima, M., Visseren-Hamakers, I.J., Brana-Varela, J., Gupta, A., 2017b. A reality check on the landscape approach to REDD+: Lessons from Latin America. Forest Policy and Economics 78, 10 20 
Bellfield, H., Sabogal, D., Goodman, L., Leggett, M., 2015. "Case Study Report: Community-Based Monitoring Systems for REDD+ in Guyana." Forests 6 (1): 133-56.

https://doi.org/10.3390/f6010133.

Bennett, N. J., Satterfield, T., 2018. "Environmental Governance: A Practical Framework to Guide Design, Evaluation, and Analysis." Conservation Letters, November 2017: e12600. https://doi.org/10.1111/conl.12600.

Bergsten, A., Senbeto Jiren T., Leventon, J., Dorresteijn, I., Schultner, J., Fischer, J., 2019. "Identifying Governance Gaps among Interlinked Sustainability Challenges." Environmental Science and Policy 91 (February 2018): 27-38. https://doi.org/10.1016/j.envsci.2018.10.007.

Bernard, F., Minang, P.A., van Noordwijk, M., Freeman, O.E., Duguma, L.A. 2013. “Towards a Landscape Approach for Reducing Emissions: Substantive Report of the Reducing Emissions from All Land Uses (REALU) Project." Nairobi, Kenya.

Bernard, F., Minang, P.A., Adkins, B., Freund, J.T., 2014. "REDD+ Projects and National-Level Readiness Processes: A Case Study from Kenya.” Climate Policy, no. August 2014 (May): 1-13. https://doi.org/10.1080/14693062.2014.905440.

Bertrand, A., Aubert, S., Montagne, P., Clovis, L.A. 2014. "Madagascar, Politique Forestière: Bilan 1990 - 2013 et Propositions.” Madagascar Conservation and Development 9 (1): 20-30. https://doi.org/10.4314/mcd.v8i2.7.

Bicalho, T., Bessou, C., Sergio, A.P. 2016. Land Use Change within EU Sustainability Criteria for Biofuels: The Case of Oil Palm Expansion in the Brazilian Amazon. Renew. Energy, 89, 588-597

Biermann, F., Abbott, K., Andresen, S., Bäckstrand, K., Bernstein, S., Betsill, M.M., Bulkeley, H. et al. 2012. "Transforming Governance and Institutions for Global Sustainability: Key Insights from the Earth System Governance Project." Current Opinion in Environmental Sustainability 4 (1): 51-60. https://doi.org/10.1016/j.cosust.2012.01.014.

Blanc-Pamard, C., 2009. “The Mikea Forest Under Threat (Southwest Madagascar): How Public Policy Leads to Conflicting Territories." Field Actions Science Reports. Vol. 3. http:// factsreports.revues.org/341.

Blom, B., Sunderland, T., Murdiyarso D., 2010. "Getting REDD to Work Locally: Lessons Learned from Integrated Conservation and Development Projects." Environmental Science \& Policy 13 (2): 164-72. https://doi.org/10.1016/j.envsci.2010.01.002.

Blythe, J., Silver, J., Evans, L., Armitage, D., Bennett, N.J., Moore, M.L., Morrison, T.H., Brown, K., 2018. "The Dark Side of Transformation: Latent Risks in Contemporary Sustainability Discourse." Antipode 50 (5): 1206-23. https://doi.org/10.1111/anti.12405.

Börner, J., Wunder, S., Wertz-Kanounnikoff, S., Tito, M.R., Pereira, L., Nascimento, N., 2010. "Direct Conservation Payments in the Brazilian Amazon: Scope and Equity Considerations", Ecological Economics, 69, 1272 - 1282. 
Boucher, D., Elias P., 2013. "From REDD to Deforestation-Free Supply Chains: The Persistent Problem of Leakage and Scale." Carbon Management 4 (5): 473-75. https://doi.org/10.4155/cmt.13.47.

Bourgoin, J., Castella, J.C., Hett, C., Lestrelin, G., Heinimann, A., 2013. “Engaging Local Communities in Low Emissions Land-Use Planning: A Case Study from Laos." Ecology and Society 18 (2) (9).

Brack, D., Bailey, R., 2013. "Ending Global Deforestation: Policy Options for Consumer Countries."

Brickell, E., Mcfarland, W., Mwayafu, D.M. 2012. “Unlocking Progress on REDD+: Sector Coordination in Uganda."

Brimont, L., Karsenty, A., 2015. "Between Incentives and Coercion: The Thwarted Implementation of PES Schemes in Madagascar's Dense Forests.” Ecosystem Services 14: 1-9. https://doi.org/10.1016/j.ecoser.2015.04.003.

Brockhaus, M., Di Gregorio, M., Mardiah, S., 2013. "Governing the Design of National REDD+: An Analysis of the Power of Agency." Forest Policy and Economics, August. https://doi.org/10.1016/j.forpol.2013.07.003.

Brockhaus, M., Obidzinski, K., Dermawan, A., Laumonier, Y., Luttrell, C., 2012. “An Overview of Forest and Land Allocation Policies in Indonesia: Is the Current Framework Sufficient to Meet the Needs of REDD+?" Forest Policy and Economics 18 (May): 30-37. https://doi.org/10.1016/i.forpol.2011.09.004.

Broekhoven, G., Wit, M. (eds.) 2014. Linking FLEGT and REDD+ to Improve Forest Governance. Tropenbos International, Wageningen, the Netherlands.

Brown, M.I., 2013. Redeeming REDD: Policies, Incentives and Social Feasibility for Avoided Deforestation. Abingdon, UK: Routledge.

Bugalho, M. N., Caldeira, M.C., Pereira, J.S., Aronson, J., Pausas, J.G., 2011. “Mediterranean Cork Oak Savannas Require Human Use to Sustain Biodiversity and Ecosystem Services." Frontiers in Ecology and the Environment 9 (5): 278-286.

Buizer, M., Humphreys, D., de Jong, W., 2013. "Climate Change and Deforestation: The Evolution of an Intersecting Policy Domain.” Environmental Science \& Policy, August, 1-11. https://doi.org/10.1016/j.envsci.2013.06.001.

Busch, J., Lubowski, R. N., Godoy, F., Steininger, M., Yusuf, A. A., Austin, K., 2012. "Structuring Economic Incentives to Reduce Emissions from Deforestation within Indonesia." Proceedings of the National Academy of Sciences of the United States of America 109 (4): 1062 - 1067.

Bush, S. R., Oosterveer, P., 2007. "The Missing Link: Intersecting Governance and Trade in the Space of Place and the Space of Flows." Sociologia Ruralis 47 (4): 384-99. https://doi.org/10.1111/j.1467-9523.2007.00441.x. 
Bush, S. R., Oosterveer, P., Bailey, M., Mol, A.P.J., 2015. "Sustainability Governance of Chains and Networks: A Review and Future Outlook." Journal of Cleaner Production 107: 8-19. https://doi.org/10.1016/j.jclepro.2014.10.019.

Bustamante M, Robledo-Abad C, Harper R, Mbow C, Ravindranat NH, Sperling F, Haberl H, de Siqueira PA, Smith P., 2014. "Co-Benefits, Trade-Offs, Barriers and Policies for Greenhouse Gas Mitigation in the Agriculture, Forestry and Other Land Use (AFOLU) Sector." Global Change Biology 20: 3270-90.

Butler, R. A., Pin Koh, L., Ghazoul, J., 2009. "REDD in the Red: Palm Oil Could Undermine Carbon Payment Schemes." Conservation Letters 2 (2): 67-73. https://doi.org/10.1111/j.1755263X.2009.00047.x.

Cabello, J., Gilbertson, T., 2012. "A Colonial Mechanism to Enclose Lands: A Critical Review of Two REDD+ Focused Special Issues." Ephemera 12 (1): 162-80. https://doi.org/10.1016/0378-2166(87)90004-X.

Campbell, B. 2009. "Beyond Copenhagen: REDD+, Agriculture, Adaptation Strategies and Poverty." Global Environmental Change 19 (4): 397-99.

Canadell, J. G., Raupach, M.R., 2008. "Managing Forests for Climate Change Mitigation.” Science 320 (5882): 1456-57. https://doi.org/10.1126/science.1155458.

Caplow, S., Jagger, P., Lawlor, K., Sills, E., 2011. "Evaluating Land Use and Livelihood Impacts of Early Forest Carbon Projects: Lessons for Learning about REDD+." Environmental Science \& Policy 14 (2): 152-67. https://doi.org/10.1016/j.envsci.2010.10.003.

Carlisle, K., Gruby, R.L., 2017. "Polycentric Systems of Governance: A Theoretical Model for the Commons.” Policy Studies Journal 00 (00). https://doi.org/10.1111/psj.12212.

Cerbu, G.A., Swallow, B.M., Thompson, D.Y., 2011. "Locating REDD: A Global Survey and Analysis of REDD Readiness and Demonstration Activities." Environmental Science \& Policy 14 (2): 168-80. https://doi.org/10.1016/j.envsci.2010.09.007.

Chaffin, B., Garmestani, A.S., Gunderson, L., Harm Benson, M., Angeler, D.G., Arnold, C.A., Cosens, B.A., Craig, R.K., Ruhl, J.B., Allen, C., 2016. "Transformative Environmental Governance." Annual Review of Environment and Resources 41: 399-423. https://doi.org/10.1146/annurev-environ-110615-085817.

Chagas, T., Streck, C., O’Sullivan, R., Olander, J., Seifert-Granzin, J., 2011. “Nested Approaches to REDD+: An Overview of Issues and Options", Forest Trends and Climate Focus, Washington, DC.

Chhatre, A., Lakhanpal, S., Larson, A.M., Nelson, F., Ojha, H., Rao, J., 2012. "Social Safeguards and Co-Benefits in REDD+: A Review of the Adjacent Possible." Current Opinion in Environmental Sustainability 4 (6): 654-60. https:// doi.org/10.1016/j.cosust.2012.08.006. 
Ciplet, D., Adams, K.M., Weikmans, R., Roberts, J.T., 2018. “The Transformative Capability of Transparency in Global Environmental Governance." Global Environmental Politics 18 (3): 130 50. https://doi.org/10.1162/GLEP.

Clement, S., Standish, R.J. 2018. "Novel Ecosystems: Governance and Conservation in the Age of the Anthropocene." Journal of Environmental Management 208: 36-45. https://doi.org/10.1016/j.jenvman.2017.12.013.

Climate Focus. 2016. "Progress on the New York Declaration on Forests: Eliminating Deforestation from the Production of Agricultural Commodities - Goal 2 Assessment Report."

Colloff, M. J., Martín-López, B., Lavorel, S., Locatelli, B., Gorddard, R., Longaretti, P.Y., Walters, G. et al. 2017. "An Integrative Research Framework for Enabling Transformative Adaptation." Environmental Science and Policy 68: 87-96. https://doi.org/10.1016/j.envsci.2016.11.007.

Conservation International. 2014. "Ecosystem Profile: Madagascar and Indian Ocean Islands."

Corbera, E. 2012. "Problematizing REDD+ as an Experiment in Payments for Ecosystem Services." Current Opinion in Environmental Sustainability 4 (6): 612-19. https://doi.org/10.1016/j.cosust.2012.09.010.

Corbera, E., Schroeder, H., 2011. “Governing and Implementing REDD+.” Environmental Science \& Policy 14 (2): 89-99. https://doi.org/10.1016/j.envsci.2010.11.002.

Costanza, R., D’Arge, R., de Groot, R. Farber, S., Grasso, M., Hannon,B., Limburg, K., et al. 1997. "The Value of the World's Ecosystem Services and Natural Capital." Nature 387: 253-60. https://doi.org/10.1017/CBO9781107415324.004.

Costenbader, J., 2011. "Redd+ Benefit Sharing: A Comparative Assessment of Three National Policy Approaches.” Forest Carbon Partnership Facility and UN-REDD Programme.

COWI, 2017. "Draft Feasibility Study on Options to Step up EU Action against Deforestation, Part 1 (Problems, Drivers, Objectives, Interventions)." http://illegallogging-deforestationconference.eu/wp-content/uploads/2017/06/Draft_Feasibility_Study-PART_I-.pdf.

COWI, 2018. "Feasibility Study on Options to Step up EU Action against Deforestation." http://ec.europa.eu/environment/forests/pdf/feasibility study deforestation kh0418199enn main report.pdf.

Creswell, J.W., Plano Clark, V.L., Designing and Conducting Mixed Methods Research, $2^{\text {nd }}$ Edition, SAGE, Thousand Oaks, California

Cronkleton, P., Barton Bray, D., Medina, G., 2011. “Community Forest Management and the Emergence of Multi-Scale Governance Institutions: Lessons for REDD+ Development from Mexico, Brazil and Bolivia." Forests 2 (4): 451-473.

Curtis, P. G., Slay,C.M., Harris, N.L., Tyukavina, A., Hansen, M.C., 2018. “Classifying Drivers of Global Forest Loss." Science 361 (September): 1108-11. 
DAI. 2009. "Madagascar: Ecoregional Initiatives Program."

Davis C., Daviet F., 2010. "Investing in Results: Enhancing Coordination for More Effective Interim REDD+ Financing. WRI Working Paper."

Dawson, N.; Mason, M.M.; Mwayafu, D.M.; Dhungana, H.; Satyal, P.; Janet, A.F.; Zeitoun, M., Schroeder, H., 2018. Barriers to equity in REDD+: Deficiencies in national interpretation processes constrain adaptation to context. Environ. Sci. Policy, 88, 1-9

De Man, R.; German, L., 2017. Certifying the sustainability of biofuels: Promise and reality. Energy Policy, 109, 871-883.

De Sy, V., Herold, M., Achard, F., Asner, G.P., Held, A., Kellndorfer, J., De Verbesselt, J. 2012. "Synergies of Multiple Remote Sensing Data Sources for REDD+ Monitoring." Current Opinion in Environmental Sustainability 4: 696-706.

De Sy, V. , Herold, M., Achard, F., Beuchle, R., Clevers, J.G.P.W., Lindquist, E., Verchot, L., 2015. "Land Use Patterns and Related Carbon Losses Following Deforestation in South America." Environmental Research Letters 10 (12). https://doi.org/10.1088/1748-9326/10/12/124004.

Den Besten, J.W., Arts, B., Verkooijen, P., 2014. “The Evolution of REDD+: An Analysis of Discursive-Institutional Dynamics.” Environmental Science \& Policy 35: 40-48.

Denier, L., Korwin, S., Leggett, M., MacFarquhar, C., 2014. The Little Book of Legal Frameworks for REDD +. Oxford: Global Canopy Programme.

Desbureaux, S., Brimont, L., 2015. "Between Economic Loss and Social Identity: The MultiDimensional Cost of Avoiding Deforestation in Eastern Madagascar." Ecological Economics 118: 10-20. https://doi.org/10.1016/j.ecolecon.2015.07.002.

Dewi, S., Feri, J., Ekadinata, A., Agung, P., 2013. "Land-Use Planning for Low Emission Development Strategies (LUWES).” ASB Policy brief 35, Nairobi, Kenya.

Dickson, B., Kapos, V., 2012. "Biodiversity Monitoring for REDD+." Current Opinion in Environmental Sustainability 4 (6): 717-25. https://doi.org/10.1016/j.cosust.2012.09.017.

Di Gregorio, M., Brockhaus, M., Cronin, T., 2012. "Politics and Power in National REDD+ Policy Processes." In Analysing REDD+ Challenges and Choices, Angelsen, A., Brockhaus, M., Sunderlin, W.D., Verchot, L.V., (eds.) 69-90. Bogor, Indonesia: CIFOR.

Di Gregorio, M, Santoso, L., Mardiah, S., Muharrom, E., Cronin, T., Brockhaus, M., 2015. "Deadlock or Transformational Change? Exploring Public Discourse on REDD+ Across Seven Countries." Global Environmental Politics 15: 46-64. https://doi.org/10.1162/GLEP.

Dimitrov, R. S., 2005. "Hostage to Norms: States, Institutions and Global Forest Politics." Global Environmental Politics 5 (November): 1-24. https://doi.org/10.1162/152638005774785499.

Dkamela, G.P., Brockhaus, M., Djiegni, F.K., Schure, J., Mvondo, S.A., 2014. “Lessons for REDD + from Cameroon's Past Forestry Law Reform : A Political.” Ecology and Society 19 (3). 
Dooley, K., Okereke, C., 2010. "Distributive Equity Concerns in an International REDD

Mechanism: Towards a Copenhagen Climate Agreement." Global Environmental Change 20: 8295. https://doi.org/10.1088/1755-1307/6/11/112022.

Dooley, K., Ozinga, S. 2011. "Building on Forest Governance Reforms through FLEGT: The Best Way of Controlling Forests' Contribution to Climate Change?” Review of European Community and International Environmental Law 20 (2): 163-70. https://doi.org/10.1111/j.14679388.2011.00717.x.

Duchelle, A., Simonet, E.G., Sunderlin, W.D., Wunder, S., 2018. What is REDD+ achieving on the ground? Curr. Opin. Environ. Sustain., 32, 134-140.

Duffy, R. 2006. "Non-Governmental Organisations and Governance States: The Impact of Transnational Environmental Management Networks in Madagascar.” Environmental Politics 15 (5): 731-49. https://doi.org/10.1080/09644010600937173.

Dwyer, M.B., Ingalls, M.L., Baird, I.G., 2016. "The Security Exception: Development and Militarization in Laos's Protected Areas." Geoforum 69: 207-17. https://doi.org/10.1016/j.geoforum.2015.11.002.

Edwards, R., Tepper D., Lowery, S., 2014. "Jurisdictional REDD+ Bonds: Leveraging Private Finance for Forest Protection, Development, and Sustainable Agriculture Supply Chains." https://doi.org/10.1007/s13398-014-0173-7.2.

Eilenberg, M. 2015. "Shades of Green and REDD: Local and Global Contestations over the Value of Forest versus Plantation Development on the Indonesian Forest Frontier." Asia Pacific Viewpoint 56 (1): 48-61. https://doi.org/10.1111/apv.12084.

Erdmann, T.K. 2010. "Eco-Regional Conservation and Development in Madagascar: A Review of USAID-Funded Efforts in Two Priority Landscapes." Development in Practice 20 (3): 380-94. https://doi.org/10.1080/09614521003709999.

Essomba, E.P., Amougou, J.A., Mbianda, F., 2013. “Assessing Cameroon REDD Potential through a Participatory Method: Case Study of Akak Community Forest.” International Journal of Geoinformatics 9 (1): 19 - 29.

EU FLEGT Facility, 2015. The Report: FLEGT and REDD+ Linkages, Report from EU FLEGT Week 19 March 2015, http://www.flegtweek.org/report-flegt-redd-linkages

European Commission, 1996. "Council Regulation on the Protection of Species of Wild Fauna and Flora by Regulating Trade Therein.” , 2003. "Forest Law Enforcement, Governance and Trade (FLEGT) - Proposal for an EU Action Plan." 
2009. Directive 2009/28/EC of the European Parliament and of the Council on the Promotion of the Use of Energy from Renewable Sources and Amending and Subsequently Repealing Directives 2001/77/EC and 2003/30/EC. Available online: https:/ / eurlex.europa.eu/LexUriServ/ LexUriServ.do?uri=OJ:L:2009:140:0016:0062:en:PDF (accessed on 30 November 2018).

, 2011. "Our Life Insurance, Our Natural Capital: An EU Biodiversity Strategy to 2020.” http://eur-lex.europa.eu/legal-content/EN/TXT/?uri=CELEX:52011DC0244.

, 2013. The Impact of EU Consumption on Deforestation: Comprehensive Analysis of the Impact of EU Consumption on Deforestation. Available online:

http://ec.europa.eu/environment/forests/

pdf $/ 1 . \% 20$ Report $\% 20$ analysis $\% 20$ of $\% 20$ impact.pdf (accessed on 12 September 2018).

, 2015. "An EU Action Plan for the Circular Economy.” Com 614: 21.

https://doi.org/10.1017/CBO9781107415324.004.

, 2016. "Communication from the Commission to the European Parliament, the Council, the European Economic and Social Committee and the Committee of the Regions. Next Steps for a Sustainable European Future. European Action for Sustainability." COM(2016) 739 Final.

European Coalition for Corporate Justice ECCJ. 2018. "Evidence for Mandatory HRDD

Legislation.” Brussels. http://corporatejustice.org/policy-evidence-mhrdd-november-2018final_1.pdf.

European Parliament, 2017. "Report on Palm Oil and Deforestation of Rainforests" A8-0066/20:

39. http://www.europarl.europa.eu/sides/getDoc.do?pubRef $=-$

//EP//NONSGML+REPORT+A8-2017-0066+0+DOC+PDF+V0//EN.

Eurostat, 2017. "Sustainable Development in the European Union: Monitoring Progress towards the SDGs in an EU Context." https://doi.org/10.2785/999711.

Evers, S. J.T.M., Van Den Haak, M., Lingnau, I., Lokhorst, N., Pronk, C., 2006. "National Legislation and Local Practices: Competing Jurisdictions in Land Management in Madagascar." TALOHA: Revue Scientifique Internationale Des Civilisations 16-17: 1-9.

http://www.taloha.info/document.php?id=336.

FAO, 2015. Global Forest Resources Assessment 2015. How Are the World's Forests Changing? Rome.

—, 2016. “STATE OF THE WORLD’S FORESTS. Forests and Agriculture: Land-Use Challenges and Opportunities." Rome.

Fast, S., McCormick, K. 2012. "Biofuels: From a Win-Win Solution to a Wicked Problem?” Biofuels 3 (6): 737-48. https://doi.org/10.4155/bfs.12.56.

Federici, S., Tubiello, F.N., Salvatore, M., Jacobs, H., Schmidhuber, J., 2015. "Forest Ecology and Management New Estimates of CO 2 Forest Emissions and Removals : 1990 - 2015.” Forest Ecology and Management 352: 89-98. https://doi.org/10.1016/j.foreco.2015.04.022. 
Ferguson, B., 2009. "REDD Comes into Fashion in Madagascar." Madagascar Conservation \& Development 4 (2). https://doi.org/10.4314/mcd.v4i2.48654.

Fischer, R., Hargita, Y., Günter, S., 2016. "Insights from the Ground Level? A Content Analysis Review of Multi-National REDD+ Studies since 2010." Forest Policy and Economics 66: 47-58. https://doi.org/10.1016/i.forpol.2015.11.003.

Fisher, B., Lewis, S.L., Burgess, N.D., Rogers, Malimbwi, E., Panteleo, K., Munishi, Swetnam, R.D., Turner, R.K., Willcock, S., Balmford, A., 2011. "Implementation and Opportunity Costs of Reducing Deforestation and Forest Degradation in Tanzania." Nature Climate Change 1 (3): 161164.

Fishbein, G., Lee, D., 2015. "Early Lessons from Jurisdictional REDD + and Low Emissions Development Programs.” Arlington.

Fletcher, R., Dressler, W., Büscher, B., Anderson, Z.R., 2016. "Questioning REDD+ and the Future of Market-Based Conservation." Conservation Biology 30 (3): 673-75. https://doi.org/10.1111/cobi.12680.

Franklin, S. L., Pindyck, R.S., 2018. “Tropical Forests, Tipping Points, and the Social Cost of Deforestation.” Ecological Economics 153 (June): 161-71. https://doi.org/10.1016/j.ecolecon.2018.06.003.

Furman, R., 2009. "Lessons from implementing a theory of change M\&E system in the livelihoods and landscapes strategy initiative", IUCN.

Galaz, V., Biermann, F., Crona, B., Loorbach, D., Folke, C., Olsson, P., Nilsson, M. Allouche, J., Persson, A., Reischl, G. 2012. "'Planetary Boundaries'-Exploring the Challenges for Global Environmental Governance." Current Opinion in Environmental Sustainability 4 (1): 80-87. https://doi.org/10.1016/j.cosust.2012.01.006.

Gallemore, C., 2017. "Transaction Costs in the Evolution of Transnational Polycentric Governance." International Environmental Agreements: Politics, Law and Economics 17 (5): 639-54. https://doi.org/10.1007/s10784-016-9335-8.

Gardner, C. J., Nicoll, M.E., Mbohoahy, T., Oleson, K.L.L., Ratsifandrihamanana, A.N., Ratsirarson, J., de Roland, L-A., R., Virah-Sawmy, M., Zafindrasilivonona, B., Davies, Z.G., 2013. "Protected Areas for Conservation and Poverty Alleviation: Experiences from Madagascar." Hulme, P. (ed.). Journal of Applied Ecology 50 (6): 1289-94. https://doi.org/10.1111/1365-2664.12164.

Gardner, T. A., Benzie, M., Börner, J., Dawkins, E., Fick, S., Garrett, R., Godar, J. et al. 2018. "Transparency and Sustainability in Global Commodity Supply Chains." World Development. https://doi.org/10.1016/j.worlddev.2018.05.025.

Gari, J. A. 2013. “UN REDD Pilot Projects and National Approaches.Pdf.” UN REDD Programme Newsletter, Issue 39 June/July. 2013. 
Ghazoul, J., Butler, R.A., Mateo-Vega, J., Koh, L.P., 2010. “REDD: A Reckoning of Environment and Development Implications." Trends in Ecology and Evolution 25 (7): 396-402. https://doi.org/10.1016/j.tree.2010.03.005.

Giessen, L., Krott, M., Möllmann, T., 2014. “Increasing Representation of States by Utilitarian as Compared to Environmental Bureaucracies in International Forest and Forest-Environmental Policy Negotiations." Forest Policy and Economics 38: 97-104. https://doi.org/10.1016/j.forpol.2013.08.008.

Goldstein, A., Gonzalez, G., 2014. "Turning over a New Leaf State of the Forest Carbon Market 2014." Available at: Www. Forest-Trends.Org/ Publication_details.Php. https://doi.org/10.1016/S0165-9936(03)00406-0.

Golub, A. A., Fuss, S., Lubowski, R., Hiller, J., Khabarov, N., Koch, N., Krasovskii, A. et al. 2018. "Escaping the Climate Policy Uncertainty Trap: Options Contracts for REDD+." Climate Policy 0 (0): 1-8. https://doi.org/10.1080/14693062.2017.1422478.

Gupta A, Vijge MJ, Turnhout E, Pistorius T. 2014. "Making REDD+ Transparent: The Politics of Measuring, Reporting, and Verification Systems." In Transparency in Global Environmental Governance: Critical Perspectives. Cambridge, UK: MIT Press.

Gupta, A., Lövbrand, E., Turnhout, E., and Vijge, M.J. 2012. "In Pursuit of Carbon Accountability: The Politics of REDD+ Measuring, Reporting and Verification Systems." Current Opinion in Environmental Sustainability 4 (6): 726-31. https://doi.org/10.1016/j.cosust.2012.10.004.

Gupta, A., Pistorius, T. and Vijge, M.J. 2016. "Managing Fragmentation in Global Environmental Governance: The REDD+ Partnership as Bridge Organization.” International Environmental Agreements: Politics, Law and Economics 16 (3): 355-74. https://doi.org/10.1007/s10784-0159274-9.

Gupta, J., 2012. “Glocal Forest and REDD+ Governance: Win-Win or Lose-Lose?” Current Opinion in Environmental Sustainability 4 (6): 620-27. https://doi.org/10.1016/j.cosust.2012.09.014.

Hansen L, Hoffman J, Drews C, Mielbrecht E. 2010. "Designing Climate-Smart Conservation: Guidance and Case Studies.” Conservation Biology 24: 63-69.

Hansen, M. C., Potapov, P.V., Moore, R., Hancher, M., Turubanova, S.A., Tyukavina, A. 2013. "High-Resolution Global Maps Of." Science 342 (November): 850-54.

Harnesk, D., Brogaard, S., Peck, P., 2017. Regulating a global value chain with the European Union's sustainability criteria-Experiences from the Swedish liquid transport biofuel sector. J. Clean. Prod., 153, 580-591.

Harper, G. J., Steininger, M.K., Tucker, C.J., Juhn, D., Hawkins, F., 2007. “Fifty Years of Deforestation and Forest Fragmentation in Madagascar." Environmental Conservation 34 (04): 325-33. https://doi.org/10.1017/S0376892907004262. 
Harvey, C.A., Chacon, M., Donatti, C.I., Garen, E., Hannah, L., Andrade, A., Bede, L., et al. 2014. Climate-Smart Landscapes: Opportunities and Challenges for Integrating Adaptation and Mitigation in Tropical Agriculture, Conservation Letters, 7, 2, 77 - 90.

Harvey, C.A., Dickson, B., Kormos, C., 2010. “Opportunities for Achieving Biodiversity Conservation through REDD.” Conservation Letters 3 (1): 53-61. https://doi.org/10.1111/j.1755-263X.2009.00086.x.

Hein, J., Guarin, A., Frommé, E., Pauw, P., 2018. "Deforestation and the Paris Climate Agreement: An Assessment of REDD + in the National Climate Action Plans." Forest Policy and Economics 90 (February): 7-11. https://doi.org/10.1016/j.forpol.2018.01.005.

Henders, S., Ostwald, M., Verendel, V., Ibisch, P., 2018. "Do National Strategies under the UN Biodiversity and Climate Conventions Address Agricultural Commodity Consumption as Deforestation Driver?" Land Use Policy 70 (November 2017): 580-90. https://doi.org/10.1016/j.landusepol.2017.10.043.

Herold, M., Johns, T., 2007. "Linking Requirements with Capabilities for Deforestation Monitoring in the Context of the UNFCCC-REDD Process." Environmental Research Letters 2 (4). https://doi.org/10.1088/1748-9326/2/4/045025.

Herold, M., Skutsch, M., 2011. "Monitoring, Reporting and Verification for National REDD + Programmes: Two Proposals.” Environmental Research Letters 6 (1): 014002. https://doi.org/10.1088/1748-9326/6/1/014002.

Hirsch, P.D., Adams, W.M., Brosius, J.P., Zia, A., Bariola, N., Dammert, J.L., 2011. “Acknowledging Conservation Trade-Offs and Embracing Complexity." Conservation Biology 25 (2): 259-64. https://doi.org/10.1111/j.1523-1739.2010.01608.x.

Hölscher, K., Wittmayer, J.M., Loorbach, D., 2018. “Transition versus Transformation: What's the Difference?" Environmental Innovation and Societal Transitions 27 (April 2017): 1-3. https://doi.org/10.1016/j.eist.2017.10.007.

Horning, N.R. 2012. “Debunking Three Myths about Madagascar's Deforestation.” Madagascar Conservation \& Development 7 (3).

Hosonuma, N., Herold, M., De Sy, V., De Fries, R.S., Brockhaus, M., Verchot, L., Angelsen, A., Romijn, E. 2012. "An Assessment of Deforestation and Forest Degradation Drivers in Developing Countries." Environmental Research Letters 7 (4): 044009. https://doi.org/10.1088/1748-9326/7/4/044009.

Houghton, R.A. 2012. "Carbon Emissions and the Drivers of Deforestation and Forest Degradation in the Tropics." Current Opinion in Environmental Sustainability 4 (6): 597-603. https://doi.org/10.1016/j.cosust.2012.06.006.

Hrabanski, M., Bidaud, C., Le Coq, J.F., Méral, P., 2013. “Environmental NGOs, Policy Entrepreneurs of Market-Based Instruments for Ecosystem Services? A Comparison of Costa Rica, Madagascar and France." Forest Policy and Economics 37: 124-32. https://doi.org/10.1016/j.forpol.2013.09.001. 
Hufty, M., Haakenstad, A., 2011. "Reduced Emissions for Deforestation and Degradation: A Critical Review." Consilience: The Journal of Sustainable Development 5 (1): 1-24.

Hunsberger, C.; Corbera, E.; Borras, S.M.; Franco, J.C.; Woods, K.; Work, C.; de la Rosa, R.; Eang, V.; Herre, R.; Kham, S.S.; et al. 2017. Climate change mitigation, land grabbing and conflict: Towards a landscape-based and collaborative action research agenda. Can. J. Dev. Stud., 38, 305-324

Ingalls, M., Meyfroidt, P., To, P.X., Kenney-Lazar, M., 2018. “The Transboundary Dispacement of Forest Change under REDD+: Problematic Intersections between Land-Grabbing and Trade Flows in the Mekong Region." Global Environmental Change 50 (April): 255-67. https://doi.org/10.1016/j.gloenvcha.2018.04.003.

IPCC, 2006. “2006 IPCC Guidelines for National Greenhouse Gas Inventories.” http://www.ipccnggip.iges.or.jp/public/2006gl/index.html.

Irawan, S., Tacconi, L., Ring, I., 2013. “Stakeholders' Incentives for Land-Use Change and REDD+: The Case of Indonesia." Ecological Economics 87 (March): 75-83. https://doi.org/10.1016/j.ecolecon.2012.12.018.

IUCN, 2009. "REDD-plus and Benefit Sharing: Experiences in Forest Conservation and Other Resource Management Sectors", IUCN.

Jagger, P., Brockhaus, M., Duchelle, A.E., Gebara, M.F., Lawlor, K., Resosudarmo, I.A.P., Sunderlin, W.D. 2014. "Multi-Level Policy Dialogues, Processes, and Actions: Challenges and Opportunities for National REDD+ Safeguards Measurement, Reporting, and Verification (MRV)." Forests 5 (9): 2136-62. https://doi.org/10.3390/f5092136.

Jedd, T., 2015. “Accountability and Legitimacy in Transboundary Networked Forest Govervance: A Case Study of the Roundtable on the Crown of the Continent." ColoradoState University.

Jedd, T., Bixler, R.P., 2015. “Accountability in Networked Governance: Learning from a Case of Landscape-Scale Forest Conservation.” Environmental Policy and Governance 25 (3): 172-87. https://doi.org/10.1002/eet.1670.

Jia, F., Gong, Y., Brown, S., 2018. "Multi-Tier Sustainable Supply Chain Management: The Role of Supply Chain Leadership." International Journal of Production Economics, no. June: 0-1. https://doi.org/10.1016/j.ijpe.2018.07.022.

Juerges, N., Newig, J., 2015. "How Interest Groups Adapt to the Changing Forest Governance Landscape in the EU: A Case Study from Germany." Forest Policy and Economics 50: 228-35. https://doi.org/10.1016/j.forpol.2014.07.015.

Kanowski, P.J., McDermott, C.L., Cashore, B.W., 2011. "Implementing REDD+: Lessons from Analysis of Forest Governance.” Environmental Science and Policy 14 (2): 111-17. https://doi.org/10.1016/j.envsci.2010.11.007.

Karky, B. S., Vaidya, R., Karki, S., Tulachan, B., 2013. "What Is REDD + Additionality in Community Managed Forest for Nepal ?” Journal of Forest and Livelihood 11 (2): 37-45. 
Karlsson-Vinkhuyzen, S., Dahl, A.L., Persson, A. 2018. “The Emerging Accountability Regimes for the Sustainable Development Goals and Policy Integration: Friend or Foe?" Environment and Planning C: Politics and Space 36 (8): 1371-90. https://doi.org/10.1177/2399654418779995.

Karsenty, A., Ongolo, S., 2012. “Can 'Fragile States' Decide to Reduce Their Deforestation? The Inappropriate Use of the Theory of Incentives with Respect to the REDD Mechanism." Forest Policy and Economics 18 (May): 38-45. https://doi.org/10.1016/j.forpol.2011.05.006.

Karsenty, A., Vogel, A., Castell, F., 2014. “'Carbon Rights', REDD+ and Payments for Environmental Services." Environmental Science \& Policy 35 (January): 20-29. https://doi.org/10.1016/j.envsci.2012.08.013.

Kashwan, P., Holahan, R., 2014. "Nested Governance for Effective REDD + : Institutional and Political Arguments." International Journal of the Commons 8 (2): 554-75.

Keenan, R. J., Reams, G.A., Achard, F., De Freitas, J.V., Grainger, A., Lindquist, E., 2015. “Forest Ecology and Management Dynamics of Global Forest Area : Results from the FAO Global Forest Resources Assessment 2015." Forest Ecology and Management 352: 9-20. https://doi.org/10.1016/j.foreco.2015.06.014.

Kissinger, G., Herold, M., De Sy, V., Angelsen, A., Bietta, F., Bodganski, A., Boucher, D., et al. 2012. "Drivers of Deforestation and Forest Degradation: A Synthesis Report for REDD+ Policymakers." Vancouver, Canada.

Koberg, E., Longoni, A., 2019. "A Systematic Review of Sustainable Supply Chain Management in Global Supply Chains.” Journal of Cleaner Production 207: 1084-98. https://doi.org/10.1016/i.jclepro.2018.10.033.

Korhonen-Kurki, K., Brockhaus, M., Efrian, M., Sirkku, J., 2017. “Analyzing REDD+ as an Experiment of Transformative Climate Governance_ Insights from Indonesia." Environmental Science and Policy 73 (March): 61-70. https://doi.org/10.1016/j.envsci.2017.03.014.

Korhonen-Kurki, K., Sehring, J., Brockhaus, M., Di Gregorio, M. 2014. “Enabling Factors for Establishing REDD+ in a Context of Weak Governance." Climate Policy 14 (July 2014): 167-86. https://doi.org/10.1080/14693062.2014.852022.

Kosoy, N., Corbera, E. 2010. "Payments for Ecosystem Services as Commodity Fetishism.” Ecological Economics 69 (6): 1228-36.

Kotzé, L. J., French, D. 2018. “A Critique of the Global Pact for the Environment: A Stillborn Initiative or the Foundation for Lex Anthropocenae?" International Environmental Agreements: Politics, Law and Economics 18 (6): 811-38. https://doi.org/10.1007/s10784-018-9417-x.

Lambin, E. F., Geist, H.J., 2002. "Proximate Causes and Underlying Driving Forces of Tropical Deforestation.” BioScience 52 (2): 143-50.

Lambin, E. F., Geist, H.J., 2003. “Regional Differences in Tropical Deforestation.” Environment: Science and Policy for Sustainable Development 45 (6): 22-36. https://doi.org/10.1080/00139157.2003.10544695. 
Lambin, E. F., Meyfroidt, P., 2011. "Global Land Use Change, Economic Globalization, and the Looming Land Scarcity." Proceedings of the National Academy of Sciences of the United States of America 108 (9) (1): 3465-72.

Lambin, E. F., Turner, B.L., Geist, H.J., Agbola, S.B., Angelsen, A., Bruce, J.W., Coomes, O.T. et al. 2001. "The Causes of Land-Use and Land-Cover Change: Moving beyond the Myths." Global Environmental Change 11 (4): 261-69. https://doi.org/10.1016/S0959-3780(01)00007-3.

Larsen, F. W., Londoño-Murcia, M.C., Turner, W.R. 2011. "Global Priorities for Conservation of Threatened Species, Carbon Storage, and Freshwater Services: Scope for Synergy?” Conservation Letters 4 (5): 355-63. https://doi.org/10.1111/j.1755-263X.2011.00183.x.

Larson, A. M. 2011. "Forest Tenure Reform in the Age of Climate Change: Lessons for REDD+." Global Environmental Change 21 (2): 540-49. https://doi.org/10.1016/j.gloenvcha.2010.11.008.

Larson, A.M., Barry, D., Dahal, G.R. and Colfer, J.P., Carol, (eds.) 2010. Forests for People: Community Rights and Forest Tenure Reform. London: Earthscan. https://doi.org/10.4324/9781849774765.

Larson, A. M., Brockhaus, M., Sunderlin, W.D., Duchelle, A., Babon, A., Dokken, T., Pham, T.T. et al. 2013. "Land Tenure and REDD+: The Good, the Bad and the Ugly." Global Environmental Change 23 (3): 678-89. https://doi.org/10.1016/i.gloenvcha.2013.02.014.

Larson, A. M., Petkova, E., 2011. "An Introduction to Forest Governance, People and REDD+ in Latin America: Obstacles and Opportunities.” Forests 2 (4) (18): 86-111.

Lasco, R. D., Mallari, N.A.D., Pulhin, F.B., Florece, A.M., Rico, E.L.B., Baliton, R.S., Urquiola, J.P., 2013. "Lessons from Early REDD+ Experiences in the Philippines." International Journal of Forestry Research, 1-12.

Lasco, R., Pulhin, F., Bugayong, L., Mendoza, M., 2011. “An Assessment of Potential Benefits to Smallholders of REDD + Components in the Philippines." Annals of Tropical Research 33 (1): $31-48$.

Lawlor, K., Madeira, E., Blockhus, J., Ganz, D., 2013. "Community Participation and Benefits in REDD+: A Review of Initial Outcomes and Lessons.” Forests 4 (2): 296-318. https://doi.org/10.3390/f4020296.

Lawson, S., Blundell, A., Cabarle, B., Basik, N., Jenkins, M., Canby, K. 2014. "Consumer Goods and Deforestation: An Analysis of the Extent and Nature of Illegality in Forest Conversion for Agriculture and Timber Plantations." Forest Trends Report Series. http:/ /www.foresttrends.org/embargoed/logging_2014/infographic.pdf.

Leach, M., Scoones, I. 2013. "Carbon Forestry in West Africa: The Politics of Models, Measures and Verification Processes." Global Environmental Change 23 (5): 957-67. https://doi.org/10.1016/j.gloenvcha.2013.07.008.

Leblois, A., Damette, O., Wolfersberger, J. 2017. "What Has Driven Deforestation in Developing Countries Since the 2000s? Evidence from New Remote-Sensing Data." World Development 92: 82-102. https://doi.org/10.1016/j.worlddev.2016.11.012. 
Lederer, M., 2012. “REDD+ Governance.” Wiley Interdisciplinary Reviews: Climate Change 3 (1): 107-13. https://doi.org/10.1002/wcc.155.

Lee, D., Pistorius, T., 2015. “The Impacts of International REDD+ Finance.”

Lesniewska, F., McDermott, C.L. 2014. "FLEGT VPAs: Laying a Pathway to Sustainability via Legality Lessons from Ghana and Indonesia." Forest Policy and Economics 48: 16-23. https://doi.org/10.1016/i.forpol.2014.01.005.

Leventon, J., Kalaba, F.K., Dyer, J.C., et al. 2014. "Delivering Community Benefits through REDD+: Lessons from Joint Forest Management in Zambia." Forest Policy and Economics 44: 10-17. doi:10.1016/j.forpol.2014.03.005. http://dx.doi.org/10.1016/j.forpol.2014.03.005.

Limberg, G.A., Moeliono, M., Indriatmoko, Y., Iwan, R., Utomo, N.A., Purwanto, E. Mulyana, A., 2009. "Incentives to Conserve or Convert? Can Conservation Compete with Coal in Kutai National Park, Indonesia?” International Journal of Biodiversity Science \& Management 5 (4): 190-98. https://doi.org/10.1080/17451590903525226.

Locatelli, B., Evans, V., Wardell, A., Andrade, A., Vignola, R. 2011. "Forests and Climate Change in Latin America: Linking Adaptation and Mitigation." Forests 2 (1): 431-50. https://doi.org/10.3390/f2010431.

Locatelli, B., Pavageau, C., Pramova, E., Di Gregorio, M., 2015. "Integrating Climate Change Mitigation and Adaptation in Agriculture and Forestry: Opportunities and Trade-Offs." Wiley Interdisciplinary Reviews: Climate Change 6 (6): 585-98. https://doi.org/10.1002/wcc.357.

Lohmann, L., 2005. "Marketing and Making Carbon Dumps: Commodification, Calculation and Counterfactuals in Climate Change Mitigation." Science as Culture 14 (3): 203-35. https://doi.org/10.1080/09505430500216783.

Longhurst, R., 2016. "Semi Structured Interviews and Focus Groups." In Key Methods in Geography, S. Clifford, N., Cope, M., Gillespie, T., French, (eds.) Third, 143-56. London: SAGE.

Loorbach, D., Frantzeskaki, N., Avelino, F., 2017. "Sustainability Transitions Research: Transforming Science and Practice for Societal Change." Annual Review of Environment and Resources 42 (1): 599-626. https://doi.org/10.1146/annurev-environ-102014-021340.

Lowry, P P, Schatz, G.E., Phillipson, P.B. 1997. "The Classification of Natural and Anthropogenic Vegetation in Madagascar." In Natural Change and Human Impact in Madagascar, Goodman, S.M, Patterson, B.D., (eds.) 93-123. Washington D.C.: Smithsonian Inst. Press.

Lusiana, B., van Noordwijk, M., Cadisch, G., 2012. "Land Sparing or Sharing? Exploring Livestock Fodder Options in Combination with Land Use Zoning and Consequences for Livelihoods and Net Carbon Stocks Using the FALLOW Model." Agriculture, Ecosystems \& Environment 159: $145-160$.

Luttrell, C., Loft, L., Gebara, M.F., Kweka, D. 2012. "Who Should Benefit and Why? Discourses on REDD+ Benefit Sharing." In Analysing REDD+ Challenges and Choices, Angelsen, A., Brockhaus, M., Sunderlin, W.D., Verchot, L., (eds.) 129-52. Bogor, Indonesia: CIFOR. 
Luttrell, C., Loft, L., Gebara, M.F., Kweka, D., Brockhaus, M., Angelsen, A., 2013. “Who Should Benefit from REDD+? Rationales and Realities." Ecology and Society 18 (4).

Massarella, K.; Susannah, M.S.; Jonathan, E.E.; Marchant, R. 2018. REDD+, hype, hope and disappointment: The dynamics of expectations in conservation and development pilot projects. World Dev., 109, 375-385

Mahanty, S., Milne, S., Dressler, W., Filer, C., 2012. “The Social Life of Forest Carbon: Property and Politics in the Production of a New Commodity.” Human Ecology 40 (5): 661-64. https://doi.org/10.1007/s10745-012-9524-1.

Mahanty, S., Suich, H., Tacconi, L., 2013. "Access and Benefits in Payments for Environmental Services and Implications for REDD+: Lessons from Seven PES Schemes." Land Use Policy 31 (March): 38-47. https://doi.org/10.1016/j.landusepol.2011.10.009.

Mbow, C. Smith, P., Skole, D., Duguma, L., Bustamante, M., 2014. “Achieving Mitigation and Adaptation to Climate Change through Sustainable Agroforestry Practices in Africa." Current Opinion in Environmental Sustainability 6 (1): 8-14. https://doi.org/10.1016/j.cosust.2013.09.002.

McAfee, K.. 2012. “The Contradictory Logic of Global Ecosystem Services Markets.” Development and Change 43 (1): 105-31. https://doi.org/10.1111/j.1467-7660.2011.01745.x.

McCall, M.K. 2016. "Beyond 'Landscape' in REDD+: The Imperative for 'Territory.” World Development 85: 58-72. https://doi.org/10.1016/j.worlddev.2016.05.001.

McCarthy, S., Tacconi, L., 2011. “The Political Economy of Tropical Deforestation: Assessing Models and Motives." Environmental Politics 20 (1): 115-32. https://doi.org/10.1080/09644016.2011.538171.

McDermott CL, Coad L, Helfgott A, Schroeder H. 2012. "Operationalizing Social Safeguards in REDD+: Actors, Interests and Ideas.” Environmental Science \& Policy 21: 63-72.

McDermott, C.L. 2014. "REDDuced: From Sustainability to Legality to Units of Carbon-The Search for Common Interests in International Forest Governance." Environmental Science and Policy 35: 12-19. https://doi.org/10.1016/j.envsci.2012.08.012.

McDermott, C.L., Sotirov, M., 2018. “A Political Economy of the European Union's Timber Regulation: Which Member States Would, Should or Could Support and Implement EU Rules on the Import of Illegal Wood?” Forest Policy and Economics 90: 180-90. https://doi.org/10.1016/j.forpol.2017.12.015.

McDermott, C. L., Levin, K., Cashore, B., 2011. "Building the Forest-Climate Bandwagon : REDD+ and the Logic of Problem Amelioration." Global Environmental Politics 11 (3): 85-103.

McElwee, P. D., 2012. "Payments for Environmental Services as Neoliberal Market-Based Forest Conservation in Vietnam: Panacea or Problem?” Geoforum 43 (3): 412-426. 
McShane, T. O., Hirsch, P.D., Trung, T.C., Songorwa, A.N., Kinzig, A., Monteferri, B., Mutekanga, D. et al. 2011. "Hard Choices: Making Trade-Offs between Biodiversity Conservation and Human Well-Being." Biological Conservation 144 (3): 966-72. https://doi.org/10.1016/j.biocon.2010.04.038.

Meijer, K.S., 2015. A comparative analysis of the effectiveness of four supply chain initiatives to reduce deforestation. Trop. Conserv. Sci., 8, 583-597

Meyfroidt, P., Lambin, E.F., Erb, K-H, Hertel, T.W., 2013. "Globalization of Land Use: Distant Drivers of Land Change and Geographic Displacement of Land Use." Current Opinion in Environmental Sustainability 5 (5): 438-44. https://doi.org/10.1016/j.cosust.2013.04.003.

Millennium Ecosystem Assessment. 2005. "Ecosystems and Human Well-Being: Synthesis." Washington D.C. https://doi.org/10.1196/annals.1439.003.

Milligan, B., O’Keeffe, M., 2018. “Global Governance of Resources and Implications for Resource Efficiency in Europe.” Ecological Economics, no. January. https://doi.org/10.1016/j.ecolecon.2018.01.007.

Minang, P. A., van Noordwijk, M., 2013. "Design Challenges for Achieving Reduced Emissions from Deforestation and Forest Degradation through Conservation: Leveraging Multiple Paradigms at the Tropical Forest Margins." Land Use Policy 31 (March): 61-70. https://doi.org/10.1016/j.landusepol.2012.04.025.

Minang, P.A., Duguma, L.A., Bernard, F., Mertz, O., van Noordwijk, M. 2014. "Prospects for Agroforestry in REDD+ Landscapes in Africa." Current Opinion in Environmental Sustainability 6 (February): 78-82. https://doi.org/10.1016/j.cosust.2013.10.015.

Minang, P. A., van Noordwijk, M., 2014. “The Political Economy of Readiness for REDD.” Climate Policy 14 (6): 677-84. https://doi.org/10.1080/14693062.2014.912979.

Minang, P.A., Van Noordwijk, M., Duguma, L.A., Alemagi, D., Do, T.H., Bernard, F., Agung, P. et al. 2014. "REDD+ Readiness Progress across Countries: Time for Reconsideration." Climate Policy 14 (6): 685-708. https://doi.org/10.1080/14693062.2014.905822.

Ministere de l'environnement. 2014. "Readiness Preparation Proposal (R-PP) Madagascar." . 2015. "Rapport de Progression Annuel REDD+ Madagascar."

Molua, E. L. 2012. "Discourse on Climate-Smart Agriculture for REDD+ Strategy in the Congo Basin.” Journal of Sustainable Development 5 (10): 77-88. https://doi.org/10.5539/jsd.v5n10p77.

Moonen, P.C.J., Verbist, B., Schaepherders, J., Meyi, M.B., Van Rompaey, A., Muys, B. 2016. "Actor-Based Identification of Deforestation Drivers Paves the Road to Effective REDD+ in DR Congo.” Land Use Policy 58: 123-32. https://doi.org/10.1016/j.landusepol.2016.07.019. 
Morales-Hidalgo, D., Oswalt, S.N., Somanathan, E. 2015. "Forest Ecology and Management Status and Trends in Global Primary Forest, Protected Areas, and Areas Designated for Conservation of Biodiversity from the Global Forest Resources Assessment 2015." Forest Ecology and Management 352: 68-77. https://doi.org/10.1016/j.foreco.2015.06.011.

Morgera, E. 2012. “Ambition, Complexity and Legitimacy of Pursuing Mutual Supportiveness through the EU's External Environmental Action.” In: The Legal Dimension of Global Governance: What Role for the EU?, Vooren Van, B., Blockmans S., Wouters, J., (eds.) Oxford Univ. Press.

Mullan, K., 2014. “The Value of Forest Ecosystem Services to Developing Economies”, CGD Climate and Forest Paper Series \#6, Working Paper 379.

Müller, R., Müller, D., Schierhorn, F., Gerold, G., Pacheco, P., 2011. "Proximate Causes of Deforestation in the Bolivian Lowlands: An Analysis of Spatial Dynamics." Regional Environmental Change 12 (3) (28): 445-459.

Muradian, R., M. Arsel, L. Pellegrini, F. Adaman, B. Aguilar, B. Agarwal, E. Corbera, et al. 2013. "Payments for Ecosystem Services and the Fatal Attraction of Win-Win Solutions." Conservation Letters 6 (4): 274-79. https://doi.org/10.1111/j.1755-263X.2012.00309.x.

Muradian, R. 2013. "Payments for Ecosystem Services as Incentives for Collective Action." Society and Natural Resources 26 (10). https://doi.org/10.1080/08941920.2013.820816.

Murdiyarso, D., Brockhaus, M., Sunderlin, W.D., Verchot, L. 2012. "Some Lessons Learned from the First Generation of REDD+ Activities." Current Opinion in Environmental Sustainability 4 (6): 678-85. https://doi.org/10.1016/i.cosust.2012.10.014.

Mustalahti, I., Bolin, A., Boyd, E., Paavola, J., 2012. "Can REDD + Reconcile Local Priorities and Needs with Global Mitigation Benefits? Lessons from Angai Forest, Tanzania.” Ecology and Society 17 (1).

Myers, N., Fonseca, G.A.B., Mittermeier, R.A., Kent, J. 2000. "Biodiversity Hotspots for Conservation Priorities.” Nature 403 (6772): 853-58. https://doi.org/10.1038/35002501.

Naughton-Treves, L., Wendland, K., 2014. "Land Tenure and Tropical Forest Carbon Management." World Development 55 (March): 1-6. https://doi.org/10.1016/j.worlddev.2013.01.010.

Nepstad, D., Irawan, S., Bezerra, T., Boyd, W., Stickler, C., Shimada, J., Carvalho, O. et al. 2013. "More Food, More Forests, Fewer Emissions, Better Livelihoods: Linking REDD+, Sustainable Supply Chains and Domestic Policy in Brazil, Indonesia and Colombia." Carbon Management 4 (6): 639-58. https://doi.org/10.4155/cmt.13.65.

Nepstad, D., Moutinho, P., Boyd, W., Azevedo, A., Bezerra, T., Smid, B., Stabile, M.C.C, Stickler C. and Osvaldo, S. 2012. "Unlocking Jurisdictional REDD+ as a Policy Framework for LowEmission Rural Development: Research Results and Recommendations for Governments." 
Newton, P., Agrawal, A. and Wollenberg, L. 2013. "Enhancing the Sustainability of Commodity Supply Chains in Tropical Forest and Agricultural Landscapes." Global Environmental Change 23 (6): 1761-72. https://doi.org/10.1016/j.gloenvcha.2013.08.004.

Newton, P., Benzeev, R. 2018. "The Role of Zero-Deforestation Commitments in Protecting and Enhancing Rural Livelihoods." Current Opinion in Environmental Sustainability 32: 126-33. https://doi.org/10.1016/j.cosust.2018.05.023.

Ngendakumana, S., Minang, P.A., Feudjio, M., Speelman, S., Van Damme, P., Tchoundjeu, Z. 2014. "Institutional Dimensions of the Developing REDD+ Process in Cameroon." Climate Policy 14 (6): 769-87. https://doi.org/10.1080/14693062.2014.877221.

Nielsen, T. D. 2014. "The Role of Discourses in Governing Forests to Combat Climate Change." International Environmental Agreements: Politics, Law and Economics 14 (3): 265-80. https://doi.org/10.1007/s10784-013-9223-4.

Nilsson, M., Persson, A., 2012. "Reprint of 'Can Earth System Interactions Be Governed? Governance Functions for Linking Climate Change Mitigation with Land Use, Freshwater and Biodiversity Protection." Ecological Economics 81: 10-20. https://doi.org/10.1016/j.ecolecon.2012.06.020.

Norman, M., Nakhooda, S., 2015. "The State of REDD+ Finance." CGD Climate and Forest Paper, https://doi.org/10.2139/ssrn.2622743.

Nunes, F., Soares-Filho, B., Giudice, R., Rodrigues, H., 2012. "From Brazil Nut Concessions in Madre de Dios , Peru , to Channel REDD +.” Environmental Conservation 39 (2): 132-43.

Ochieng, R. M., Visseren-Hamakers, I.J., Arts, B., Brockhaus, M., Herold, M., 2016. “Institutional Effectiveness of REDD+ MRV: Countries Progress in Implementing Technical Guidelines and Good Governance Requirements." Environmental Science and Policy 61: 42-52. https://doi.org/10.1016/j.envsci.2016.03.018.

Ochieng, R. M., Visseren-Hamakers, I.J., Nketiah, K.S., 2013. "Interaction between the FLEGTVPA and REDD+ in Ghana: Recommendations for Interaction Management." Forest Policy and Economics 32 (July): 32-39. https://doi.org/10.1016/i.forpol.2012.07.003.

Oliveira, G.L.T., McKay, B., Plank, C., 2017. How biofuel policies backfire: Misguided goals, inefficient mechanisms, and political-ecological blind spots. Energy Policy, 108, 765-775

Ostrom, E., 1990. Governing the Commons: The Evolution of Institutions for Collective Action. Cambridge, UK: Cambridge University Press.

Ostrom, E., 2010. "Polycentric Systems for Coping with Collective Action and Global Environmental Change." Global Environmental Change 20 (4): 550-57. https://doi.org/10.1016/j.gloenvcha.2010.07.004.

Pacheco, P., Aguilar-Støen, M., Börner, J., Etter, A., Putzel, L., Del Carmen Vera Diaz, M., 2011. "Landscape Transformation in Tropical Latin America: Assessing Trends and Policy Implications for REDD+.” Forests 2 (1): 1-29. https://doi.org/10.3390/f2010001. 
Pacheco, P., Putzel, L., Obidzinski, K., Schoneveld, G., 2012. "REDD and the Global Economy: Competing forces and policy options", In: Analysing REDD+ Challenges and Choices, Angelsen, A., Brockhaus, M., Sunderlin, W.D., Verchot, L., Bogor, (eds.) Indonesia: CIFOR, $129-152$.

Pahl-Wostl, C., Bhaduri, A., Bruns, A., 2018. "Editorial Special Issue: The Nexus of Water, Energy and Food - An Environmental Governance Perspective." Environmental Science and Policy 90 (July): 161-63. https://doi.org/10.1016/j.envsci.2018.06.021.

Pandey, S.S., Cockfield, G., Maraseni, T.N. 2014. "Dynamics of Carbon and Biodiversity under REDD+ Regime: A Case from Nepal.” Environmental Science \& Policy 38: 272-81.

Paoli, G. D., Wells, P.L., Meijaard, E., Struebig, M.J., Marshall, A.J., Obidzinski, K., Tan, A., Rafiastanto, A., Yaap, B., Slik, J.F. 2010. "Biodiversity Conservation in the REDD." Carbon Balance and Management 5 (7): 1-9.

Pattanayak, S.K., Wunder, S., Ferraro, P.J., 2010. "Show Me the Money: Do Payments Supply Environmental Services in Developing Countries?" Review of Environmental Economics and Policy, 4, 2, 254-274.

Patterson, J., Schulz, K., Vervoort, J., van der Hel, S., Widerberg, O., Adler, C., Hurlbert, M., Anderton, K., Sethi, M., Barau, A. 2017. "Exploring the Governance and Politics of Transformations towards Sustainability." Environmental Innovation and Societal Transitions 24: 1-16. https://doi.org/10.1016/j.eist.2016.09.001.

Peters-Stanley, M., Gonzalez, G., Yin, D., Goldstein, A., Hamrick, K. 2013. “Covering New Ground: State of the Forest Carbon Markets 2013.”

Pham, T.T., Moeliono, M., Brockhaus, M., Le, D.N., Wong, G.Y., Le, T.M., 2014. Local "Preferences and Strategies for Effective, Efficient, and Equitable Distribution of PES Revenues in Vietnam: Lessons for REDD+", Human Ecology, 42, 885-899.

Phelps, J., Carrasco, L.R., Webb, E.L., Koh, L.P., Pascual, U., 2013. “Agricultural Intensification Escalates Future Conservation Costs." Proceedings of the National Academy of Sciences of the United States of America 110 (19): 7601-6.

Phelps, J., Webb, E.L., Koh, L.P. 2011. "Risky Business: An Uncertain Future for Biodiversity Conservation Finance through REDD+." Conservation Letters 4 (2): 88-94. https://doi.org/10.1111/j.1755-263X.2010.00155.x.

Phelps, J., Webb, E.L., Agrawal, A. 2010. "Does REDD + Threaten to Recentralize Forest Governance?”' Science 328.

Pirard, R., Belna, K., 2012. Agriculture and Deforestation: Is REDD+ Rooted In Evidence? Forest Policy and Economics, 21, 62-70. http://doi.org/10.1016/j.forpol.2012.01.012

Pirlot, P., Delreux, T., Farcy, C., 2018. "Forests: A Multi-Sectoral and Multi-Level Approach to Sustainable Forest Management." In: European Union External Environmental Policy, Adelle, C., Biedenkopf, K., Torney, D., (eds.), Springer Nature, Switzerland. 
Pistorius, T. 2012. "From RED to REDD+: The Evolution of a Forest-Based Mitigation Approach for Developing Countries." Current Opinion in Environmental Sustainability 4 (December): 638-45. https://doi.org/10.1016/j.cosust.2012.07.002.

Pistorius, T., Freiberg, H., 2014. "From Target to Implementation: Perspectives for the International Governance of Forest Landscape Restoration.” Forests 5 (3): 482-97. https://doi.org/10.3390/f5030482.

Pistorius, T. Reinecke, S., Carrapatoso, A. 2017. "A Historical Institutionalist View on Merging LULUCF and REDD+ in a Post-2020 Climate Agreement." International Environmental Agreements: Politics, Law and Economics 17 (5): 623-38. https://doi.org/10.1007/s10784-016$9330-0$.

Pistorius, T., Schaich, H., Winkel, G., Plieninger, T., Bieling C., Konold, W., Volz, K.R., 2012. "Lessons for REDDplus: A Comparative Analysis of the German Discourse on Forest Functions and the Global Ecosystem Services Debate." Forest Policy and Economics 18: 4-12. https://doi.org/10.1016/i.forpol.2011.09.001.

Plumb, S.T., Nielsen, E.A., Kim, Y.S., 2012. "Challenges of Opportunity Cost Analysis in Planning REDD+: A Honduran Case Study of Social and Cultural Values Associated with Indigenous Forest Uses." Forests 3 (4): 244-264.

Poffenberger, M., 2009. "Cambodia's Forests and Climate Change: Mitigating Drivers of Deforestation.” Natural Resources Forum 33: 285-296.

Pokorny, B., Scholz, I., de Jong, W. 2013. "REDD+ for the Poor or the Poor for REDD+? About the Limitations of Environmental Policies in the Amazon and the Potential of Achieving Environmental Goals through pro-Poor Policies." Ecology and Society 18 (2). https://doi.org/10.5751/ES-05458-180203.

Pollini, J. 2010. "Environmental Degradation Narratives in Madagascar: From Colonial Hegemonies to Humanist Revisionism." Geoforum 41 (5): 711-22. https://doi.org/10.1016/j.geoforum.2010.04.001.

Potts, M. D., Kelley, L.C., Doll, H.M., 2013. "Maximizing Biodiversity Co-Benefits under REDD+: A Decoupled Approach.” Environmental Research Letters 8 (2). https://doi.org/10.1088/17489326/8/2/024019.

Pratihast, A.K., Herold, M., De Sy, V., Murdiyarso, D., Skutsch, M., 2013. "Linking CommunityBased and National REDD+ Monitoring: A Review of the Potential." Carbon Management 4 (1): 91-104. https://doi.org/10.4155/cmt.12.75.

Putz, F. E., Romero, C., 2012. “Helping Curb Tropical Forest Degradation by Linking REDD+ with Other Conservation Interventions: A View from the Forest." Current Opinion in Environmental Sustainability 4 (6): 670-677.

Randriamalala, H, and Liu, Z. 2010. "Rosewood of Madagascar: Between Democracy and Conservation." Madagascar Conservation \& Development 5 (1): 11-22. https://doi.org/10.4314/mcd.v5i1.57336. 
Rautner, M., Leggett, M., Davis, F., 2013. The Little Book of Big Deforestation Drivers. Oxford: Global Canopy Programme.

Redford, K. H., Adams, W.M., 2009. "Payment for Ecosystem Services and the Challenge of Saving Nature: Editorial." Conservation Biology 23 (4): 785-87. https://doi.org/10.1111/j.15231739.2009.01271.x.

Reinecke, S., Pistorius, T., Pregernig, M., 2014. "UNFCCC and the REDD+ Partnership from a Networked Governance Perspective.” Environmental Science and Policy 35: 30-39. https://doi.org/10.1016/j.envsci.2012.09.015.

Resosudarmo, I.A.P., Atmadja, S., Ekaputri, A.D., Intarini, D.Y., Indriatmoko, Y., Astri, P., 2013. "Does Tenure Security Lead to REDD+ Project Effectiveness? Reflections from Five Emerging Sites in Indonesia." World Development (March): 1-16.

Rival, L. M. 2013. "From Carbon Projects to Better Land-Use Planning: Three Latin American Initiatives." Ecology and Society 18 (3).

Robiglio, V., Armas, A.D., Aguad, C.S., White, D., 2014. "Beyond REDD+ Readiness: Land-Use Governance to Reduce Deforestation in Peru." Climate Policy 14 (6): 734-47. https://doi.org/10.1080/14693062.2014.962467.

Robinson, E. J. Z., Albers, H.J., Meshack, C., Razack B.L., 2013. "Implementing REDD through Community-Based Forest Management: Lessons from Tanzania.” Natural Resources Forum 37 (3): 141-152.

Romijn, E., Herold, M., Kooistra, L., Murdiyarso, D., Verchot, L., 2012. “Assessing Capacities of Non-Annex I Countries for National Forest Monitoring in the Context of REDD+." Environmental Science \& Policy 19-20 (May): 33-48. https://doi.org/10.1016/i.envsci.2012.01.005.

Ros-Tonen, M.A.F., Insaidoo, T.F.G., Acheampong, E., 2013. "Promising Start, Bleak Outlook: The Role of Ghana's Modified Taungya System as a Social Safeguard in Timber Legality Processes." Forest Policy and Economics 32: 57-67.

Salvini, G., Ligtenberg, A., van Paassen, A., Bregt, A.K., Avitabile, V., Herold, M., 2016. "REDD+ and Climate Smart Agriculture in Landscapes: A Case Study in Vietnam Using Companion Modelling." Journal of Environmental Management 172: 58-70. https://doi.org/10.1016/j.jenvman.2015.11.060.

Salvini, G, Herold, M., De Sy, V., Kissinger, G., Brockhaus, M., Skutsch, M., 2014. "How Countries Link REDD+ Interventions to Drivers in Their Readiness Plans: Implications for Monitoring Systems.” Environmental Research Letters 9 (7): 074004. https:/ / doi.org/10.1088/17489326/9/7/074004.

Sandbrook, C., Nelson, F., Adams, W.M., Agrawal, A. 2019. "Carbon, Forests and the REDD Paradox." Oryx 44 (3): 330-34. 
Sattler, C., Loft, L., Mann, C., Meyer, C., 2018. "Methods in Ecosystem Services Governance Analysis: An Introduction.” Ecosystem Services 34 (November): 155-68. https://doi.org/10.1016/j.ecoser.2018.11.007.

Satyal, P. 2018. "Civil Society Participation in REDD+ and FLEGT Processes: Case Study Analysis from Cameroon, Ghana, Liberia and the Republic of Congo." Forest Policy and Economics 97 (July 2017): 83-96. https://doi.org/10.1016/j.forpol.2018.09.012.

Sayer, J., T., Sunderland, J., Ghazoul, J.-L., Pfund, D., Sheil, E., Meijaard, M., et al. 2013. “Ten Principles for a Landscape Approach to Reconciling Agriculture, Conservation, and Other Competing Land Uses." Proceedings of the National Academy of Sciences 110 (21): 8349-56. https://doi.org/10.1073/pnas.1210595110.

Scherer, L., Behrens, P., de Koning, A., Heijungs, R., Sprecher, B., Tukker, A., 2018. "Trade-Offs between Social and Environmental Sustainable Development Goals." Environmental Science and Policy 90 (October): 65-72. https://doi.org/10.1016/j.envsci.2018.10.002.

Schulz, T., Lieberherr, E., Zabel, A. 2016. "Network Governance in National Swiss Forest Policy: Balancing Effectiveness and Legitimacy." Forest Policy and Economics. https://doi.org/10.1016/j.forpol.2016.10.011.

Seagle, C. W. 2010. "Deforestation and Impoverishment in Rural Madagascar: Links between State Governance, Land Degradation, and Food Insecurity over Time.” Taloha 19: 1-14. http:/ / www.taloha.info/document.php?id=859\#tocto8.

Secretariat of the Convention on Biological Diversity, 2001. "The Value of Forest Ecosystems", Montreal, SCBD, Technical Series no. 4.

Secretariat of the Convention on Biological Diversity. 2011. "Report on How to Improve Sustainable Use of Biodiversity in a Landscape Perspective."

Skutsch, M., Borrego, A., Morales-Barquero, L., Paneque-Galvez, J., Salinas-Melgoza, M., Ramirez, M.I., Perez-Salicrup, D., Benet, D., Monroy, S., Gao, Y., 2015. "Opportunities, Constraints and Perceptions of Rural Communities Regarding Their Potential to Contribute to Forest Landscape Transitions under REDD+: Case Studies from Mexico." International Forestry Review 17 (1): 65-84. https://doi.org/10.1505/146554815814669025.

Skutsch, M. 2013. "Slicing the REDD+ Pie: Controversies around the Distribution of Benefits." CAB Reviews: Perspectives in Agriculture, Veterinary Science, Nutrition and Natural Resources 8 (020). https://doi.org/10.1079/PAVSNNR20138020.

Skutsch, M. M., McCall, M.K., 2010. "Reassessing REDD: Governance, Markets and the Hype Cycle." Climatic Change 100 (3-4): 395-402. https://doi.org/10.1007/s10584-009-9768-y.

Skutsch, M., Turnhout, E., Vijge, M.J., Herold, M., Wits, T., Den Besten, J.W., Balderas Torres, A. 2014. "Options for a National Framework for Benefit Distribution and Their Relation to Community-Based and National REDD+ Monitoring." Forests 5 (7): 1596-1617. https://doi.org/10.3390/f5071596. 
Sloan, S., Sayer, J.A., 2015. “Forest Ecology and Management Forest Resources Assessment of 2015 Shows Positive Global Trends but Forest Loss and Degradation Persist in Poor Tropical Countries." Forest Ecology and Management 352: 134-45. https://doi.org/10.1016/j.foreco.2015.06.013.

Someshwar, S. 2008. “Adaptation as 'Climate-Smart' Development.” Development 51: 366-74.

Somorin, O. A., Visseren-Hamakers, I.J., Arts, B., Sonwa, D.J., Tiani, A.M., 2014. "REDD+ Policy Strategy in Cameroon: Actors, Institutions and Governance." Environmental Science and Policy 35: 87-97. https://doi.org/10.1016/j.envsci.2013.02.004.

Soto Golcher, C., Arts, B., Visseren-Hamakers, I., 2018. Seeing the Forest, Missing the Field: Forests and Agriculture in Global Climate Change Policy. Land Use Policy, 77, 627-640.

Soto Golcher, C., Visseren-Hamakers, I., 2018. "Framing and Integration in the Global Forest, Agriculture and Climate Change Nexus." Environment and Planning C: Politics and Space 36 (8): 1415-36. https://doi.org/10.1177/2399654418788566.

Springate-Baginski, O., Thein, A.K., Neil, A., Thu, W.M., Doherty, F., 2014. "Democratising Timber: An Assessment of Myanmar's Emerging 'Forest Law Enforcement, Governance and Trade' (FLEGT) Process." Forest Policy and Economics 48 (1): 33-45. https://doi.org/10.1016/j.forpol.2014.09.004.

Stephan, B., 2012. "Bringing Discourse to the Market: The Commodification of Avoided Deforestation." Environmental Politics 21 (4): 621-39. https://doi.org/10.1080/09644016.2012.688357.

Stern, N. 2007. The Economics of Climate Change: The Stern Review. The Economics of Climate Change: The Stern Review. Vol. 9780521877. Cambridge, UK: Cambridge University Press. https://doi.org/10.1017/CBO9780511817434.

Strassburg, B.B.N., Kelly, A., Balmford, A., Davies, R.G., Gibbs, H.K., Lovett, A., Miles, L. et al. 2010. "Global Congruence of Carbon Storage and Biodiversity in Terrestrial Ecosystems." Conservation Letters 3: 98-105. https://doi.org/10.1111/j.1755-263X.2009.00092.x.

Streck, C, Keenlyside P, von Unger, M. 2016. “The Paris Agreement: A New Beginning?” Journal of Energy and Natural Resources Law 34 (1): 16-26. https://doi.org/10.1080/02646811.2016.1133983.

Streck, C. 2012. "Financing REDD+: Matching Needs and Ends." Current Opinion in Environmental Sustainability 4 (6): 628-37. https://doi.org/10.1016/j.cosust.2012.10.001.

Sunderlin W.D., Ekaputri, A.D., Sills, E.O., Duchelle, A.E., Kweka, D., Diprose, R., Doggart, N., Ball, S., Lima, R., Enright, A. 2014. "The Challenge of Establishing REDD+ on the Ground: Insights from 23 Subnational Initiatives in Six Countries." CIFOR. Vol. 104. Bogor, Indonesia. https://doi.org/http://dx.doi.org/110.21043/equilibrium.v3i2.1268. 
Sunderlin, F. W.D., Sills, E.O., 2012. "REDD+ Projects as a Hybrid of Old and New Forest Conservation Approaches". In: Analysing REDD+: Challenges and Choices, Angelsen, A., Brockhaus, M., Sunderlin, W.D., Verchot, L., (eds.), Bogor, Indonesia: CIFOR, 177 - 192.

Swallow, B.M., Kallesoe, M.F., Iftikhar, U.A., van Noordwijk, M., Bracer, C., Scherr, S.J., Raju, K., Poats, S.V., Duraiappah, A.K., Ochieng, B.O., 2009. "Compensation and Rewards for Environmental Services in the Developing World: Framing Pan-Tropical Analysis and Comparison." Ecology and Society 14 (26): 2009.

Tacconi, L, Mahanty. S., Suich, H., 2013. "The Livelihood Impacts of Payments for Environmental Services and Implications for REDD+.” Society \& Natural Resources 26: 733-44.

TEEB, 2009. "The Economics of Biodiversity and Ecosystems." http://www.teebweb.org/publication/teeb-for-policy-makers-summary-responding-to-thevalue-of-nature/.

Thompson, I. D. 2015. “An Overview of the Science-Policy Interface among Climate Change, Biodiversity, and Terrestrial Land Use for Production Landscapes." Journal of Forest Research 20 (5): 423-29. https://doi.org/10.1007/s10310-015-0497-y.

Thuy, P., Brockhaus, M., Wong, G., Dung, L.N., Tjajadi, J.S., Loft, L., Luttrell, C., Mvondo, S.A., 2013. "Approaches to Benefit Sharing: A Preliminary Comparative Analysis of 13 REDD + Countries”, 108, Bogor, Indonesia.

To, P. X., Dressler W.H., Mahanty, S., Pham, T.T., Zingerli, C., 2012. “The Prospects for Payment for Ecosystem Services (PES) in Vietnam: A Look at Three Payment Schemes." Human Ecology 40: 237-49. https://doi.org/10.1007/s10745-012-9480-9.

Tollefson, J. 2015. “Stopping Deforestation: Battle for the Amazon.” Nature 520 (7545): 20-23. https://doi.org/10.1038/520020a.

Tondrasoa, R. T., 2007. “Analyses Socio-Economiques Des Dix Sites de Transfert de Gestion Dans l'aire Protégée Makira.”

Toni, F., 2011. "Decentralization and REDD+ in Brazil." Forests 2 (4): 66-85. https://doi.org/10.3390/f2010066.

Tseng, M.L., Shamimul Islam, M.D., Karia, N., Fauzi, A.F., Afrin, S. 2019. “A Literature Review on Green Supply Chain Management: Trends and Future Challenges.” Resources, Conservation and Recycling 141 (June 2018): 145-62. https://doi.org/10.1016/j.resconrec.2018.10.009.

Turnhout E., Skutsch M., de Koning J., 2015. “Carbon Accounting.” In: Research Handbook on Climate Governance, Bäckstrand, L.E. K., (ed.), Cheltenham: Edward Elgar Publishing.

Turnhout, E., Gupta, A., Weatherley-Singh, J., Vijge, M.J., de Koning J., Visseren-Hamakers, I.J., Herold, M., Lederer, M., 2016. "Envisioning REDD+ in a Post-Paris Era: Between Evolving Expectations and Current Practice." Wiley Interdisciplinary Reviews: Climate Change. https://doi.org/10.1002/wcc.425. 
Ty, S., Saski, N., Ahmad, A.H., Ahmad, Z.A., 2011. "REDD Development in Cambodia Potential Carbon Emission Reductions in a REDD Project." FORMATH 10: 1-23.

UNEP, 2014. "Building Natural Capital: How REDD+ Can Support a Green Economy.” Nairobi, Kenya.

UNFCCC, 2005. "Reducing Emissions from Deforestation in Developing Countries: Approaches to Stimulate Action.” http://unfccc.int/resource/docs/2005/cop11/eng/misc01.pdf.

- 2007. "Report of the Conference of the Parties on Its Thirteenth Session, Held in Bali from 3 to 15 December 2007."

— 2011. "Report of the Conference of the Parties at Its Sixteenth Session Held in Cancun from 29 November to 10 December 2010.”

_ 2013a. "Report of the Conference of the Parties on Its Nineteenth Session, Held in Warsaw from 11 to 23 November 2013. Addendum. Part Two: Action Taken by the Conference of the Parties at Its Nineteenth Session.”

—, 2013b. Decision 15/CP.19, Addressing the drivers of deforestation and forest degradation.

_ 2015a. "Adoption of the Paris Agreement, Draft Decision -/CP.21." https://doi.org/10.1007/BF02327128.

_ 2015b. "Methodological Issues Related to Non-Carbon Benefits Resulting from the Implementation of the Activities Referred to in Decision 1/CP.16, Paragraph 70." https://unfccc.int/files/meetings/paris_nov_2015/application/pdf/sbsta_42_agenda_item_4 _methodological_issues_related_to_non-carbon_benefits_auv_template.pdf.

United Nations, 2006. "International Tropical Timber Agreement."

Vaillancourt, F. 2008. "Decentralization in Madagascar: A String of Unfinished Races.” 08-37. International Studies Program.

Van Heeswijk, L., Turnhout, E., 2013. “The Discursive Structure of FLEGT (Forest Law Enforcement, Governance and Trade): The Negotiation and Interpretation of Legality in the EU and Indonesia." Forest Policy and Economics 32: 6-13. https://doi.org/10.1016/i.forpol.2012.10.009.

Van Noordwijk, M., Agus, F., Dewi, S., Purnomo, H., 2014. "Reducing Emissions from Land Use in Indonesia: Motivation, Policy Instruments and Expected Funding Streams." Mitigation and Adaptation Strategies for Global Change 19(6):677-92.https:/ / doi.org/10.1007/s11027-013-9502-y.

Van Noordwijk, M., Leimona, B., 2010. "Principles for Fairness and Efficiency in Enhancing Environmental Services in Asia: Payments, Compensation, or Co-Investment?” Ecology and Society 15 (4). https://doi.org/10.5751/ES-03664-150417.

van Oosten, C., 2013. Forest Landscape Restoration, Who Decides? A Governance Approach to Forest Landscape Restoration, Natureza and Conservação, 11(2), 119-126 
Vanderhaegen, K., Verbist, B., Hundera,K., Muys, B., 2015. "REALU vs. REDD+: Carbon and Biodiversity in the Afromontane Landscapes of SW Ethiopia." Forest Ecology and Management 343: 22-33. https://doi.org/10.1016/j.foreco.2015.01.016.

Vatn, A., Vedeld, P.O., 2013. "National Governance Structures for REDD+" Global Environmental Change, 23 (2): $422-432$.

Verchot, L.V., Petkova, E., 2010. “The State of REDD Negotiations Consensus Points, Options for Moving Forward and Research Needs to Support the Process.” Bogor, Indonesia. http://www.cgdev.org/sites/default/files/state_redd_finance_FINAL-REVISED.pdf.

Vergara-Asenjo, G., Sharma, D., Potvin, C., 2015. "Engaging Stakeholders: Assessing Accuracy of Participatory Mapping of Land Cover in Panama." Conservation Letters 8 (6): 432-39. https://doi.org/10.1111/conl.12161.

Vieilledent, G., Grinand, C., Vaudry, R., 2013. "Forecasting Deforestation and Carbon Emissions in Tropical Developing Countries Facing Demographic Expansion: A Case Study in Madagascar." Ecology and Evolution 3 (6): 1702-16. https://doi.org/10.1002/ece3.550.

Vijge, M. J., Brockhaus, M., Di Gregorio, M., Muharrom, E., 2016. "Framing National REDD+ Benefits, Monitoring, Governance and Finance: A Comparative Analysis of Seven Countries." Global Environmental Change 39: 57-68. https://doi.org/10.1016/j.gloenvcha.2016.04.002.

Vijge, M. J., Gupta, A., 2014. "Framing REDD+ in India: Carbonizing and Centralizing Indian Forest Governance?” Environmental Science \& Policy, November, 1-11. https://doi.org/10.1016/j.envsci.2013.10.012.

Vijge, M. J., 2016. “Carbonizing Forest Governance: Analyzing the Consequences of REDD+ for Multilevel Forest Governance.” Wageningen University.

Visseren-Hamakers, I.J., 2015. "Integrative Environmental Governance: Enhancing Governance in the Era of Synergies." Current Opinion in Environmental Sustainability 14: 136-43. https://doi.org/10.1016/j.cosust.2015.05.008.

Visseren-Hamakers, I.J., Gupta, A., Herold, M., Peña-Claros, M., Vijge, M.J., 2012. "Will REDD+ Work? The Need for Interdisciplinary Research to Address Key Challenges." Current Opinion in Environmental Sustainability 4 (6): 590-96. https://doi.org/10.1016/j.cosust.2012.10.006.

Visseren-Hamakers, I.J., McDermott, C., Vijge, M.J., Cashore, B., 2012. "Trade-Offs, Co-Benefits and Safeguards: Current Debates on the Breadth of REDD+." Current Opinion in Environmental Sustainability 4 (6): 646-53. https://doi.org/10.1016/j.cosust.2012.10.005.

Voigt, C., Ferreira, F., 2015. “The Warsaw Framework for REDD+: Implications for National Implementation and Access to Results-Based Finance." Carbon Climate Law Review. Vol. 2.

Waeber, P.O., Wilme, L., Mercier, J-R., et al. 2016. How Effective have Thirty Years of Internationally Driven Conservation and Development Efforts been in Madagascar, PLOS ONE, http://dx.doi.org/10.1371/journal.pone.0161115 
Wang, C., Ghadimi, P., Lim, M.K., Tseng, M.L., 2019. “A Literature Review of Sustainable Consumption and Production: A Comparative Analysis in Developed and Developing Economies." Journal of Cleaner Production 206: 741-54. https://doi.org/10.1016/j.jclepro.2018.09.172.

Weatherley-Singh, J., Gupta, A., 2017. “An Ecological Landscape Approach to REDD + in Madagascar: Promise and Limitations?" Forest Policy and Economics 85. https://doi.org/10.1016/j.forpol.2017.08.008.

Weatherley-Singh, J., Gupta, A., 2015. "Drivers of Deforestation and REDD+ Benefit-Sharing: A Meta-Analysis of the (Missing) Link." Environmental Science \& Policy 54: 97-105. https://doi.org/10.1016/j.envsci.2015.06.017.

Weber, N., Christophersen, T., 2002. "The Influence of Non-Governmental Organisations on the Creation of Natura 2000 during the European Policy Process." Forest Policy and Economics 4 (1): 1-12. https://doi.org/10.1016/S1389-9341(01)00070-3.

Wehkamp, J., Aquino, A., Fuss, S., Reed, E.W., 2015. “Analyzing the Perception of Deforestation Drivers by African Policy Makers in Light of Possible REDD+ Policy Responses.” Forest Policy and Economics 59: 7-18. https://doi.org/10.1016/j.forpol.2015.05.005.

Weitz, N., Strambo, C., Kemp-Benedict, E., Nilsson, M., 2017. "Closing the Governance Gaps in the Water-Energy-Food Nexus: Insights from Integrative Governance.” Global Environmental Change 45 (July): 165-73. https:/ /doi.org/10.1016/j.gloenvcha.2017.06.006.

Well, M., Carrapatoso, A. 2017. "REDD+ Finance: Policy Making in the Context of Fragmented Institutions." Climate Policy 17 (6): 687-707. https://doi.org/10.1080/14693062.2016.1202096.

Winkel, G., Sotirov, M., 2016. "Whose Integration Is This? European Forest Policy between the Gospel of Coordination, Institutional Competition, and a New Spirit of Integration." Environment and Planning C: Government and Policy 34 (3): 496-514. https://doi.org/10.1068/c1356j.

World Bank. 2010. "Madagascar Governance and Development Effectiveness Review."

Wunder, S., 2010. "Forest Decentralization for REDD? A Response to Sandbrook et Al." Oryx 44 (3): 335-37. https://doi.org/10.1017/s0030605310000694.

Yang, W., Liu, W., Viña, A., Luo, J., He, G., Ouyang, Z., Zhang, H., Liu, J., 2013. "Performance and Prospects of Payments for Ecosystem Services Programs: Evidence from China." Journal of Environmental Management 127: 86-95.

Yasmeen, R., Li, Y., Hafeez, M., Ahmad, H., 2018. “The Trade-Environment Nexus in Light of Governance: A Global Potential." Environmental Science and Pollution Research 25 (34): 34360-79. https://doi.org/10.1007/s11356-018-3390-3.

Yin, R. K. 2014. Case Study Research Design and Methods, Sage, Thousand Oaks, CA. https://doi.org/10.3138/cjpe.30.1.108. 


\section{Appendices}

\section{Appendix 1 List of Project Design Documents (PDDs) analysed}

1 ADPML Para REDD, Brazil, Latin America, 17 $7^{\text {th }}$ January 2013

2 Alto Maya, Peru, Latin America, June 2012

3 April Salumei, Papua New Guinea, Oceania, June 2011

$4 \quad$ Boden Creek, Belize, Latin America, 14 ${ }^{\text {th }}$ July 2010

5 Bolivian Amazon, Bolivia, Latin America, 15 ${ }^{\text {th }}$ March 2012

$6 \quad$ Bull Run, Belize, Latin America, 24 $4^{\text {th }}$ January 2012

7 Central Volcanic Range, Costa Rica, Latin America, March 2009

8 Chaco-Panatal, Paraguay, Latin America, April 2012

9 Choco Darien, Columbia, Latin America, 26 ${ }^{\text {th }}$ January 2012

10 Coffee Forest, El Salvador, Latin America, 23 ${ }^{\text {rd }}$ September 2008

11 Cordillera Azul, Peru, Latin America, 20 $0^{\text {th }}$ December 2012

12 Juma, Brazil, Latin America, 29 $9^{\text {th }}$ September 2008

13 Kariba, Zimbabwe, Africa, $8^{\text {th }}$ February 2012

14 Kasigau, Kenya, Africa, 27 ${ }^{\text {th }}$ April 2011

15 Kikonda, Uganda, Africa, 23 ${ }^{\text {rd }}$ April 2009

16 Lower Zambezi, Zambia, Africa, 21 ${ }^{\text {st }}$ June 2013

17 Madre de Dios, Peru, Latin America, October 2011

18 Madre de Dios, Brazil, Latin America, 6th May 2013

19 Mai Ndombe, Congo, Africa, 31st October 2012

20 Makira, Madagascar, Africa, December 2012

21 Martin Sagrado, Peru, Latin America, December 2012

22 Oddar Meanchey, Cambodia, Asia, September 2012

23 Paraguay Forest, Paraguay, Latin America, October 2010

24 Rimba Raya, Indonesia, Asia, 15th May 2011

25 RMDLT Para REDD, Brazil, Latin America, 17th January 2013

26 Sofala, Mozambique, Africa, April 2010

27 Surui, Brazil, Latin America, 13th October 2011

28 Ulu Masen, Indonesia, Asia, 29th December 2007 


\section{Appendix 2 List of EU policy documents analysed}

\begin{tabular}{|c|c|c|c|c|}
\hline & Policy Area and Document Title & Date & Institution & Document Type \\
\hline & Climate Change \& Energy & & & \\
\hline 1 & $\begin{array}{l}\text { On the proposal for a regulation on the } \\
\text { inclusions of GHG emissions and LULUCF }\end{array}$ & 03.05.2017 & EP DEV Committee & Opinion \\
\hline 2 & $\begin{array}{l}\text { On the proposal for a regulation on the } \\
\text { inclusions of GHG emissions and LULUCF }\end{array}$ & 04.05 .2017 & $\begin{array}{l}\text { EP AGRI } \\
\text { Committee }\end{array}$ & Opinion \\
\hline 3 & $\begin{array}{l}\text { A policy framework for climate and energy in } \\
\text { the period from } 2020 \text { to } 2030\end{array}$ & 22.01 .2014 & EC & Communication \\
\hline 4 & $\begin{array}{l}\text { A policy framework for climate and energy in } \\
\text { the period from } 2020 \text { to } 2030 \text { - impact } \\
\text { assessment }\end{array}$ & 22.01 .2014 & $\mathrm{EC}$ & $\begin{array}{l}\text { Staff working } \\
\text { paper }\end{array}$ \\
\hline 5 & $\begin{array}{l}\text { On Towards a new international agreement in } \\
\text { Paris }\end{array}$ & 30.09 .2015 & $\begin{array}{l}\text { EP ENV Committee } \\
\text { (plenary) }\end{array}$ & report \\
\hline 6 & $\begin{array}{l}\text { On Towards a new international agreement in } \\
\text { Paris }\end{array}$ & 30.09 .2015 & $\begin{array}{l}\text { EP Industry \& } \\
\text { research committee }\end{array}$ & opinion \\
\hline 7 & $\begin{array}{l}\text { On Towards a new international agreement in } \\
\text { Paris }\end{array}$ & 30.09 .2015 & EP DEV Committee & opinion \\
\hline 8 & $\begin{array}{l}\text { The Paris Protocol - A blueprint for tackling } \\
\text { global climate change beyond } 2020 \text { - staff } \\
\text { working document }\end{array}$ & 25.02 .2015 & EC & $\begin{array}{l}\text { Staff working } \\
\text { paper } \\
\text { accompanying a } \\
\text { communication }\end{array}$ \\
\hline 9 & $\begin{array}{l}\text { European Union. (2015). Forests, Climate and } \\
\text { People: EU support to combat tropical } \\
\text { deforestation (REDD+) 2006-2014. }\end{array}$ & 2015 & EC DG Clima & Brochure \\
\hline 10 & $\begin{array}{l}\text { Directive amending Directives on petrol and } \\
\text { diesel fuels and renewable energy }\end{array}$ & 15.09 .15 & EC & Directive \\
\hline 11 & $\begin{array}{l}\text { Proposal for a Directive on the promotion of } \\
\text { renewable energy use }\end{array}$ & 23.02 .2017 & $\mathrm{EC}$ & $\begin{array}{l}\text { Proposed } \\
\text { directive }\end{array}$ \\
\hline \multirow[t]{2}{*}{12} & DG Clima Strategic Plan $2016-2020$ & 26.04 .2016 & EC DG Clima & Strategic plan \\
\hline & Trade & & & \\
\hline 13 & $\begin{array}{l}\text { On the impact of international trade and the } \\
\text { EU's trade policies on global value chains }\end{array}$ & 10.05.2017 & $\begin{array}{l}\text { EP Trade } \\
\text { Committee }\end{array}$ & Draft report \\
\hline \multirow[t]{2}{*}{14} & $\begin{array}{l}\text { Trade for all: towards a more responsible trade } \\
\text { and investment policy }\end{array}$ & 2014 & EC & Strategy \\
\hline & Sustainable development & & & \\
\hline 15 & On EU action for sustainability & 27.06 .2017 & $\begin{array}{l}\text { EP ENV Committee } \\
\text { (plenary) }\end{array}$ & Report \\
\hline 16 & On EU action for sustainability & 27.06 .2017 & EP DEV report & Report \\
\hline 17 & $\begin{array}{l}\text { Next steps for a sustainable European future: } \\
\text { European action for sustainability }\end{array}$ & 22.11 .2016 & $\mathrm{EC}$ & Communication \\
\hline \multirow[t]{2}{*}{18} & $\begin{array}{l}\text { Key European action supporting the } 2030 \\
\text { agenda and SDGs }\end{array}$ & 22.11 .2016 & EC & $\begin{array}{l}\text { Staff working } \\
\text { paper }\end{array}$ \\
\hline & Agriculture & & & \\
\hline 19 & $\begin{array}{l}\text { On a new EU forest strategy: for forests and } \\
\text { the forest-based sector }\end{array}$ & 25.02.2015 & EP ENV Committee & Opinion \\
\hline 20 & $\begin{array}{l}\text { On a new EU forest strategy: for forests and } \\
\text { the forest-based sector }\end{array}$ & 01.04 .2015 & $\begin{array}{l}\text { EP AGRI } \\
\text { Committee (plenary) }\end{array}$ & Report \\
\hline
\end{tabular}




\begin{tabular}{|c|c|c|c|c|}
\hline & Foreign policy & & & \\
\hline 21 & On EU political relations with Latin America & 31.05 .2017 & EP DEV Committee & Opinion \\
\hline \multirow[t]{2}{*}{22} & $\begin{array}{l}\text { A strategic approach to resilience in the EU's } \\
\text { external action }\end{array}$ & 07.06 .2017 & $\mathrm{EC}$ & Communication \\
\hline & Environment & & & \\
\hline 23 & On palm oil and deforestation of rainforests & 17.03.2017 & $\begin{array}{l}\text { EP ENV Committee } \\
\text { (plenary) }\end{array}$ & Report \\
\hline 24 & On palm oil and deforestation of rainforests & 02.03 .2017 & EP DEV Committee & Report \\
\hline 25 & On palm oil and deforestation of rainforests & 24.01.2017 & $\begin{array}{l}\text { EP INTA } \\
\text { Committee }\end{array}$ & Opinion \\
\hline 26 & On palm oil and deforestation of rainforests & 02.03 .2017 & $\begin{array}{l}\text { EP AGRI } \\
\text { Committee }\end{array}$ & Opinion \\
\hline 27 & $\begin{array}{l}\text { Transparency and accountable management of } \\
\text { natural resources in developing countries: the } \\
\text { case of forests }\end{array}$ & May-17 & $\begin{array}{l}\text { DG for external } \\
\text { policies for the EP } \\
\text { Dev Committee }\end{array}$ & Study \\
\hline 28 & $\begin{array}{l}\text { Analysis and evidence in support of the EU } \\
\text { Action Plan against Wildlife Trafficking }\end{array}$ & 26.02 .2016 & - & $\begin{array}{l}\text { Staff working } \\
\text { paper }\end{array}$ \\
\hline 29 & $\begin{array}{l}\text { EU Action Plan against Wildlife Trafficking } \\
\text { COM (2016) } 87\end{array}$ & 26.02 .2016 & EC & Communication \\
\hline 30 & Evaluation of the EU FLEGT Action Plan & 27.04 .2016 & & $\begin{array}{l}\text { Independent } \\
\text { consultancy } \\
\text { report }\end{array}$ \\
\hline 31 & Evaluation of the EU FLEGT Action Plan & 02.08 .2016 & EC & $\begin{array}{l}\text { Staff working } \\
\text { paper }\end{array}$ \\
\hline 32 & $\begin{array}{l}\text { EU REDD Facility: Highlights and insights } \\
\text { from } 2016\end{array}$ & 03.03 .2017 & EU REDD Facility & Report \\
\hline 33 & $\begin{array}{l}\text { On the mid-term review of the EU's } \\
\text { biodiversity strategy }\end{array}$ & 08.12 .2015 & EP DEV Committee & Opinion \\
\hline 34 & $\begin{array}{l}\text { On the mid-term review of the EU's } \\
\text { biodiversity strategy }\end{array}$ & 07.01 .2016 & $\begin{array}{l}\text { EP ENV Committee } \\
\text { (plenary) }\end{array}$ & Report \\
\hline 35 & $\begin{array}{l}\text { The mid-term review of the biodiversity } \\
\text { strategy to } 2020\end{array}$ & 02.10 .2015 & EC & Report \\
\hline 36 & $\begin{array}{l}\text { EU assessment of progress in implementing the } \\
\text { EU biodiversity strategy to } 2020\end{array}$ & 02.10 .2015 & EC & $\begin{array}{l}\text { Staff working } \\
\text { paper }\end{array}$ \\
\hline 37 & DG Environment strategic plan $2016-2020$ & 23.03 .2016 & EC & Strategic plan \\
\hline 38 & Environmental indicator report 2017 & 13.11 .17 & EEA & Monitoring report \\
\hline 39 & Mid-term review of the 7th EAP & Nov-17 & EPRS & Research report \\
\hline 40 & $\begin{array}{l}\text { Draft feasibility study on options to step up EU } \\
\text { action against deforestation part I }\end{array}$ & June-17 & $\begin{array}{l}\text { COWI (for DG } \\
\text { ENV) }\end{array}$ & $\begin{array}{l}\text { Independent } \\
\text { consultancy } \\
\text { report }\end{array}$ \\
\hline 41 & $\begin{array}{l}\text { Draft feasibility study on options to step up EU } \\
\text { action against deforestation part II }\end{array}$ & June-17 & $\begin{array}{l}\text { COWI (for DG } \\
\text { ENV) }\end{array}$ & $\begin{array}{l}\text { Independent } \\
\text { consultancy } \\
\text { report }\end{array}$ \\
\hline & Development aid & & & \\
\hline 42 & $\begin{array}{l}\text { The new European Consensus on } \\
\text { Development 'Our world, our dignity, our } \\
\text { future' }\end{array}$ & 07.06.2017 & EC, EP, Council & Joint statement \\
\hline
\end{tabular}




\begin{tabular}{|c|l|r|l|l|}
\hline 43 & $\begin{array}{l}\text { Collect more - spend better - achieving } \\
\text { development in an inclusive and sustainable } \\
\text { way }\end{array}$ & Oct-15 & EC & $\begin{array}{l}\text { Staff working } \\
\text { paper }\end{array}$ \\
\hline 44 & DG Development strategic plan 2016 - 2020 & 01.05 .16 & EC & Strategic plan \\
\hline 45 & $\begin{array}{l}\text { Monitoring report on progress towards the } \\
\text { SDGs in an EU context }\end{array}$ & 20.11 .2017 & Eurostat & Monitoring report \\
\hline 46 & Larger than elephants - synthesis & 2015 & & $\begin{array}{l}\text { Consultant's } \\
\text { report }\end{array}$ \\
\hline 47 & $\begin{array}{l}\text { A global partnership for poverty alleviation and } \\
\text { sustainable development }\end{array}$ & 05.02 .2015 & EC & Communication \\
\hline 48 & $\begin{array}{l}\text { A global partnership for poverty alleviation and } \\
\text { sustainable development - annex }\end{array}$ & 05.02 .2015 & EC & $\begin{array}{l}\text { annex to a } \\
\text { communication }\end{array}$ \\
\hline & General EU strategy/budget & 01.03 .2017 & EC & White paper \\
\hline 49 & White Paper on the Future of Europe & 17.04 .2017 & EC & White paper \\
\hline 50 & $\begin{array}{l}\text { Reflection paper on the social dimension of } \\
\text { Europe }\end{array}$ & 10.05 .2017 & EC & White paper \\
\hline 51 & Reflection paper on harnessing globalisation \\
\hline 52 & Reflection paper on the future of EU finances & 28.06 .2017 & EC & White paper \\
\hline & $\begin{array}{l}\text { Future Financing of the EU: Final report and } \\
\text { recommendations of the High Level Group on } \\
\text { Own Resources }\end{array}$ & Dec-16 & High level group & Report \\
\hline 54 & $\begin{array}{l}\text { EP report on the post electoral revision of the } \\
\text { MFF 2014 - 2020 }\end{array}$ & 30.06 .2016 & EP & Report \\
\hline & $\begin{array}{l}\text { Strengthening European Investments for jobs } \\
\text { and growth: Towards a second phase of the } \\
\text { European Fund for Strategic Investments and a } \\
\text { new European External Investment Plan }\end{array}$ & 14.09 .2016 & EC & Communication \\
\hline
\end{tabular}




\section{Appendix 3 Interviewees with knowledge of national-level REDD+ processes}

1. Laura Brimont, Research Fellow, IDDRI, France

2. Anne Branthomme, Forestry Officer, UNREDD Programme / FAO, Italy

3. Christian Burran, Forests and Climate Advisor, Wildlife Conservation Society, Madagascar

4. Barry Ferguson, Lecturer and Researcher, Libanona Ecology Centre, Madagascar

5. Andrew Cooke, Corporate Sustainability and Environment Manager, Madagascar Oil, Madagascar

6. Lisa Gaylord, Communities, Corporate Relations and Sustainable Development Manager, Rio Tinto, Madagascar

7. Sarah Osterhoudt, Co-founder, Lafaza Foods, United States

8. Liliane Parany, Conservation Officer, Madagascar National Parks, Madagascar

9. Bruno Rajaspera, Projects Director, Conservation International, Madagascar

10. Nirina Razafy Raholivelo Rajaonah, Environmental Expert (Retired), Ministère de l'Agriculture, Madagascar

11. Mamy Rakotoarijaona, Operations Director, Madagacar National Parks, Madagascar

12. Laza Hasinarijaona Rakotondrasoa, Programme Officer, WWF, Madagascar

13. Jean Roger Ralotoarijaona, Directeur des Informations Environnementales, Office National pour l'Environnement, Madagascar

14. Bruno Ramamonijsoa, Chef de Département - Eaux et Forêts, Université d'Antananarivo, Madagascar

15. Julia Randimbisoa, Assistant Director, Helvetas, Madagascar

16. Jeannicq Randrianarisoa, Sustainable Finance Manager, Conservation International, Madagascar

17. Tiana Razafimahatrata, Environmental Focal Point, USAID, Madagascar

18. Jenny Rust, Technical Advisor, GIZ, Madagascar

19. Gianni Ruta, Senior Environmental Economist, World Bank, Madagascar

20. Olaf Zerbock, Forestry Specialist, USAID, Washington

Additional information provided by: Mark van der Waal, Senior Ecologist, IUCN Netherlands Committee, the Netherlands 


\section{Appendix 4 List of stakeholders interviewed for the 'embodied deforestation' analysis}

\begin{tabular}{|l|l|l|l|}
\hline Job Function & Institution type & Date of Interview & Location \\
\hline Policy-maker & European Commission & $1^{\text {st }}$ February 2018 & Brussels, Belgium \\
\hline Forest Expert & UN agency & $2^{\text {nd }}$ February 2018 & Skype \\
\hline Policy Manager (former) & Environmental NGO & $15^{\text {th }}$ February 2018 & Skype \\
\hline Lawyer & Environmental NGO & $23^{\text {rd }}$ February 2018 & Skype \\
\hline Campaigner & Environmental NGO & $16^{\text {th }}$ March 2018 & Skype \\
\hline Campaigner & Environmental NGO & $12^{\text {th }}$ April 2018 & Skype \\
\hline Forest Expert & EU agency & $12^{\text {th }}$ April 2018 & Skype \\
\hline Forest Expert & Freelance consultant & $18^{\text {th }}$ April 2018 & Skype \\
\hline PhD Student & University & $26^{\text {th }}$ April 2018 & Brussels, Belgium \\
\hline Senior Policy Officer & Environmental NGO & $18^{\text {th }}$ May 2018 & Skype \\
\hline Negotiator & National government & $24^{\text {th }}$ May 2018 & Skype \\
\hline Policy-maker & European Commission & $24^{\text {th }}$ May 2018 & Brussels, Belgium \\
\hline Senior Researcher & Research institute & $24^{\text {th }}$ May 2018 & Skype \\
\hline Policy Advisor & European Parliament & $28^{\text {th }}$ June 2018 & Brussels, Belgium \\
\hline Forest Policy Expert & Independent consultant & $17^{\text {th }}$ August 2018 & Skype \\
\hline
\end{tabular}




\section{Appendix 5 Questions for interviews with REDD+ project beneficiaries}

Name:

Village:

Sex: Male $\square$ Female $\square$

Age: $\quad<20 \square \quad 20-40 \square \quad>40 \square$

\section{General Questions}

1. How long have you been involved in the project?

2. In what way are you involved?

\section{Project Results}

3. What are the results of the project for:

a) You?

b) Your family?

c) Your community?

4. Has the project had an impact on the forest? If yes, in what way?

5. Do you use the forest (or any forest products)? If yes, what?

6. Do you use the forest (or forest products) more or less since the beginning of the project?

7. If less, do you face any problems because you are using the forest (or forest products) less?

8. What are the benefits of the forest for:

a) You?

b) Your family?

c) Your community?

9. What are the benefits of this REDD+ project for:

a) You?

b) Your family?

c) Your community?

10. What are the negative impacts of this REDD+ project for:

a) You?

b) Your family?

c) Your community? 
11. Who receives the most project benefits in your community?

12. Who receives the least project benefits in your community?

13. In general are you happy with the REDD+ project?

14. Which people in your community like the project?

15. Which people in your community don't like the project?

\section{Behaviour Change}

16. Have you changed your activities as a result of the project? If so, which?

17. How have other people in your community changed their activities as a result of the project? 


\section{Appendix 6 Questionnaire for semi-structured interviews with national level REDD+ stakeholders}

1. Which stakeholders are most/least dominant in REDD+ discussions?

2. Which stakeholders are most/least dominant in the media?

3. Which stakeholders most/least successful in influencing REDD+ decision-making?

4a. How easy/difficult has it been for your company/organisation to engage in REDD+?

4b. If difficult - what have been the barriers to engagement (internal or external)?

5. What do you stand to lose/gain from your engagement?

6. Which stakeholders do you perceive as having the most to gain/lose from engagement in REDD in Madagascar?

7. What is the main mission of your company/organisation?

8. Why is your company/organisation engaged in REDD?

9. How easy/difficult has it been to get information on REDD+ policy development?

10. What are your main sources of information?

11. What is your main point of engagement in REDD+ discussions in Madagscar?

12. Are there strong or weak connections between national and sub-national interventions?

13. What do you think would be the best scale of REDD+ interventions?

14. What do you think are the main challenges to the implementation of REDD+ in Madagascar?

15a. How much of a role do agricultural companies play in REDD+ implementation in Madagascar? 15b. If not much - what are the main barriers to their engagement?

$15 \mathrm{c}$. If yes - what role are they playing?

16. Which drivers of deforestation and forest degradation are being targeted by REDD + in Madagascar?

17. Which drivers of deforestation and forest degradation are being missed by REDD + in Madagascar?

18. Where/who are incentives being targeted? 


\section{Appendix 7 Questionnaires for international-level stakeholders involved in policy discussions on 'embodied deforestation'}

1. a) The EU has mentioned the concept of embodied/imported deforestation - have you come across it?

b) If so, do you think it is a useful concept?

2. Why are you involved in this policy discussion?

3. Do you think there has been a change in the balance between demand versus supply measures?

4. What would you like to see result from the policy discussion on embodied deforestation?

5. Do you consider that REDD+ still has a role to play in addressing tropical deforestation?

6. What role should the EU have in relation to the implementation of REDD?

7. Do you have any other comments? 


\section{Executive Summary}

Tropical deforestation and forest degradation is a pressing and urgent global challenge, with extremely high environmental and social costs. Deforestation and forest degradation often lie at the intersection of local, direct (proximate) drivers with indirect, underlying drivers acting at multiple scales. Indirect drivers linked to globalisation are, however, now recognised as critically important due to the continued growth in international trade in agricultural commodities. Given the multi-level and geographically disparate nature of many drivers, combating deforestation and forest degradation presents a particularly complex environmental governance challenge. Furthermore, the absence of a single overarching international agreement on forests has historically led to a highly fragmented approach to forest governance, from the international to the local level. Forest governance is multiscale and networked in nature, and implemented through a wide range of policy instruments at different levels.

One key such policy initiative, which has been the subject of sustained scholarly and policy attention, is 'reducing emissions from deforestation' in developing countries (known as RED). Discussions were initiated under the umbrella of the United Nations Framework Convention on Climate Change (UNFCCC) by a group of developing countries in 2005. The aim was to set up a mechanism under the climate regime to financially reward developing countries for conserving the carbon stored in tropical forests. The RED concept was expanded in 2007 to also include compensation for the sustainable management of forests and the enhancement of forest carbon stocks in developing countries. It then became widely known as REDD+. Recent discussions in the environmental governance literature have been characterised by a renewed emphasis on such integrated policy approaches at the nexus of different environmental policy areas, as essential to stimulating 'transformational change'. One quintessential example of the effort to integrate diverse policy arenas are the UN Sustainable Development Goals (SDGs). As a policy initiative that has developed at the nexus of two environmental policy areas, which is multi-level in nature and brought together a wide range of diverse actors, REDD + is ideally placed to shed light on whether and how integrated approaches to policy-making can stimulate the hoped-for transformational change needed to address environmental challenges, and achieve the environmental SDGs.

This thesis uses a networked governance perspective to examine the evolution of the REDD+ initiative and its transformational potential to tackle tropical deforestation and forest degradation. Diverse evolving conceptualisations and operationalisations of REDD + at local, landscape and international levels are examined to assess the ability of each to combat the direct and indirect drivers of tropical forest loss and degradation. In so doing, the thesis also examines how the evolution and implementation of REDD + has been influenced by its integration into other policy areas beyond forest and climate policies over time, and the extent to which growing integration of REDD+ into a broader policy landscape impacts upon its ability to deliver transformational change.

The thesis answers the following two overarching research questions, through detailed qualitative analysis in four chapters (published in international peer reviewed journals):

- To what extent have evolving conceptualisations of REDD+ effectively tackled direct and indirect drivers of deforestation and forest degradation, operating at different levels? 
- From a networked governance perspective, to what extent is REDD+ becoming integrated across policy domains and how is this impacting its ability to deliver transformational change?

Chapter 2 analyses and synthesises how REDD+ is being conceptualised in practice. The three conceptualisations of REDD+ described and examined in this chapter are: a co-benefit-centred REDD+ (wherein REDD+ aims to achieve co-benefits for biodiversity and communities); a carbon-centred REDD+ (in which REDD+ is mainly a climate mitigation strategy); and a landscape-oriented REDD+ (in which REDD+ is instituted along with broader agricultural and sustainable land use practices). The chapter assesses the extent to which these diverse conceptualisations are addressing direct and indirect drivers of deforestation and forest degradation, and how well they are meeting the high expectations associated with REDD+. The chapter shows that, in assessing evolving expectations against existing REDD+ experiences, a mixed picture emerges. Some expectations, relating to forest carbon financing for example, are not being adequately met, while others, notably the delivery of co-benefits, hold out more promise. It concludes that the future of REDD+ may lie not in one conceptualisation coming to dominate, but rather in the coexistence of heterogeneous practices, which may provide building blocks for the polycentric governance of the world's remaining tropical forests.

Chapter 3 analyses the co-benefit conceptualisation in more detail, through a meta-analysis of REDD+ projects spread across the globe. This analysis identifies the links, if any, between the benefits accruing from and being shared through REDD+ projects, and the multiple and diverse drivers of deforestation operating at different levels. The nature of the link between benefits and drivers was assessed in (a) scholarly analysis, through an in-depth analysis of the posited relationship between drivers and REDD+ benefit-sharing, as examined in the peer-reviewed literature; and (b) in policy practice, through analysing how this link is being conceptualised and operationalised, if at all, in REDD+ project design documents. The analysis suggested that while some local, direct drivers and a few regional indirect drivers of deforestation and forest degradation are being targeted by specific REDD+ interventions and associated benefit-sharing mechanisms at the project-level, most national and international indirect drivers are not.

Chapter 4 moves on to examine the next step in the evolution of REDD+, namely the landscape approach, and its ability to tackle drivers of deforestation and forest degradation. An examination of the grey and peer-reviewed literature revealed the emergence of a typology of landscape approaches. We characterise these here as: economic (which defines landscapes as commodity production areas); political (which defines landscape on the basis of administrative or jurisdictional boundaries); and ecological (which defines landscape on the basis of ecological characteristics). The chapter then analyses in detail the 'ecological landscape approach' and its ability to address drivers of deforestation and forest degradation. The landscape approach has received the least attention to date in the REDD+ literature. The chapter focuses on Madagascar as a case study to analyse the development and implementation of such an approach. While such a rendition of REDD+ showed some promise in addressing drivers beyond the local and direct, in comparison to conservation and development approaches (ICDP) that pre-date REDD+ in the country, it was still limited in its ability to do so. Hurdles included a lack of inter-sectoral coordination and national-level political 
support for combating deforestation, as well as a lack of community engagement in multilevel political processes.

Chapter 5 focuses on the international level by analysing new discussions emerging in the international forest policy realm, and the implications for the continued evolution and conceptualisation of REDD+ and its ability to address drivers. The chapter describes the emergence of a new policy debate at European Union (EU) level termed 'embodied deforestation'. This notion views deforestation as an externality generated by EU imports and seeks to reduce indirect international drivers of deforestation and forest degradation linked to EU commodity imports. The chapter uses a networked governance approach to examine whether this novel debate represents a shift in EU policy towards acknowledging and tackling international drivers of tropical deforestation. It also examines whether this new debate fuels further fragmentation or rather a move towards a more integrated approach to combating tropical forest loss within EU policy, and what the implications are for other forest governance initiatives, most notably REDD + . The chapter finds that, despite growing debate around the concept of embodied deforestation, policy measures necessary to reduce the impact of EU consumption of agricultural commodities associated with tropical deforestation have not yet been developed. It concludes that 'embodied deforestation' remains more an idea than reality thus far, with the burden of responsibility for addressing international deforestation drivers still largely remaining on developing (exporting) countries. However, there is still potential for this debate to lead to a more integrated approach to tackling tropical deforestation within EU policy, if it comes to be seen, with REDD+, as a set of linked approaches in EU efforts to combat tropical deforestation.

Chapter 6 concludes by first summarising the research findings from the four empirical chapters and then answering the two overarching research questions posed in the introduction. Thus, it first distils insights generated by the research regarding different conceptualisations of REDD + , and whether and how, taken as a whole, REDD + is able to tackle direct and indirect drivers of deforestation and forest degradation operating at different levels. The chapter then discusses how REDD+ is continuing to evolve, and the prospects of more integrated approaches to REDD+ to deliver transformational change. It concludes by identifying how thesis findings apply to other networked environmental governance issue-areas, and distils lessons learned and implications for stimulating transformational change in the sustainability domain.

In answering the first research question, thesis findings reveal that several conceptualisations of REDD+ exist at local, landscape and international levels, which are able to address some local, direct drivers of deforestation and forest degradation. They are less able, however, to tackle indirect drivers operating at national and international levels. While local drivers are being targeted with some success, one weak point in REDD + networked governance lies at the national level, and another at the international level. Examining the new 'embodied deforestation' discussion at the international forest policy level shows however, that, if implemented, it may have the potential to tackle indirect international drivers, especially relating to the trade and consumption of agricultural commodities linked to deforestation. This holds out the hope for transformational change. The conclusion thus also discusses how these newly emerging policy initiatives at the international level, which bring together configurations of stakeholders in informal decision-making processes, may help to 'leapfrog' over political inertia at national level. It remains to be seen, however, whether 
consumer countries will take the steps needed to move beyond political rhetoric and formally adopt such policies.

In answering the second research question, the chapter distils thesis findings showing that REDD+ is becoming increasingly integrated with new policies to secure more sustainable production and consumption. This engagement with sustainable production and consumption issues has also begun to indirectly link REDD + to the trade policy domain. REDD + is therefore becoming increasingly integrated with other policies within the environmental realm, but also with policy domains beyond the environment, particularly trade and agriculture, although links here are weaker. REDD+ can thus now be described as being increasingly situated at the forest-climate-agriculture-trade policy nexus. Such a highly integrated approach presents the risk that REDD+ becomes so overloaded by different expectations that it no longer resembles its original conceptualisations and aims, and/or is superseded and ultimately replaced by new, alternative policy mechanisms. But this greater integration also offers the opportunity to increase effectiveness of REDD+ in addressing national and international drivers, thereby effecting transformational change. 


\section{About the Author}

Janice Weatherley-Singh was born in 1975 in the UK. She gained a BSc in Geography from the University of Birmingham, before completing a MSc in Rural Resources and Environmental Policy at Wye College, University of London. This was followed by a year working on an agrienvironmental research project in Mexico and a few years working on project development for a local Wildlife Trust in the UK.

Since 2003, Janice has been based in Brussels, Belgium where she has worked for a variety of nature conservation organisations as an employee and a consultant, including, IUCN, A Rocha

International, WWF European Policy Office and Eurosite. During this time, she has worked to support government fundraising and project development including through field visits to projects in Peru, India, Papua New Guinea, France, Portugal, Kenya and elsewhere. She is currently the Director of EU Strategic Relations for WCS EU. Her main expertise is analysing and influencing the development and implementation of EU biodiversity policies and funding programmes, particularly in relation to wildlife trade and trafficking, development, and tropical forests. 


\section{List of Publications by the Author}

\section{Peer-reviewed publications}

- Weatherley-Singh, J., and A. Gupta. 2018. "Embodied Deforestation" as a new EU Policy Debate to Tackle Forest Loss: Assessing Implications for REDD+ Performance, Forests, 9 (12) 751. https://doi.org/10.3390/f9120751

- Weatherley-Singh, J., and A. Gupta. 2017. "An Ecological Landscape Approach to REDD + in Madagascar: Promise and Limitations?" Forest Policy and Economics, 85. https://doi.org/10.1016/i.forpol.2017.08.008.

- Turnhout, E., Gupta, A., Weatherley-Singh, J., Vijge, M.J., de Koning, J., Visseren-Hamakers, I.J., Herold, M., Lederer, M., 2016. Envisioning REDD + in a post-Paris era: between evolving expectations and current practice, WIREs Climate Change, https://doi.org/10.1002/wcc.425.

- Weatherley-Singh, J., Gupta, A., 2015, Drivers of deforestation and REDD+ benefit-sharing: A meta-analysis of the (missing) link, Environmental Science and Policy, 54: 97-105. https://doi.org/10.1016/j.envsci.2015.06.017.

- Sluka, R.D., Kaonga, M., Weatherley, J., Anand V., Bosu D., Jackson, C. 2011. Christians, biodiversity conservation and poverty alleviation: a potential synergy?, Biodiversity, 12 (2). DOI:10.1080/14888386.2011.599780

\section{Other publications}

- Weatherley, J. (Ed) 2009. A Rocha Conservation Science Review 2007 - 2009. A Rocha International, Cambridge, UK

- Walder, C., Baumueller, A., Dick G., Weatherley, J. 2006. Towards European Biodiversity Monitoring, European Habitats Forum, Brussels, Belgium 
Cover design by: Janice Weatherley-Singh and Aruna Safri-Singh

Printed by: ProefschriftMaken 


\section{Propositions}

1. The imposition of sustainability rather than legality standards by consuming countries on imports of agricultural commodities, undermines the sovereignty of producer countries.

(this thesis)

2. New international policy tools being considered to address tropical deforestation need to address the loss of all natural ecosystems.

(this thesis)

3. China is stepping into the void created by the withdrawal of the US from the international environmental policy arena.

4. Multilateral environmental agreements need to include sanctions for non-compliance in order to be effective.

5. Brexit has generated a British national identity crisis.

6. It is not advisable to combine working full-time with doing a $\mathrm{PhD}$ on the side.

Propositions belonging to the thesis, entitled:

An Assessment of the Transformational Potential of REDD+ in Tackling Drivers of Deforestation Janice Weatherley-Singh

Wageningen, 9 December 2019 


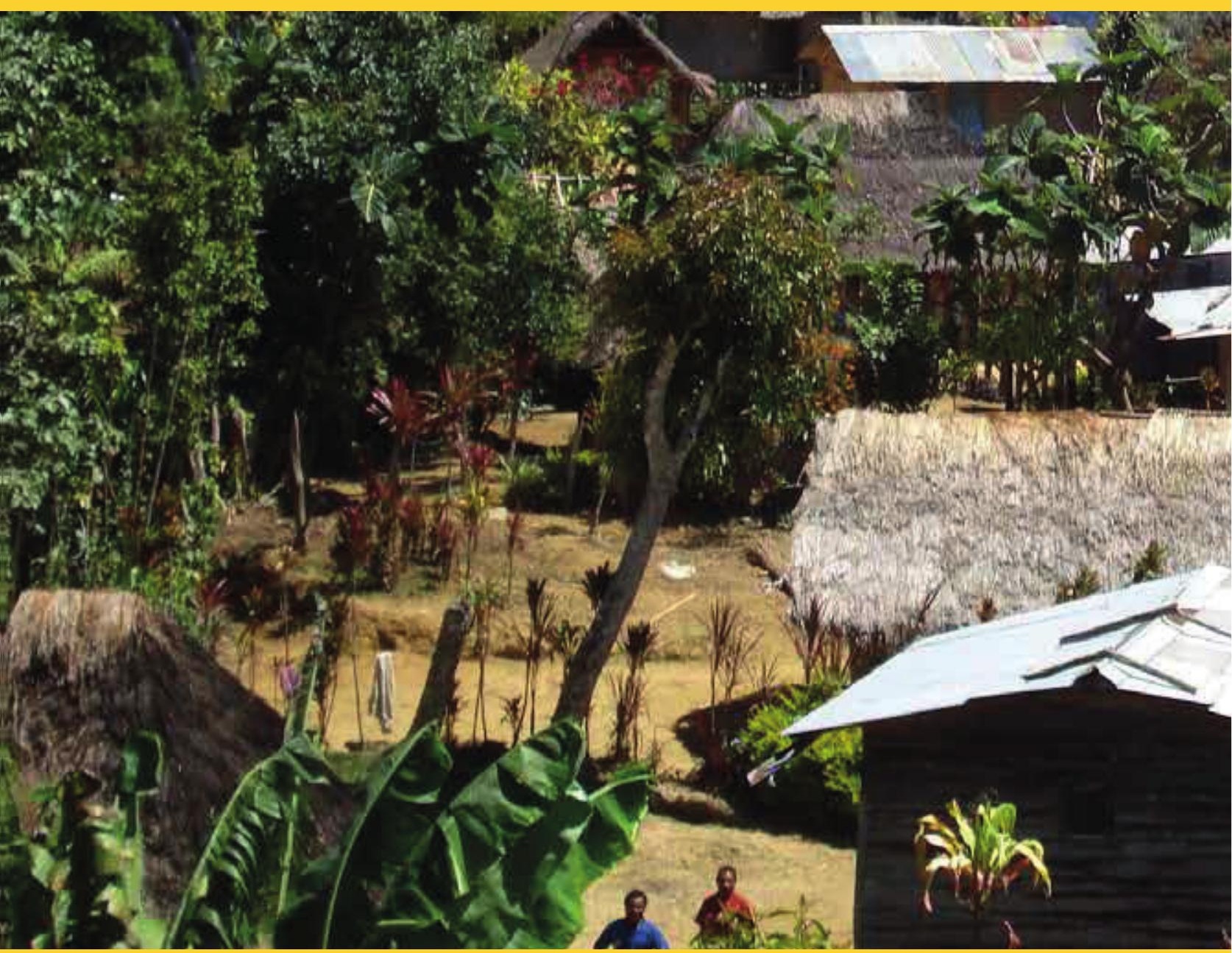

